UNIVERSIDADE DE SÃO PAULO

ESCOLA DE ENFERMAGEM

CATHARINA FERREIRA DE MEIRA PACHIONI

AVALIAÇÃO PRÉ-OPERATÓRIA TRANSDISCIPLINAR:

ELABORAÇÃO E VALIDAÇÃO DE UM INSTRUMENTO PARA SEGURANÇA DO PACIENTE CIRÚRGICO. 


\section{AVALIAÇÃO PRÉ-OPERATÓRIA TRANSDISCIPLINAR: ELABORAÇÃO E VALIDAÇÃO DE UM INSTRUMENTO PARA SEGURANÇA DO PACIENTE CIRÚRGICO.}

Versão corrigida da Dissertação apresentada ao Programa de Pós-Graduação em Enfermagem na Saúde do Adulto da Escola de Enfermagem da Universidade de São Paulo para obtenção do título de Mestre em Ciências.

Área de concentração: Enfermagem Saúde do Adulto.

Orientadora: Prof. ${ }^{a}$ Dr. ${ }^{\underline{a}}$ Aparecida de Cássia Giani Peniche

\section{VERSÃO CORRIGIDA}

A versão original encontra-se disponível na Biblioteca da Escola de Enfermagem da Universidade de São Paulo e na Biblioteca Digital de Teses e Dissertações da Universidade de São Paulo.

\section{SÃO PAULO}


AUTORIZO A REPRODUÇÃO E DIVULGAÇÃO TOTAL OU PARCIAL DESTE TRABALHO, POR QUALQUER MEIO CONVENCIONAL OU ELETRÔNICO, PARA FINS DE ESTUDO E PESQUISA, DESDE QUE CITADA A FONTE.

Assinatura:

Data:

\section{Catalogação na Publicação (CIP)}

Biblioteca "Wanda de Aguiar Horta"

Escola de Enfermagem da Universidade de São Paulo

Pachioni, Catharina Ferreira de Meira

Avaliação pré-operatória transdisciplinar: elaboração e validação de um instrumento para segurança do paciente cirúrgico / Catharina

Ferreira de Meira Pachioni. São Paulo, 2018.

$107 \mathrm{p}$.

Dissertação (Mestrado) - Escola de Enfermagem da Universidade de São Paulo.

Orientadora: Prof. ${ }^{\text {a }}$ Dr. ${ }^{\text {a }}$ Aparecida de Cássia Giani Peniche

Área de concentração: Enfermagem na Saúde do Adulto

1. Estudos de validação. 2. Cuidados pré-operatórios. 3. Cuidados de enfermagem. 4. Enfermagem. I. Título.

Ficha catalográfica elaborada por Fabiana Gulin Longhi Palacio (CRB-8: 7257) 
Nome: Catharina Ferreira de Meira Pachioni

Título: Avaliação Pré-Operatória Transdisciplinar: Elaboração e Validação de um Instrumento Para Segurança do Paciente Cirúrgico.

Dissertação apresentada ao Programa de Pós-Graduação em Enfermagem na Saúde do Adulto e do Idoso da Escola de Enfermagem da Universidade de São Paulo para obtenção de título de Mestre em Ciências da Saúde.

Aprovada em

Banca Examinadora

Prof. Dr. Instituição

Julgamento: Assinatura:

Prof. Dr. Instituição

Julgamento: Assinatura:

Prof. Dr. Instituição

Julgamento: Assinatura:

Prof. Dr. Instituição Julgamento: Assinatura: 


\section{DEDICATÓRIA}

Agradeço a Deus por sempre me fortalecer e me guiar nesta trajetória.

Aos meus pais, Raphael e Tereza, pelo amor incondicional e ensinamentos aprendidos. Obrigada por me inspirarem a ser uma pessoa humilde, carinhosa e dedicada.

Ao Henrique, meu grande amor e companheiro, que sempre me apoiou nos momentos de dificuldades, me dando carinho e amor. Obrigada por me incentivar a nunca desistir dos meus sonhos.

A minha irmã Veridiana e meu cunhado Estevão que sempre me ajudaram a percorrer este caminho com fé e coragem.

Aos meus sogros e cunhados, pelo incentivo e apoio constantes.

A minha família por vibrarem a cada conquista e momentos memoráveis. 


\section{AGRADECIMENTOS}

A Profa. Dra. Aparecida de Cassia Giani Peniche por toda dedicação de seu tempo em me orientar e me direcionar para um mundo de possibilidades. Obrigada por ser esta pessoa tão especial e carinhosa.

A minha amiga Gabrielle, guerreira e determinada como eu, sempre em busca de novos conhecimentos e saberes. Obrigada por todos os momentos de angustias, dores e alegrias vividos.

Aos meus grandes amigos, eternos companheiros e parceiros de longa caminhada. Obrigada por toda compreensão diante das ausências e por me incentivarem a conclusão deste trabalho.

A toda equipe de enfermagem perioperatória e anestesiologia do A.C. Camargo Cancer Center por acreditarem na minha capacidade e por todo conhecimento compartilhado. Obrigada por fazerem parte desta intensa trajetória.

A Escola de Enfermagem da USP, onde aprendi que a pesquisa é capaz de permitir grandes mudanças e um novo mundo de infinitas descobertas. 
"A mente que se abre a uma nova ideia jamais voltará ao seu tamanho original".

Albert Einstein 
Pachioni CFM. Avaliação Pré-Operatória Transdisciplinar: Elaboração e Validação de um Instrumento Para Segurança do Paciente Cirúrgico. [dissertação]. São Paulo (SP), Brasil: Escola de Enfermagem da Universidade de São Paulo; 2018.

\section{RESUMO}

A cultura da segurança do paciente cirúrgico está em evidência devido ao crescente número de erros e eventos adversos, os quais poderiam ser prevenidos. A avaliação pré-operatória permite que o enfermeiro do Centro Cirúrgico junto com os demais enfermeiros e o anestesiologista, elabore um plano de cuidados para reduzir e prevenir as complicações pós-operatórias. Com os dados obtidos com a avaliação pré-operatória, e as dúvidas dos pacientes esclarecidas, identificam-se as necessidades de cada um, traçando intervenções que buscam solucionar os problemas que possam dificultar o procedimento cirúrgico. Acredita-se que a vivência dos pacientes relacionada aos questionamentos, muitas vezes repetida e dispersa, decorra da coleta efetuada por diversos profissionais envolvidos com as avaliações, da inexistência de um instrumento transdisciplinar de avaliação préoperatória que na maioria das vezes, está associada uma falha na comunicação entre os profissionais. Objetivo: elaborar e validar um instrumento de avaliação préoperatória transdisciplinar para garantir a segurança do paciente cirúrgico no período transoperatório. Método: estudo metodológico com técnicas psicométricas baseado na revisão dos guidelines da Associação Brasileira de Enfermeiros de Centro Cirúrgico, Recuperação Anestésica e Centro de Material e Esterilização (SOBECC), Association of periOperative Registered Nurse (AORN), American Society of Anaesthesiologists (ASA) e European Society of Anaesthesiology (ESA), sendo realizado através da etapa de validação de conteúdo de um instrumento de avaliação pré-operatória transdisciplinar. Resultado: o instrumento desenvolvido foi elaborado com base na revisão dos guidelines relevantes das áreas de enfermagem perioperatória e anestesiologia. Foram encontradas semelhanças nos guidelines preconizados pela SOBECC e AORN em quatro categorias. Já os guidelines preconizados pela ASA e ESA eram similares em três categorias. Em relação a validação de conteúdo, o instrumento apresentou índices satisfatórios na validação de conteúdo pelo coeficiente de conteúdo total, variando de 0,83 a 0,99. Recomenda-se a aplicação-piloto informatizada deste instrumento. Conclusão: Nas fases de validação, o instrumento apresentou resultados significativos, tornando-se uma importante ferramenta para garantir a segurança do paciente no período perioperatório.

Palavras-chave: Estudo de Validação. Cuidados Pré-operatórios. Cuidados de Enfermagem. 
Pachioni CFM. Transdisciplinary Preoperative Evaluation: Elaboration and Validation of an Instrument for Surgical Patient Safety. [dissertation]. Sao Paulo (SP), Brazil: School of Nursing, University of Sao Paulo; 2018.

\begin{abstract}
The safety of the surgical patient is at the forefront of society due to the increasing number of incidents and adverse events that have been extensively documented and could have been otherwise prevented. The preoperative evaluation allows the nurse of the Surgical Center, along with the other nurses and the anesthesiologist, to develop procedures to reduce and prevent postoperative complications. Using the data obtained from the preoperative evaluation and clarifying the doubts of patients, the needs of each patient are identified, tracing interventions that seek to solve the problems that may hinder the surgical procedure. It is believed that the current practice of asking repetitive questions to patients, often exaggerated and dispersed throughout the medical record, results from the uncoordinated actions of several professionals involved in the evaluation and the lack of a transdisciplinary preoperative evaluation instrument, which more often than not leads to miscommunication among professionals. Objective: elaborate and validate a transdisciplinary preoperative evaluation instrument to guarantee the safety of the surgical patient in the transoperative period. Method: a methodological with psychometric techniques study based on the revision of the guidelines of Brazilian Association of Nurses of Surgical Center, Anesthetic Recovery and Material and Sterilization Center (SOBECC), Association of periOperative Registered Nurse (AORN), American Society of Anaesthesiologists (ASA) and European Society of Anaesthesiology (ESA), being carried out through the validation stage of content of a transdisciplinary preoperative evaluation instrument. Result: the developed instrument was elaborated based on the revision of the relevant guidelines of the areas of perioperative nursing and anesthesiology. Similarities were found between the guidelines recommended by SOBECC and AORN in four categories. In turn, the guidelines favored by ASA and ESA were similar in three categories. With regards to content validation, the instrument presented satisfactory contents indexes for coefficient of total content, ranging from 0.83 to 0.99 . The pilot application of this computadorized instrument is recommended. Conclusion: In the validation phases, the instrument presented significant results, consisting in an important tool to guarantee patient safety during the perioperative period.
\end{abstract}

Key words: Validation Study. Preoperative Care. Nursing Care. 


\section{LISTA DE ILUSTRAÇÕES}

Figura 1 - Catalogação dos Guidelines Nacional e Internacional. São Paulo-SP, 2018.

Figura 2 - Instrumento final após Validação de Conteúdo. São Paulo-SP, 2018......70 


\section{LISTA DE TABELAS}

Tabela 1 - Resultados do levantamento dos guidelines nacional e internacional de avaliação pré-operatória, de acordo com as áreas de atuação.

Tabela 2 - Questões avaliadas pelos juízes especialistas e resultado do Índice de

Validade de Conteúdo Total. São Paulo-SP, 2018. 


\section{LISTA DE SIGLAS}

$\begin{array}{ll}\text { APA } & \text { Avaliação Pré-Anestésica } \\ \text { ASA } & \text { American Society of Anaesthesiologists } \\ \text { AORN } & \text { Association of periOperative Registered Nurse } \\ \text { CC } & \text { Centro Cirúrgico } \\ \text { CVCi } & \text { Coeficiente de Validação de Conteúdo de cada item } \\ \text { CVCic } & \text { Coeficiente de Validação de Conteúdo de cada item com a } \\ \text { CVCt } & \text { Coeficiente de Conteúdo Total } \\ \text { DPOC } & \text { Doença Pulmonar Obstrutiva Crônica } \\ \text { DRGE } & \text { Doença do Refluxo Gastrointestinal } \\ \text { EORNA } & \text { European Operating Room Nurses Association } \\ \text { ERAS } & \text { Enhanced Recovery After Surgery } \\ \text { ESA } & \text { European Society of Anaesthesiology } \\ \text { NVPO } & \text { Náuseas e Vômitos Pós-Operatórios } \\ \text { OMS } & \text { Organização Mundial da Saúde } \\ \text { PNSP } & \text { Programa Nacional de Segurança do Paciente } \\ \text { VC } & \text { Validação de Conteúdo } \\ \text { VF } & \text { Validação de Face } \\ \text { SAEP } & \text { Sistematização da Assistência de Enfermagem Perioperatória } \\ \text { SOBECC } & \text { Associação Brasileira de Enfermeiros de Centro Cirúrgico, } \\ \text { TEP } & \text { Trocuperação Anestésica e Centro de Material e Esterilização } \\ \text { TVoembolismo Pulmonar }\end{array}$




\section{SUMÁRIO}

1 JUSTIFICATIVA DO ESTUDO

2 INTRODUÇÃO

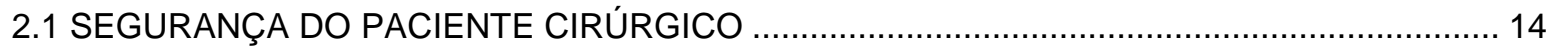

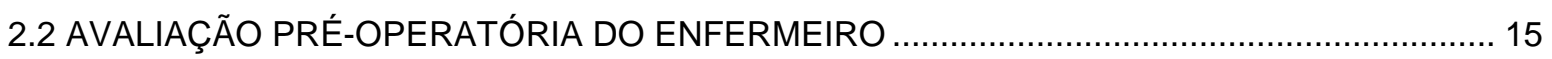

2.3 AVALIAÇÃO PRÉ-OPERATÓRIA DO ANESTESIOLOGISTA ................................................. 18

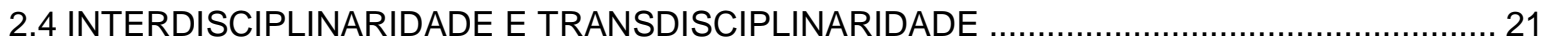

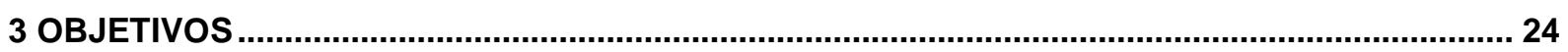

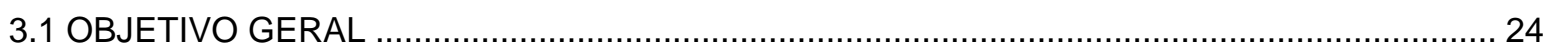

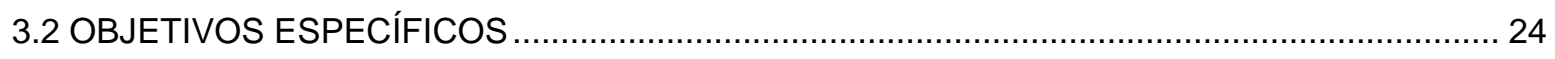

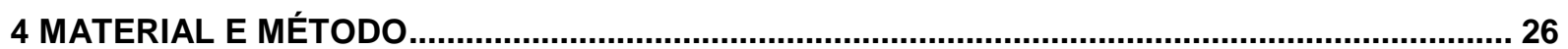

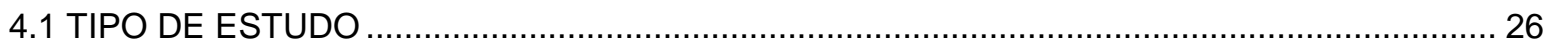

4.1.1 Estudo metodológico empregando técnicas psicométricas ............................................ 26

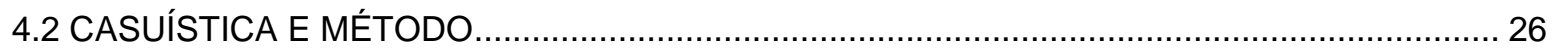

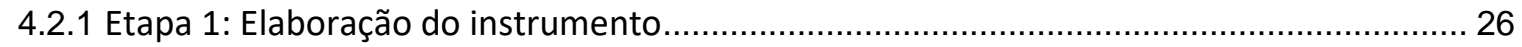

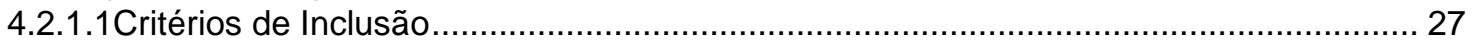

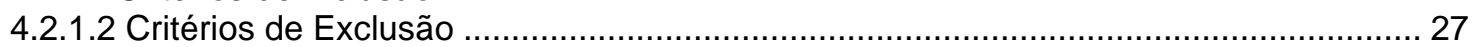

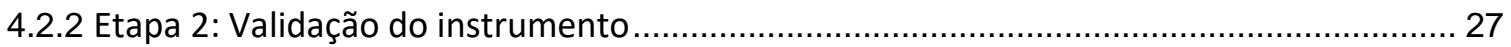

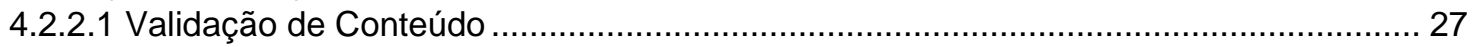

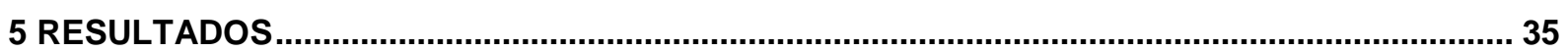

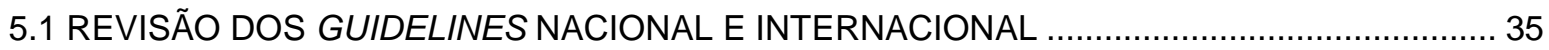

5.1.1 Sintese do conteúdo das diretrizes práticas em enfermagem cirúrgica e processamento de produtos para saúde - SOBECC 2017 ................................................................. 36

5.1.2 Síntese do conteúdo da AORN, Guidelines for Perioperative Practice of the American Association ..................................................................................................... 40

5.1.3 Síntese do conteúdo da ASA, Guidelines for Patient Care in Anesthesiology ...................... 50

5.1.3 Síntese do conteúdo da ESA, Guidelines of the European Society of Anaesthesiology ..... 56

5.2 Validação do Instrumento de Avaliação Pré-Operatória Transdisciplinar ................................... 64

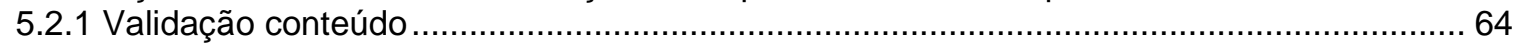

6 DISCUSSÃO

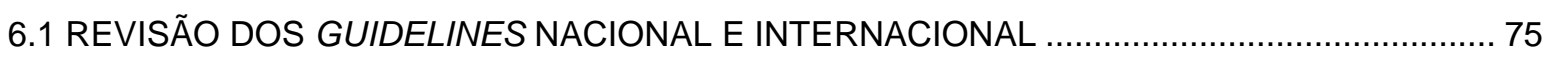

6.2 Validação do Instrumento de Avaliação Pré-Operatória Transdisciplinar .................................. 77

7 CONCLUSÃO

8 IMPLICAÇÕES PARA A PRÁTICA E PESQUISA

REFERÊNCIAS

APÊNDICES 


\section{Justificativa do estudo}




\section{JUSTIFICATIVA DO ESTUDO}

O tema do estudo foi selecionado desde a minha graduação de enfermagem, sendo o foco da pesquisa de conclusão de curso. Para tanto, realizei uma revisão integrativa da literatura. A conclusão obtida com essa metodologia demonstrou a escassez de estudos sobre o tema referente à visita pré-operatória de enfermagem. Somando-se a isso, vivenciei, ao realizar a avaliação pré-operatória em um hospital escola, a repetição de questionamentos feitos pelos profissionais da saúde como o anestesiologista, nutricionista, enfermeiro da clínica cirúrgica e de centro cirúrgico. Embora o objetivo dessa avaliação fosse esclarecer as dúvidas, muitas vezes tornava-se estressante e cansativa para os pacientes responderem às mesmas perguntas feitas por diversos profissionais da equipe, causando certo desconforto.

Desde então, venho estudando o tema avaliação pré-operatória, identificando as dificuldades enfrentadas pelos enfermeiros perioperatórios, as quais interferem na segurança do paciente cirúrgico no período perioperatório.

Assim, esse estudo propõe um instrumento para a avaliação pré-operatória, que centralize as informações necessárias para a equipe multiprofissional, envolvendo o enfermeiro perioperatório e o anestesiologista, que evite as repetições de questionamentos como também erros e eventos adversos que afetam não só o paciente, mas também a assistência perioperatória. 


\section{Introdução}




\section{INTRODUÇÃO}

\subsection{SEGURANÇA DO PACIENTE CIRÚRGICO}

A cultura da segurança do paciente cirúrgico está em evidência devido ao crescente número de erros e eventos adversos relatados na literatura, os quais poderiam ser prevenidos.

Em 2004 foi criada a Aliança Mundial para Segurança do Paciente pela Organização Mundial da Saúde (OMS), incluindo o Programa Cirurgias Seguras Salvam Vidas, que tem como objetivo elevar os padrões de qualidade em serviços de assistência à saúde através do estabelecimento de práticas para cirurgia segura. O programa apresentou uma lista de verificação, ou checklist, cujo objetivo é auxiliar na conferência de elementos essenciais relativos à segurança do paciente (MAZIERO et al., 2015; OMS, 2009).

Um estudo americano de 2002 mostrou que, num período de seis meses em um Centro Cirúrgico (CC) nos EUA, foi evidenciada uma taxa de mortalidade relacionada a erros médicos de um para cada 270 erros $(0,4 \%)$ e $65 \%$ desses erros foram considerados como evitáveis (CALLAND; ADAMS; BENJAMIN, 2002).

Atualmente, o ambiente cirúrgico é considerado altamente inseguro, com uma taxa de eventos adversos estimada em um para cada 10.000 cirurgias. A taxa de mortalidade cirúrgica, se comparada à da aviação civil (inferior a uma por 1.000 .000 de exposições), faz com que a saúde seja considerada mais perigosa. Somado a esses fatores, ainda há o custo social e financeiro desses erros (FILHO et al., 2013).

De acordo com a OMS, a segurança do paciente pode ser alcançada por meio de três ações complementares, a saber: evitar a ocorrência dos eventos adversos, torná-los visíveis se ocorrerem e minimizar seus efeitos com intervenções eficazes. Com base nisso, em 2008 foi lançado o desafio mundial "Cirurgias Seguras Salvam Vidas", que tem como objetivo aumentar os padrões de qualidade da assistência cirúrgica em serviços de saúde de todo o mundo. Este programa foca a atenção nos fundamentos e práticas da segurança cirúrgica, observando a necessidade de investimento na melhoria da qualidade e garantia da segurança nas intervenções cirúrgicas e que resultem progressivamente em mais vidas salvas com menos danos ao paciente. (WORLD HEALTH ORGANIZATION, 2008). Dentro desta proposta, OMS desenvolveu a lista de verificação cirúrgica (checklist) com auxílio de 
colaboradores de diversos países, guiado por três princípios, são eles: simplicidade, ampla aplicabilidade e possibilidade de mensuração do impacto (OMS, 2009).

Assim, ocorreu um alerta mundial para as instituições públicas e privadas elaborarem protocolos, visando minimizar ocorrências durante o procedimento cirúrgico (OMS, 2009).

Os protocolos estruturados tiveram como base um checklist para cirurgia segura, proposto pela OMS e incluem três etapas de verificação e conferência para ser aplicado ao paciente cirúrgico. São elas: sign in (antes da indução anestésica), time out (antes da incisão cirúrgica) e, sign out (antes do paciente sair da sala operatória) (OMS, 2009).

Diante deste fato, as instituições adaptaram para sua realidade e de acordo com o perfil de paciente atendido, o modelo de checklist da OMS, em prol da garantia de um processo cirúrgico seguro. Então, este modelo de prevenção de riscos foi inserido e adaptado para ser aplicado não somente no período intraoperatório, como também durante todo o período perioperatório. Portanto, o processo de conferência e verificação envolve toda a equipe multiprofissional.

Para que o envolvimento das equipes seja eficaz é necessária uma comunicação ativa e integrada de todos os membros da equipe, com o registro das ações de cada profissional em um único documento de assistência sistematizada.

\subsection{AVALIAÇÃO PRÉ-OPERATÓRIA DO ENFERMEIRO}

O período pré-operatório imediato consiste entre a véspera da cirurgia (24h) até o momento em que o paciente é recebido no CC, este período tem como foco planejar a assistência individualizada, bem como um elo para a continuidade do cuidado no período transoperatório. Segundo as diretrizes práticas em enfermagem cirúrgica e processamento de produtos para saúde - SOBECC, o enfermeiro do centro cirúrgico faz a prescrição de cuidados de enfermagem e a implementação do Sistema de Enfermagem da Assistência Perioperatória (SAEP), promovendo maior interação entre 0 enfermeiro do centro cirúrgico e o paciente (BIANCHI; CAREGNATO; OLIVEIRA, 2016; SOBECC, 2017; MEIRA; FRERIA, 2011).

A realização do SAEP é uma atividade privativa do enfermeiro, segundo a Decisão do Conselho Federal de Enfermagem (COFEN) n. 001/200 de 04/01/2000 
(CONSELHO FEDERAL DE ENFERMAGEM, 2000) e tem como objetivos: identificar e analisar as necessidades individuais do paciente a ser submetido ao procedimento anestésico-cirúrgico; reduzir ao máximo os riscos decorrentes da utilização dos materiais e equipamentos necessários as cirurgias; prever, providenciar e controlar os recursos humanos; implementar a assistência de enfermagem integral, individualizada, documentada, participativa e avaliada, com foco ao paciente no préoperatório, durante a cirurgia e no pós-operatório; e diminuir a ansiedade do paciente, contribuindo para sua recuperação (SOBECC, 2017; POSSARI, 2004).

A avaliação pré-operatória imediata (primeira etapa do SAEP) realizada por meio de uma visita deverá ser de responsabilidade do enfermeiro do CC, pois garante segurança para o paciente, ampliando seu olhar holístico sobre as necessidades a serem encontradas (SOBECC, 2017).

O SAEP consiste em um modelo de intervenções de enfermagem que visa garantir a segurança do paciente durante o período perioperatório. Este modelo está estruturado para atender as necessidades humanas básicas, definido por cinco etapas: 1-Visita pré-operatória de enfermagem, 2-Planejamento de assistência perioperatória, 3-Implementação da assistência, 4-Avaliação da assistência e 5Reformulação da assistência (BIANCHI; CAREGNATO; OLIVEIRA, 2016). Ao avaliar o paciente no período pré-operatório imediato devem ser considerados alguns fatores, tais como: porte cirúrgico, duração do procedimento, tipo de anestesia, estado físico geral, idade, gravidade da doença cirúrgica, estado nutricional, riscos no transoperatório e possíveis complicações no período pós-operatório imediato. Logo, é necessário avaliar criteriosamente todos os riscos para prevenção ou redução de possíveis complicações posteriores (SOBECC, 2017).

Entretanto, neste momento devem ser analisados alguns fatores importantes, sempre com o consentimento do paciente, tais como: pesquisar sobre alergias, patologias, medicamentos em uso, cirurgias prévias, uso de órtese e prótese, marcapasso, estado civil, religião, nível de instrução, profissão, levantar exames laboratoriais e diagnósticos, identificar seus problemas, formular os diagnósticos de enfermagem, fazer as prescrições necessárias para o preparo adequado, plano de cuidados necessário para o transoperatório; orientar jejum oral, retirada de prótese dentaria e lentes de contato, retira de esmalte e adornos, higiene corporal e oral prévia, esvaziamento vesical e intestinal, esclarecimentos sobre a recepção no CC, procedimento anestésico-cirúrgico, recuperação anestésica e pós-operatório 
imediato, desconforto causados pela dor, pela posição e permanência no leito, exercício respiratório, deambulação precoce, prevenção de complicação respiratórias, cardiovasculares e lesões de pele, estimular o autocuidado, desde 0 pré-operatório (SOBECC, 2017).

Esta avaliação permite que o enfermeiro do CC junto com os demais enfermeiros elabore um plano de cuidados, a fim de reduzir e prevenir as complicações pós-operatórias (BIANCHI; CAREGNATO; OLIVEIRA, 2016; SOBECC, 2017; MEIRA; FRERIA, 2011).

Com os dados obtidos com a avaliação pré-operatória, e as dúvidas do paciente esclarecidas, identificam-se as necessidades de cada paciente, traçando intervenções que buscam solucionar os problemas que possam dificultar o procedimento cirúrgico (BARNETT, 2005). Portanto, deverá ser realizado o histórico de enfermagem, utilizando-se da anamnese, exame físico e observação direta do paciente, além de identificar diagnósticos e realizar prescrições para o período transoperatório (SOBECC, 2017).

O enfermeiro familiarizado com as necessidades do paciente a ser submetido ao ato anestésico-cirúrgico, deverá coletar, identificar e interpretar informações importantes do paciente que, de outra forma, poderiam ser ignoradas. Visto que, os enfermeiros encontram-se bem preparados para identificar e atender às complexas necessidades dos pacientes pré-operatórios, o treinamento avançado e a educação que eles recebem, proporcionam-Ihes as habilidades para reconhecer e gerenciar problemas médicos, educacionais e emocionais. Além disso, o enfermeiro se utiliza de referenciais metodológicos para fornecer cuidados holísticos, criando relacionamentos colaborativos com os membros da equipe perioperatória. Após certificar-se de que o paciente está realmente preparado para a cirurgia proporcionará uma experiência perioperatória mais positiva para os pacientes, aos membros da sua família e aos membros da equipe multiprofissional perioperatória (BARNETT, 2005).

Segundo Barnett (2005), a realização completa da avaliação pré-operatória permite evitar cancelamentos e atrasos cirúrgicos, causados por exemplo por situações como: alterações em eletrocardiogramas, hipertensão, angina, insuficiência cardíaca congestiva, doença de válvula, doença da artéria coronária, asma, pneumonia, doença de obstrução pulmonar crônica, infecção respiratória superior, diabetes descompensada, disfunção tireoidiana, testes elevados da função 
hepática, presença de conteúdo gástrico, ataques isquêmicos transitórios, acidente vascular cerebral, infecção do trato urinário, insuficiência renal aguda, diálise instável, teste de gravidez positivo, alteração da integridade da pele no local da cirurgia, anormalidades dos testes laboratoriais, falta informações médicas (histórico clínico e exame físico), termos de consentimentos anestésico e cirúrgico e, diagnósticos clínicos.

A ansiedade e o medo são sentimentos comuns nesse momento e o enfermeiro precisa estar apto, não só para detectar, em curto intervalo de tempo, como também, traçar um plano de cuidados perioperatórios capaz de proporcionar, segurança, tranquilidade e satisfação ao paciente durante a experiência cirúrgica (WIENS, 1998).

Desta forma, a essência da avaliação pré-operatória de enfermagem deve ser entendida como o elo entre o enfermeiro e o paciente. É neste momento, que se inicia o planejamento da assistência perioperatória, conferindo segurança durante o processo cirúrgico e minimizando medos e ansiedade (FONSECA; PENICHE, 2009).

Assim, a avaliação pré-operatória apresentou maior visibilidade, atualmente, devido à publicação pelo Ministério da Saúde do Programa Nacional de Segurança

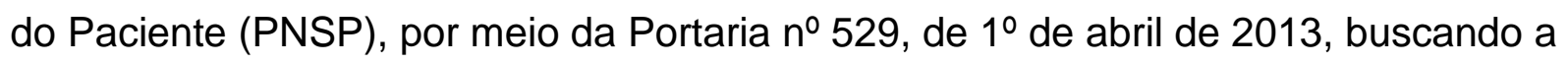
prevenção de eventos adversos nos serviços de saúde. Nesta portaria são destacadas as iniciativas para garantir a segurança do paciente, tal como gerenciamento de riscos e núcleos de segurança (BRASIL; MINISTÉRIO DA SAÚDE, 2013).

\subsection{AVALIAÇÃO PRÉ-OPERATÓRIA DO ANESTESIOLOGISTA}

Quando falamos da intervenção do profissional anestesiologista, temos como instrumento estratégico a Avaliação Pré-Anestésica (APA), a qual pode ser realizada por meio de uma consulta ambulatorial ou na visita pré-operatória feita pelo médico anestesiologista, para reconhecer as condições clínicas e mentais do paciente. Esta avaliação tem como objetivo determinar a necessidade de exames complementares, escolher a técnica e a analgesia pós-operatória e avaliar a necessidade da medicação pré-anestésica de acordo com o porte da cirurgia, por meio de anamnese e exame físico (MEIRA; FRERIA, 2011). 
A Resolução 1.363/93 do Conselho Federal de Medicina, em seu artigo 1.. inciso 1, determina: "Antes da realização de qualquer procedimento anestésico é indispensável conhecer, com antecedência, as condições clínicas do paciente, cabendo ao anestesista decidir a conveniência ou não da prática do ato anestésico, de modo soberano e intransferível" (FERNANDES et al., 2010).

$\mathrm{Na}$ anamnese ocorre a identificação e o histórico clínico essencial, a saber: idade (extremo de idade possuem maior risco), gênero (mulher são mais sensíveis à dor), peso (obesos possuem riscos maiores de infecção), investigar comorbidades, medicações em uso, histórico de alergias a drogas, etilismo, tabagismo, uso de drogas ilícitas, além de avaliar os sistemas cardiovascular, respiratório, digestório, endócrino, neurológico, hematológico, renal, musculoesquelético, imunológico e o estão nutricional. O exame físico permite ao anestesiologista conhecer e se preparar para alguns desafios que possam ocorrem no ato anestésico, como por exemplo, uma via aérea difícil. De acordo com a American Society of Anaesthesiologists (ASA), o paciente pode se classificado de acordo com suas comorbidades encontradas na avaliação pré-anestésica, sendo: Estado Físico 1 paciente sem patologias; Estado Físico 2 paciente com doença sistêmica leve e controlada; Estado Físico 3 paciente com doença sistêmica que limita atividade, mas não é incapacitante; Estado Físico 4 paciente com doença sistêmica incapacitante que representa ameaça/perigo constante à vida; Estado físico 5 paciente moribundo, com expectativa de vida menor que 24h sem cirurgia; Estado Físico 6 paciente com morte cerebral, órgãos sendo removidos para doação. Com base nessas informações é que o anestesiologista irá solicitar os exames complementares (SAKLAD, 1941).

Portanto, a APA pode ser definida como um instrumento de triagem para identificar pacientes com alto risco de complicações perioperatórias, sendo aplicado ao paciente durante a avaliação pré-operatória e/ou na consulta especializada com o anestesiologista, com intuito de reduzir a mortalidade e a morbidade pós-operatória (MENDES et al., 2013).

A avaliação do anestesiologista também é direcionada ao jejum préoperatório, o qual foi instituído no início das práticas anestésicas, para garantir o esvaziamento do conteúdo gástrico, evitar broncoaspiração, vômitos, regurgitação, administração de várias drogas para reduzir a acidez gástrica e volume (LUDWIG, 2013). 
Os protocolos atuais sugerem redução do período de jejum, principalmente para líquidos, possibilitando mais conforto aos pacientes, reduzindo risco de hipoglicemia e desidratação, sem aumentar a incidência de aspiração pulmonar perioperatória (LUDWIG, 2013; MORO, 2013).

Novas diretrizes baseadas em evidências foram publicadas nos últimos anos pelos Estados Unidos, Canadá e Europa recomendando, não só a diminuição do tempo de jejum pré-operatório, como também permitindo a administração de líquidos claros e bebidas ricas em carboidrato até poucas horas antes da cirurgia eletiva ou outros procedimentos que requerem anestesia, proporcionando qualidade ao atendimento, segurança e saúde do paciente (LUDWIG, 2013).

Do ponto de vista metabólico, o jejum prolongado incorre na diminuição dos níveis de insulina, aumento de glucagon e resistência à insulina, o que pode estender-se pelo período de até três semanas após a cirurgia, intensificando o estresse metabólico do paciente pós-cirúrgico (LUDWIG, 2013).

Baseado nestas evidências e nos estudos realizados pelo grupo europeu Enhanced Recovery After Surgery - ERAS, em que foram abordadas novos métodos de manejo perioperatório visando à diminuição de complicações cirúrgicas e, acelerando a recuperação dos pacientes (NYGREN et al., 2005); desenvolveu-se a proposta para implantação do protocolo de Aceleração da Recuperação Total PósOperatória, denominado ACERTO, em que o tempo de jejum para alimentos sólidos foi mantido e permitido a ingestão de $200 \mathrm{ml}$ de maltodextrina oferecida aos pacientes duas horas antes do procedimento cirúrgico. Esse protocolo brasileiro foi criado para minimizar a resposta ao estresse da cirurgia além de diminuir o período de internação hospitalar. Como resultado obtiveram os benefícios que uma curta estadia proporciona ao paciente, além de minimizar custos hospitalares (AGUILARNASCIMENTO et al., 2006).

O grupo europeu permite líquidos claros (água, chá e sucos sem resíduos) até duas horas antes do procedimento cirúrgico. Já a ASA inclui no seu protocolo de jejum de duas horas para pacientes adultos e pediátricos, líquidos sem resíduos, bebidas carbonadas e sucos de frutas sem polpa. A torrada e o leite não materno serão permitidos até seis horas antes da cirurgia. Para casos de ingestão de leite materno o jejum será no mínimo de quatro horas para recém-nascidos e lactentes. Alimentos mais consistentes como carnes e preparações ricas em gordura exigem 
Catharina Ferreira de Meira Pachioni

jejum prolongado de oito horas, tanto para pacientes adultos quanto pediátricos (LUDWIG, 2013; MORO, 2013; OLIVEIRA et al., 2009).

\subsection{INTERDISCIPLINARIDADE E TRANSDISCIPLINARIDADE}

$O$ conceito de interdisciplinaridade surgiu no século $X X$, porém somente a partir da década de 60, focou no ato de transcender e atravessar o conhecimento fragmentado, ampliando a visão de mundo, da realidade que nos cerca, com o intuito de superar os limites da visão disciplinar (VILELA; MENDES, 2003).

Segundo Japiassu (1976), a "interdisciplinaridade se caracteriza pela intensidade das trocas entre os especialistas e pelo grau de integração real das disciplinas no interior de um mesmo projeto de pesquisa." Além disto, ele refere que a transdisciplinaridade iria mais além, não se limitando às interações e às reciprocidades entre as disciplinas, uma vez que propõe a ausência de fronteiras entre elas. Segundo alguns pesquisadores, a saúde estaria inserida nesta dimensão.

A interdisciplinaridade ocorre no momento em que a comunicação gerar integração mútua dos conceitos entre as disciplinas, construindo um novo conhecimento ou buscando a resolução para um problema concreto. Portanto, é considerada como uma interrelação e interação das disciplinas a fim de atingir um objetivo comum. Assim, ela se apresenta como resposta à diversidade, à complexidade e à dinâmica do mundo atual (MEIRELES; ERDMANN, 1999).

Desta forma, a saúde como campo transdisciplinar pela complexidade de seu objeto, evidencia atendimentos de equipe multiprofissional, em que percebemos a organização de serviços sendo realizada de forma fragmentada. Entretanto, não devemos denominar a terminologia 'trabalho em equipe multiprofissional' como 'interdisciplinaridade ou transdisciplinaridade', mas como uma possibilidade de integração das disciplinas científicas, pois se apoiam e se operacionalizam em tecnologias que se refletem nos processos de trabalho do cotidiano (VILELA; MENDES, 2003).

A partir do conteúdo apresentado, podemos observar que atuação integrada da equipe multiprofissional, a partir de uma avaliação pré-operatória, seria responsável por minimizar a ansiedade e estresse pré-cirúrgico do paciente, assim como esse modelo de avaliação deveria repercutir positivamente na satisfação do 
paciente. Visto que, as informações, os questionamentos e dados coletados não teriam as repetições e, o paciente não se sentiria irritado ou até mesmo preocupado com a insistência questionamentos de alguns pontos de sua história.

Acredita-se que a repetição existente e vivenciada de questionamentos feitos aos pacientes, muitas vezes exagerada e dispersa em todo o prontuário, decorra da coleta efetuada por diversos profissionais envolvidos com as avaliações, da inexistência de um instrumento transdisciplinar de avaliação pré-operatória e associada uma falha na comunicação entre os profissionais.

Portanto, este estudo propõe a elaboração de um único instrumento de avaliação pré-operatória transdisciplinar que sintetize e agrupe as informações e dados dos pacientes cirúrgicos. 


\section{Objetivos}




\section{OBJETIVOS}

\subsection{OBJETIVO GERAL}

Elaborar e realizar a validação de conteúdo de um instrumento de avaliação pré-operatória transdisciplinar.

\subsection{OBJETIVOS ESPECÍFICOS}

Revisar a literatura científica sobre as estratégias pré-operatórias realizadas pelos profissionais enfermeiro perioperatório e médico anestesiologista. 
Material e método 


\section{MATERIAL E MÉTODO}

\subsection{TIPO DE ESTUDO}

\subsubsection{Estudo metodológico empregando técnicas psicométricas}

Baseado em uma revisão dos guidelines nacional e internacional de enfermagem perioperatória e da anestesiologia para criação e validação de um instrumento de avaliação pré-operatória transdisciplinar para pacientes submetidos a cirurgias eletivas.

Para a construção deste instrumento utilizou-se diretrizes sobre ações e cuidados executados pela equipe multiprofissional durante o período pré-operatório em prol da segurança do paciente cirúrgico no período transoperatório.

$\mathrm{Na}$ presente investigação foi aplicado o conceito de validação de conteúdo (VC).

\subsection{CASUÍSTICA E MÉTODO}

\subsubsection{Etapa 1: Elaboração do instrumento}

A estratégia de pesquisa tem como objetivo revisar os guidelines das seguintes associações de classe: Diretrizes práticas em enfermagem cirúrgica e processamento de produtos para saúde - SOBECC (Associação Brasileira de Enfermeiros de Centro Cirúrgico, Recuperação Anestésica e Centro de Material e Esterilização), AORN Guidelines for Perioperative Practice of the American Association, ASA Guidelines for Patient Care in Anesthesiology of the American Society e, ESA Guidelines of the European Society of Anaesthesiology. 


\subsubsection{Critérios de Inclusão}

Esta revisão considera guidelines que incluem pacientes adultos em período pré-operatório de cirurgias eletivas, os quais apresentem como intervenção as visitas pré-operatórias como estratégias de avaliação que visam garantir a segurança do paciente cirúrgico no período transoperatório.

\subsubsection{Critérios de Exclusão}

Foram excluídos os guidelines que não abordaram avaliações préoperatórias. Também não foram incluídos guidelines preconizados para pacientes de urgência e emergência e, para pacientes pediátricos.

Os guidelines da European Operating Room Nurses Association (EORNA) não foram abordados neste estudo, pois não apresentaram relevância significativa na atuação de enfermeiros perioperatórios brasileiros. Visto que, não são diretrizes práticas com aplicabilidade, quando comparados aos guidelines da SOBECC e AORN.

As diretrizes recomendadas pela Sociedade Brasileira de Anestesiologia (SBA) também não foram destacadas neste estudo, pelo fato de não evidenciarem os cuidados pré-operatórios.

\subsubsection{Etapa 2: Validação do instrumento}

\subsubsection{Validação de Conteúdo}

A validação de conteúdo (VC) é a medida em que um conjunto de itens específicos refletem um domínio de conteúdo, ou seja, se a ferramenta construída reflete a definição conceitual aplicada à escala. A VC deve ser realizada por meio de especialistas da área temática ou constructo em questão (DEVELLIS, 2016).

Desta forma, esta validação difere de outras formas de teste de validade em um aspecto importante; isto e, não é baseada na pontuação da escala, apenas no julgamento de especialistas sobre o conteúdo do item, sendo assim, a relevância do 
conteúdo e sua representatividade afetam a inferência do escore final do instrumento (STREINER; NORMAN, 2008).

Segundo DeVellis (2016) para a elaboração e VC de um instrumento, as seguintes etapas devem ser percorridas:

\section{Etapa 01 - Determinar o tema estudado}

Inicialmente deve-se definir o conteúdo do instrumento; isto é, o constructo a ser mensurado, além do nível de especificidade ou generalidade em que será medido (DEVELLIS, 2016).

$\mathrm{Na}$ presente investigação, foi proposto um instrumento de avaliação préoperatória, seguindo os critérios definidos internacionalmente pela AORN, ASA e ESA e, nacionalmente pela SOBECC.

\section{Etapa 02 - Desenvolvimento de um conjunto de itens}

Para a construção dessa ferramenta foi estruturado um conjunto de itens para eventual inclusão, criados a partir dos guidelines nacional proposto pela SOBECC e internacional destacados pela AORN, ASA e ESA, com o objetivo específico de elaborar uma ferramenta para garantir a segurança do paciente cirúrgico no período transoperatório.

Assim, os itens propostos são:

- Dados Gerais: nome do paciente / data de nascimento / gênero / idade / peso / altura / diagnóstico de base / nome do cirurgião / termos de consentimento cirúrgico e anestésico.

- Histórico Pessoal e Psicossocial: estado civil / escolaridade / espiritualidade, religião / drogas ilícitas / etilismo / tabagismo / estado nutricional / alergias, sensibilidades, intolerância / cirurgias anteriores / medicamentos em uso diário / terapias complementares / tempo de jejum.

- Sistema Cardiovascular: estudo cardíaco basal (pressão arterial, frequência cardíaca), trombose venosa profunda (profilaxia mecânica e farmacológica) / insuficiência cardíaca congestiva / infarto agudo do 
miocárdio / arritmias, coronariopatias / valvulopatias, valvulopatias periféricas / outras patologias.

- Sistema Respiratório: estado respiratório basal (saturação, frequência respiratória) / doença pulmonar obstrutiva crônica / mallampati (I, II, III e IV) / previsão de via aérea difícil / apnéia do sono, asma, tosse produtiva / infecção de vias aéreas superiores, pneumonia / dispneia de esforço / outras patologias.

- Sistema Digestório: gastrite, refluxo gastroesofágico / esofagite, úlcera péptica / hepatite, cirrose / sangramento digestivo (alto/ baixo) / outras patologias.

- Sistema Endócrino: diabetes mellitos tipo I ou II / doença da tireoide ou paratireoide / doenças da hipófise / insuficiência adrenal / outras patologias.

- Sistema Neurológico: nível de consciência, déficit cognitivo / convulsões, labirintopatias, cefaleias / alterações de sensibilidade e motricidade / acidente vascular encefálico / lesão medular / outras patologias.

- Sistema Hematológico: discrasias sanguíneas, anemias / transfusão sanguínea prévia / distúrbios de coagulação / trombose venosa pulmonar e periférica / equimoses, hematomas, epistaxe / tipagem sanguínea, reserva de hemocomponente / outras patologias.

- Sistema Renal: infecção urinária de repetição / doença renal crônica (dialítica ou não dialítica) / outras patologias.

- Sistema Tegumentar: integridade da pele (equimoses, edemas, hematomas, lesões de pele) / outras patologias.

- Sistema Musculoesquelético: malformações Osteomoleculares / limitação física ou mobilidade prejudicada / algias lombares, artrites, artroses, hérnias de disco / outras patologias.

- Sistema Imunológico: HIV positivo / tuberculose, infecção respiratória ou urinária / outras patologias.

- Sistema Sensorial: dificuldades sensoriais (visão, audição, fala, tato, paladar) / percepção sensorial da dor / hipotermia / outras patologias. 
- Educação em Saúde: classificação ASA (1, 2, 3 e 4) / dúvidas do procedimento cirúrgico / nível de ansiedade / tipo de anestesia, medicação pré-anestésica / tipo de isolamento (respiratório gotículas ou ar, contato) / demarcação cirúrgica, lateralidade / banho pré-operatório com antisséptico / tricotomia pré-operatória / protocolos de segurança perioperatória / presença de próteses, implantes ou adornos / presença de dispositivos externos (cateteres, drenos, imobilizadores ortopédicos) / capacidade de tolerar o posicionamento cirúrgico / outras considerações

- Exames Diagnósticos: exames laboratoriais / exames de imagem / outros exames.

\section{Etapa 03 - Escolha dos juízes especialistas e validação de conteúdo}

A VC do instrumento foi realizada por profissionais de saúde especialistas nas áreas de anestesiologia e enfermagem perioperatória em CC de alta complexidade.

Não há na literatura um consenso sobre a quantidade de juízes especialistas a serem selecionados para compor o painel de julgamento, variando entre três e 20 juízes especialistas (HERNÁNDEZ-NIETO, 2002). Dessa forma, esta investigação adotou a recomendação proposta por Hernández-Nieto (2002) que indica no mínimo três e no máximo cinco juízes especialistas.

Assim, considerou-se relevante selecionar 5 juízes especialistas com experiência e conhecimento prático na área de enfermagem perioperatória e anestesiologia para a VC desta ferramenta. Portanto, foram selecionados profissionais com domínio nestes setores de conhecimento; com título de mestre ou doutor na área de enfermagem/medicina, com dissertação/tese na área temática e publicação de artigos sobre estes temas em periódicos relevantes (GRANT; DAVIS, 1997; DAVIS, 1992).

Inicialmente, os pesquisadores foram contatados por meio de correio eletrônico, convidando-os a participarem do painel de juízes desta investigação (APÊNDICE A). Ao concordar, o indivíduo era direcionado a leitura do termo de compromisso para a participação desta pesquisa (APÊNDICE B). Após o aceite deste termo, o juiz visualizava uma orientação, contendo esclarecimentos sobre como deveria ser avaliado o instrumento proposto (APÊNDICE C). O retorno do questionário respondido variou entre um a 20 dias. 
Os juízes especialistas analisaram o instrumento quanto à relevância daquele item ao tema discutido, clareza ao abordar o assunto e abrangência em relação ao conteúdo científico que estava sendo avaliado.

Cada item foi avaliado pelos juízes por meio de uma escala tipo Likert. A escala Likert permite medir atitudes e/ou opiniões, por meio de uma série de afirmações relacionadas ao objeto pesquisado, nas quais o sujeito responde seu grau de concordância ou discordância relativo aos itens do instrumento avaliado, indicando por atribuição de números, a direção de sua concordância, em cinco categorias. Neste estudo, os itens foram avaliados de acordo com os seguintes critérios (DEVELLIS, 2016):

- Relevância: deve-se observar se o item é de grande importância para o instrumento.

- 1 = não relevante ou não representativo;

- 2 = item necessita de grande revisão para ser relevante;

- 3 = item necessita de moderada revisão para ser relevante;

- 4 = item necessita de pequena revisão para ser relevante;

- 5 = item relevante ou representativo.

- Clareza: deve-se observar se o item é claro; ou seja, compreensível em relação ao tema abordado.

- 1 = não apresenta clareza;

- 2 = item necessita de grande revisão para ser claro;

- 3 = item necessita de moderada revisão para ser claro;

- 4 = item necessita de pequena revisão para ser claro;

- 5 = item claro.

- Abrangência: deve-se observar se o item compreende todos os aspectos que devem ser abordados em relação à temática.

- 1 = não abrangente;

- 2 = item necessita de grande revisão para ser abrangente;

- 3 = item necessita de moderada revisão para ser abrangente;

- 4 = item necessita de pequena revisão para ser abrangente;

- 5 = item abrangente. 


\section{Etapa 04 - Análise da Validação de Conteúdo}

A concordância entre juízes sobre os aspectos do instrumento e seus itens foi avaliada por meio do Coeficiente de Validação de Conteúdo e Concordância total (CVCt), método utilizado para obter individualmente o coeficiente de cada critério avaliado, e após, o coeficiente total de cada item do instrumento, medindo-os entre validade e concordância inaceitável (menor que 0,80); validade e concordância satisfatória (maior ou igual a 0,80) e validade e concordância excelentes (igual ou maior de 0,90) (HERNANDEZ-NIETO, 2002).

Para a realização do CVCt, a princípio, calcula-se o Coeficiente de Validação de Conteúdo de cada item (CVCi), que pode ser visto pela pontuação de cada item atribuída pelos juízes (Mx), em relação a proporção total possível (Vmx), ou seja:

$$
\text { CVCi }=\frac{M x}{V m x}
$$

A seguir calcula-se a probabilidade aleatória de concordância entre os juízes para cada item $\left(\mathrm{P}_{\mathrm{e}}\right)$, onde $\mathrm{J}$ refere-se ao número de juízes, segundo a seguinte fórmula:

$$
P_{e}=(1 / J)^{J}
$$

Por fim, após os cálculos descritos anteriormente, realizou-se o Coeficiente de Validação de Conteúdo de cada item menos a probabilidade de erro $\left(\mathrm{P}_{\mathrm{e}}\right)$, nomeado CVCic, conforme a fórmula a seguir:

$$
\text { CVCic }=\text { CVCi }-P_{e}
$$

Os cálculos do CVCi e o CVCic para cada critério avaliado, ou seja, relevância, clareza e abrangência, proporcionou o CVCt entre os juízes, conforme a fórmula:

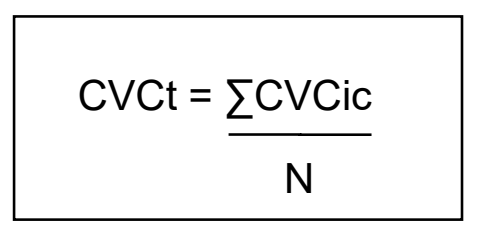


Após o cálculo do CVCt, os resultados por item iguais ou maiores a 0,80 foram mantidos tal qual apresentados. Ocasionalmente, considerando a elaboração de itens recomendados pelos guidelines, os quais foram agrupados em sistemas, se houvesse valores iguais no CVCt, seria selecionada a apresentação com maior pontuação não aproximada atribuída pelos juízes especialistas. Os itens com notas inferiores foram reelaborados, segundo as sugestões dos juízes. 


\section{Resultados}




\section{RESULTADOS}

A apresentação dos resultados foi dividida em dois tópicos: revisão dos guidelines nacional e internacional e, VC do instrumento de avaliação pré-operatória transdisciplinar.

\subsection{REVISÃO DOS GUIDELINES NACIONAL E INTERNACIONAL}

O material selecionado para o desenvolvimento do tema proposto constitui-se de 43 guidelines de enfermagem perioperatória e, 29 guidelines de anestesiologia. Entretanto, após avaliação do conteúdo e aplicação dos critérios de inclusão e exclusão resultou em 16 guidelines de enfermagem perioperatória e, 13 guidelines de anestesiologia. O material foi publicado no idioma inglês e português.

Em relação à data de publicação, os guidelines de enfermagem americana datam do ano 2017, os guidelines de enfermagem brasileira datam do ano 2017 , os guidelines de anestesiologia americana datam do ano 2012-2016 e, os guidelines de anestesiologia europeia datam do ano 2011-2017.

$\mathrm{Na}$ tabela 1 está demonstrado o quantitativo dos guidelines encontrados e selecionados de acordo com as áreas de atuação (enfermagem perioperatória e anestesiologia), usando-se as expressões descritas na seção do método.

Tabela 1 Resultados do levantamento dos guidelines nacional e internacional de avaliação pré-operatória, de acordo com as áreas de atuação.

\begin{tabular}{lcc}
\hline \multicolumn{1}{c}{ Áreas } & $\begin{array}{c}\text { Guidelines } \\
\text { encontrados }\end{array}$ & $\begin{array}{c}\text { Guidelines } \\
\text { selecionados }\end{array}$ \\
\hline $\begin{array}{l}\text { SOBECC Diretrizes e Práticas da Enfermagem Cirúrgica } \\
\text { AORN Guidelines for Perioperative Practice of the American } \\
\text { Association } \\
\begin{array}{l}\text { ASA Guidelines for Patient Care in Anesthesiology of the } \\
\text { American Society }\end{array}\end{array}$ & 32 & 7 \\
ESA Guidelines of the European Society of Anaesthesiology & 21 & 7 \\
\hline Total & 72 & 28 \\
\hline
\end{tabular}




\subsubsection{Sintese do conteúdo das diretrizes práticas em enfermagem cirúrgica e processamento de produtos para saúde - SOBECC 2017}

\begin{tabular}{|c|c|c|}
\hline \multirow{4}{*}{$\begin{array}{l}\text { Guideline } \\
\text { G_01 }\end{array}$} & \multicolumn{2}{|l|}{ Título } \\
\hline & \multicolumn{2}{|c|}{ Recomendações para atuação do enfermeiro no período pré-operatório imediato } \\
\hline & Fonte & Idioma \\
\hline & SOBECC Diretrizes e Práticas da Enfermagem Cirúrgica, 2017 & Português \\
\hline \multicolumn{3}{|c|}{ Propósito } \\
\hline \multicolumn{3}{|c|}{$\begin{array}{l}\text { Neste período, o qual antecede } 24 \text { horas do procedimento cirúrgico até o encaminhamento do paciente ao } \\
\text { centro cirúrgico (CC), é imprescindível avaliar criteriosamente todos os riscos, na tentativa de prevenir ou } \\
\text { reduzir a possibilidade de complicações posteriores. }\end{array}$} \\
\hline \multicolumn{3}{|c|}{ Recomendações } \\
\hline I. & $\begin{array}{l}\text { Dar continuidade à assistência de enfermagem entre a unidade de } \\
\text { paciente em relação às expectativas do período transoperatório. }\end{array}$ & CC, orientando o \\
\hline II. & Realizar histórico, diagnóstico e prescrição de enfermagem para o & e transoperatório. \\
\hline III. & \multicolumn{2}{|c|}{$\begin{array}{l}\text { Realizar levantamento de problemas pautado em informações contidas no prontuário, na } \\
\text { entrevista realizada com o paciente e sua família, no exame físico, na observação direta e nas } \\
\text { informações relatadas pela equipe cirúrgica. } \\
\text { * Entrevista: } \\
\text { - Perguntar ou pesquisar no prontuário sobre alergias, patologias associadas, medicamentos em } \\
\text { uso, cirurgias prévias, fumo, álcool, drogas, uso de órteses e próteses, marca-passo, estado civil, } \\
\text { religião, nível de instrução, profissão e outras informações relevantes; } \\
\text { - Fazer levantamento dos exames laboratoriais e diagnósticos realizados, como radiografia, } \\
\text { ultrassom, tomografia, ressonância magnética, eletrocardiograma e outros; } \\
\text { - Realizar entrevista com o paciente e/ou sua família. O ideal é realizar a entrevista estruturada } \\
\text { para direcionar os tópicos importantes e vitais na coleta de dados. } \\
\text { * Exame físico: } \\
\text { - Identificar seus problemas; } \\
\text { - Formular os diagnósticos de enfermagem; } \\
\text { - Fazer as prescrições necessárias para o preparo adequado do paciente no período pré- } \\
\text { operatório imediato e as intervenções necessárias para o transoperatório; } \\
\text { - Orientar sobre jejum oral (conforme rotina institucional), retirada de próteses dentárias e lentes } \\
\text { de contato, retirada de adornos e esmaltes, higiene corporal e oral prévia, esvaziamento vesical e } \\
\text { intestinal, recepção no CC, procedimentos anestésico-cirúrgicos, recuperação anestésica e pós- } \\
\text { operatório imediato, desconfortos causados pela dor e pela posição/permanência no leito, } \\
\text { deambulação precoce, prevenção de complicações respiratórias, cardiovasculares e lesões por } \\
\text { pressão; } \\
\text { - Estimular o paciente para o autocuidado, desde o período do pré-operatório imediato. }\end{array}$} \\
\hline IV. & \multicolumn{2}{|c|}{$\begin{array}{l}\text { Registrar as informações da avaliação realizada na prescrição de enfermagem ou na evolução } \\
\text { multiprofissional, conforme o protocolo da instituição. } \\
\text { * Informações: } \\
\text { - Verificar sinais vitais, com atenção especial para ocorrência de hipertensão; } \\
\text { - Marcar local ou membro a ser operado; } \\
\text { - Administrar medicação pré-anestésica quando prescrita; } \\
\text { - Verificar e anotar o peso e a altura do paciente, pois os fármacos anestésicos e os } \\
\text { medicamentos são calculados conforme o peso ou o índice de massa corpórea (IMC); }\end{array}$} \\
\hline
\end{tabular}




\begin{tabular}{|c|l|}
\cline { 2 - 2 } & $\begin{array}{l}\text { - Observar sinais de medo e ansiedade, comuns na fase pré-operatória, procurando estimular o } \\
\text { paciente e falar sobre suas expectativas e seus receios. }\end{array}$ \\
\hline & $\begin{array}{l}\text { Checar o preparo operatório do paciente (pré-anestésico, termos de consentimento e outros): } \\
\text { - Jejum conforme a idade e rotina institucional; } \\
\text { - Tricotomia da região a ser operada (deve ser realizada no máximo duas horas antes do } \\
\text { procedimento); } \\
\text { V. Higiene corporal, seguida de aplicação de antisséptico prescrito conforme protocolo da } \\
\text { instituição; } \\
\text { - Retirada de adornos metálicos (atenção especial para piercings), próteses dentárias e lentes de } \\
\text { contato } \\
\text { - Higiene oral; } \\
\text { - Esvaziamento vesical e intestinal antes do encaminhamento para o CC. }\end{array}$ \\
\hline VI. & $\begin{array}{l}\text { Verificar as dúvidas e necessidades do paciente e de sua família em relação ao ato anestésico- } \\
\text { cirúrgico. }\end{array}$ \\
\hline VII. & Reduzir, quando possível, a ansiedade do paciente, comum nesta fase. \\
\hline VIII & Comunicar alterações à equipe cirúrgica. \\
\hline
\end{tabular}

\begin{tabular}{|c|c|c|}
\hline \multirow{4}{*}{$\begin{array}{l}\text { Guideline } \\
\text { G_02 }\end{array}$} & \multicolumn{2}{|l|}{ Título } \\
\hline & \multicolumn{2}{|c|}{ Práticas recomendadas para o preparo pré-operatório da pele do paciente cirúrgico } \\
\hline & Fonte & Idioma \\
\hline & SOBECC Diretrizes e Práticas da Enfermagem Cirúrgica, 2017 & Português \\
\hline \multicolumn{3}{|c|}{ Propósito } \\
\hline \multicolumn{3}{|c|}{$\begin{array}{l}\text { O objetivo destas recomendações são prevenir infecções de sítio cirúrgico (ISC), para melhoria nos registros de } \\
\text { ocorrência e acompanhamento das taxas de ISC. }\end{array}$} \\
\hline \multicolumn{3}{|c|}{ Recomendações } \\
\hline I. & \multicolumn{2}{|c|}{$\begin{array}{l}\text { Preparo mecânico pré-operatório do intestino e antibioticoprofilaxia por via oral de pacientes adultos } \\
\text { que são submetidos a cirurgias colorretais eletivas. }\end{array}$} \\
\hline II. & \multicolumn{2}{|c|}{$\begin{array}{l}\text { Considerar a administração de dieta oral ou enteral por meio do uso de preparações ricas em } \\
\text { múltiplos nutrientes para pacientes com baixo peso que serão submetidos a cirurgias de grande } \\
\text { porte. }\end{array}$} \\
\hline III. & \multicolumn{2}{|l|}{ Desconsiderar a interrupção de medicamentos imunossupressores. } \\
\hline IV. & \multicolumn{2}{|c|}{$\begin{array}{l}\text { Pacientes devem ser submetidos a banho pré-operatório com solução antisséptica ou sabonete. } \\
\text { Além disto, orientar o paciente a não aplicar soluções à base de álcool, loções, emolientes ou } \\
\text { cosméticos na pele após a realização do banho pré-operatório. }\end{array}$} \\
\hline
\end{tabular}

\begin{tabular}{|c|c|c|}
\hline \multirow{4}{*}{$\begin{array}{l}\text { Guideline } \\
\text { G_03 }\end{array}$} & \multicolumn{2}{|l|}{ Título } \\
\hline & \multicolumn{2}{|c|}{$\begin{array}{c}\text { Práticas recomendadas para avaliação pré-operatória voltada aos fatores de risco de trombose } \\
\text { venosa profunda (TVP) }\end{array}$} \\
\hline & Fonte & Idioma \\
\hline & SOBECC Diretrizes e Práticas da Enfermagem Cirúrgica, 2017 & Português \\
\hline \multicolumn{3}{|c|}{ Propósito } \\
\hline \multicolumn{3}{|c|}{$\begin{array}{l}\text { O enfermeiro perioperatório deverá realizar uma avaliação pré-operatória do paciente para determinar fatores } \\
\text { de risco para TVP. }\end{array}$} \\
\hline \multicolumn{3}{|c|}{ Recomendações } \\
\hline I. & \multicolumn{2}{|c|}{$\begin{array}{l}\text { Fatores de risco para estase venosa: idade superior a } 40 \text { anos, câncer e tratamentos associados, } \\
\text { histórico de doença cardiovascular, obesidade, gestação e puerpério, imobilidade ou repouso } \\
\text { restrito ao leito, viagem com duração superior a } 8 \text { horas nas últimas duas semanas, procedimento } \\
\text { ao qual será submetido com duração superior a } 30 \text { minutos e varizes. }\end{array}$} \\
\hline
\end{tabular}




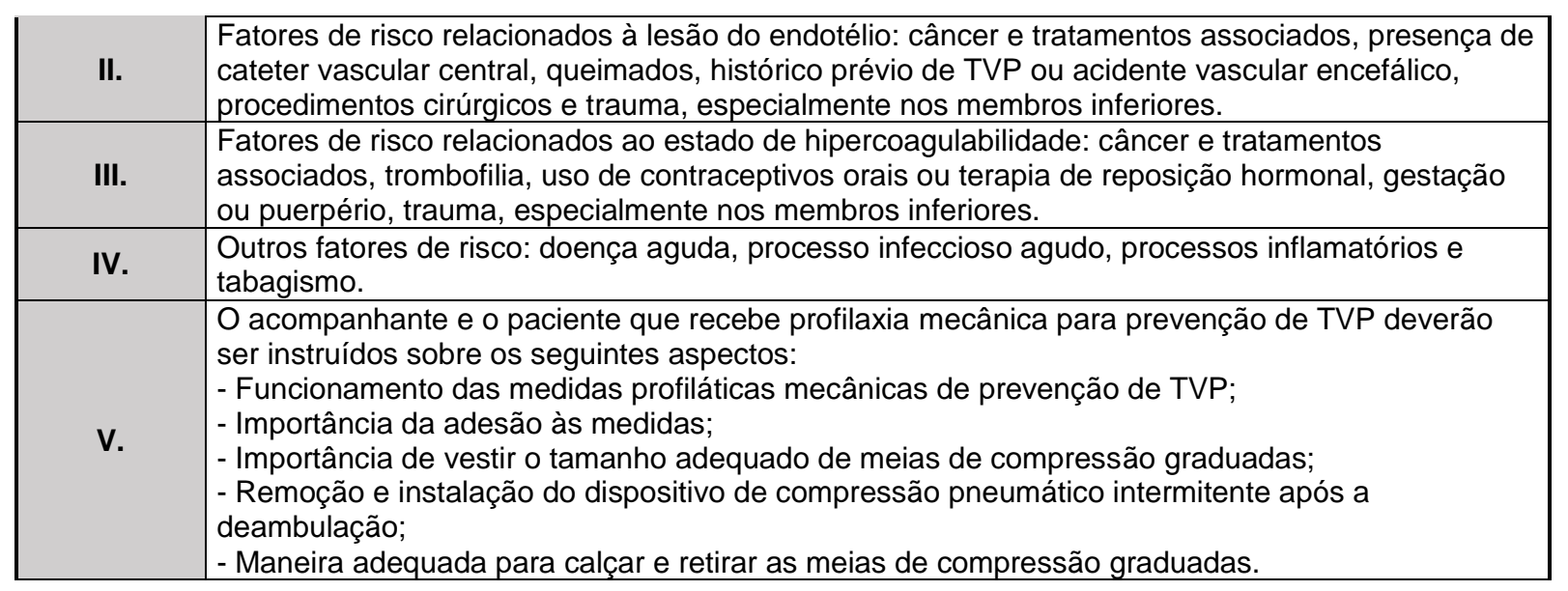

\begin{tabular}{|c|c|c|}
\hline \multirow{4}{*}{$\begin{array}{l}\text { Guideline } \\
\text { G_04 }\end{array}$} & \multicolumn{2}{|l|}{ Título } \\
\hline & \multicolumn{2}{|c|}{ Práticas recomendadas para assistência pré-operatória ao paciente cirúrgico robótico } \\
\hline & Fonte & Idioma \\
\hline & SOBECC Diretrizes e Práticas da Enfermagem Cirúrgica, 2017 & Português \\
\hline \multicolumn{3}{|c|}{ Propósito } \\
\hline \multicolumn{3}{|c|}{$\begin{array}{l}\text { O planejamento do procedimento robótico é de extrema importância para o sucesso da cirurgia e para } \\
\text { prevenção de danos ao paciente. Assim, no período pré-operatório as funções do enfermeiro são essenciais } \\
\text { para garantir a assistência segura e com qualidade ao paciente cirúrgico. }\end{array}$} \\
\hline \multicolumn{3}{|c|}{ Recomendações } \\
\hline I. & \multicolumn{2}{|c|}{$\begin{array}{l}\text { Realização do histórico de saúde do paciente: avaliação de antecedentes clínicos e cirúrgicos, } \\
\text { medicamentos em uso. }\end{array}$} \\
\hline II. & \multicolumn{2}{|c|}{$\begin{array}{l}\text { Orientação ao paciente acerca do procedimento cirúrgico: cuidados pré-operatórios com } \\
\text { alimentação e medicamentos, organização e cuidados durante a cirurgia, cuidados pós- } \\
\text { operatórios com a incisão, dor e potenciais complicações, esclarecimento de dúvidas e avaliação } \\
\text { de medo e ansiedade. }\end{array}$} \\
\hline III. & \multicolumn{2}{|c|}{$\begin{array}{l}\text { Avaliação das disponibilidades de materiais necessários para a cirurgia (instrumental, sistema } \\
\text { robótico, posicionadores para proteção de pele). }\end{array}$} \\
\hline IV. & \multicolumn{2}{|c|}{$\begin{array}{l}\text { Execução do encapamento dos braços robóticos com técnica asséptica e calibração do sistema } \\
\text { de óticas e da câmera. }\end{array}$} \\
\hline
\end{tabular}

\begin{tabular}{|c|c|c|}
\hline \multirow{4}{*}{$\begin{array}{l}\text { Guideline } \\
\text { G_05 }\end{array}$} & \multicolumn{2}{|l|}{ Título } \\
\hline & \multicolumn{2}{|c|}{ Práticas recomendadas para assistência de enfermagem durante o procedimento anestésico } \\
\hline & Fonte & Idioma \\
\hline & SOBECC Diretrizes e Práticas da Enfermagem Cirúrgica, 2017 & Português \\
\hline \multicolumn{3}{|c|}{ Propósito } \\
\hline \multicolumn{3}{|c|}{$\begin{array}{l}\text { A atuação do enfermeiro no procedimento anestésico é essencial para o planejamento e organização de } \\
\text { materiais e equipamentos, trabalho em conjunto com o anestesiologista durante a anestesia, e para } \\
\text { acompanhamento do paciente ao término do procedimento anestésico-cirúrgico. }\end{array}$} \\
\hline \multicolumn{3}{|c|}{ Recomendações } \\
\hline I. & \multicolumn{2}{|c|}{$\begin{array}{l}\text { Visita pré-anestésica, com aplicação e assinatura do termo de consentimento e orientação ao } \\
\text { paciente. }\end{array}$} \\
\hline II. & \multicolumn{2}{|c|}{$\begin{array}{l}\text { Verificação de funcionamento e disponibilidade de materiais e equipamentos para anestesia e } \\
\text { cirurgia. }\end{array}$} \\
\hline
\end{tabular}


III.

Verificação completa dos documentos presentes no prontuário do paciente (termos de consentimento, visita pré-anestésica, exames disponíveis) e da identificação do paciente, procedimento, anestesia e lateralidade.

\begin{tabular}{|c|c|c|}
\hline \multirow{4}{*}{$\begin{array}{c}\text { Guideline } \\
\text { G_06 }\end{array}$} & \multicolumn{2}{|l|}{ Título } \\
\hline & \multicolumn{2}{|c|}{$\begin{array}{l}\text { Práticas recomendadas para identificação de riscos para o desenvolvimento de lesões } \\
\text { decorrentes do posicionamento cirúrgico }\end{array}$} \\
\hline & Fonte & Idioma \\
\hline & SOBECC Diretrizes e Práticas da Enfermagem Cirúrgica, 2017 & Português \\
\hline \multicolumn{3}{|c|}{ Propósito } \\
\hline \multicolumn{3}{|c|}{$\begin{array}{l}\text { A avaliação do paciente por toda a equipe, bem como das informações pertinentes, propicia a identificação das } \\
\text { necessidades e dos riscos de cada paciente cirúrgico e, destaca a provisão de dispositivos de proteção em } \\
\text { tempo hábil para a prevenção de complicações. }\end{array}$} \\
\hline \multicolumn{3}{|c|}{ Recomendações } \\
\hline I. & \multicolumn{2}{|c|}{$\begin{array}{l}\text { Durante o pré-operatório, o enfermeiro perioperatório verificará as necessidades específicas e } \\
\text { confirmará se os equipamentos e dispositivos necessários para auxiliar no posicionamento } \\
\text { cirúrgico do paciente estarão disponíveis e funcionando corretamente antes de o paciente chegar } \\
\text { ao CC. O enfermeiro deverá coletar dados importantes do paciente, tais como: idade, peso, altura, } \\
\text { restrição de movimentação e deformidades, que possam interferir na fixação do paciente na mesa } \\
\text { operatória. }\end{array}$} \\
\hline
\end{tabular}

\begin{tabular}{|c|c|c|}
\hline \multirow{4}{*}{$\begin{array}{c}\text { Guideline } \\
\text { G_07 }\end{array}$} & \multicolumn{2}{|l|}{ Título } \\
\hline & \multicolumn{2}{|c|}{ Práticas recomendadas para prevenção da hipotermia perioperatória } \\
\hline & Fonte & Idioma \\
\hline & SOBECC Diretrizes e Práticas da Enfermagem Cirúrgica, 2017 & Português \\
\hline \multicolumn{3}{|c|}{ Propósito } \\
\hline \multicolumn{3}{|c|}{$\begin{array}{l}\text { O enfermeiro perioperatório deverá compreender as complicações e tomar medidas efetivas para prevenção e/ou } \\
\text { tratamento da hipotermia, a fim de desenvolver o planejamento da assistência e a implementação de } \\
\text { intervenções de enfermagem baseadas nas melhores evidências científicas disponíveis. }\end{array}$} \\
\hline \multicolumn{3}{|c|}{ Recomendações } \\
\hline I. & $\begin{array}{l}\text { Avaliar o paciente e o tipo de procedimento cirúrgico a que ele será s } \\
\text { fatores de risco para ocorrência de hipotermia. São eles: } \\
\text { - Extremos de idade: crianças e idosos; } \\
\text { - Peso corporal: maior peso corporal; } \\
\text { - Distúrbio metabólico: hipotireoidismo, hipopituitarismo; } \\
\text { - Fármacos: benzodiazepínicos; } \\
\text { - Tipo e duração da anestesia: períodos anestésicos maiores que un }\end{array}$ & $\begin{array}{l}\text { em busca de } \\
\text { anestesia geral. }\end{array}$ \\
\hline II. & Iniciar medidas de pré-aquecimento da pele e dos tecidos periféricos & ndução anestésica. \\
\hline III. & $\begin{array}{l}\text { Minimizar a exposição corpórea e remover roupas e campos molhad } \\
\text { calor. }\end{array}$ & mentam a perda de \\
\hline IV. & $\begin{array}{l}\text { A equipe perioperatória participará ativamente das atividades, quano } \\
\text { número adequado de pessoas para o posicionamento cirúrgico, tran } \\
\text { elevação seguros do paciente durante todas as fases do cuidado. }\end{array}$ & $\begin{array}{l}\text { ssário garantir o } \\
\text { imentação e }\end{array}$ \\
\hline V. & $\begin{array}{l}\text { O enfermeiro perioperatório deve identificar as alterações fisiológicas } \\
\text { ou procedimentos específicos durante o posicionamento. }\end{array}$ & ssitam de cuidados \\
\hline
\end{tabular}




\subsubsection{Síntese do conteúdo da AORN, Guidelines for Perioperative Practice of the American Association}

\begin{tabular}{|c|c|}
\hline \multirow{4}{*}{$\begin{array}{l}\text { Guideline } \\
\text { G_01 }\end{array}$} & Título \\
\hline & Diretriz para atendimento do paciente recebendo anestesia local \\
\hline & Idioma \\
\hline & AORN Guidelines for Perioperative Practice, 2017 \\
\hline \multicolumn{2}{|r|}{ Propósito } \\
\hline \multicolumn{2}{|c|}{$\begin{array}{l}\text { O objetivo da equipe perioperatória é fornecer cuidados seguros ao paciente que será submetido à anestesia } \\
\text { local, sem causar dor e ansiedade excessiva. Logo, o enfermeiro perioperatório deve realizar uma avaliação pré- } \\
\text { operatória em pacientes que serão submetidos a anestesia local. }\end{array}$} \\
\hline \multicolumn{2}{|r|}{ Recomendações } \\
\hline I. & $\begin{array}{l}\text { O enfermeiro perioperatório deverá realizar uma avaliação pré-operatória do paciente cirúrgico, } \\
\text { identificando histórico clínico (funções: cardíaca, renal e hepática), nível anestésico plasmático, } \\
\text { alergias, comorbidades que possam afetar a absorção da anestesia local, monitoramento de } \\
\text { sinais vitais, dor, ansiedade e alteração do nível de consciência. } \\
\text { A avaliação de enfermagem pré-operatória deve incluir uma revisão do paciente: } \\
\text { * Alergias, sensibilidades (medicamentos/ adesivos médicos); } \\
\text { * Idade, peso, altura, IMC; } \\
\text { * Medicamentos em uso diário, terapias complementares; } \\
\text { * Status nutricional; } \\
\text { * Histórico clínico; } \\
\text { * Resultados exames laboratoriais, testes diagnósticos, estudo cardíaco basal (pressão arterial, } \\
\text { frequência cardíaca), estado respiratório basal (saturação, frequência respiratória), estado } \\
\text { neurológico basal, dificuldades sensoriais (visão, audição, fala); } \\
\text { * Condição da integridade da pele (equimoses, edemas, hematomas, lesões de pele); } \\
\text { * Capacidade de tolerar o posicionamento cirúrgico; } \\
\text { * Nível de ansiedade, dor; } \\
\text { * Dúvidas do procedimento cirúrgico; } \\
\text { * Necessidade de punção venosa. }\end{array}$ \\
\hline II. & $\begin{array}{l}\text { O enfermeiro perioperatório deve monitorar e documentar as respostas fisiológicas e psicológicas } \\
\text { do paciente, identificando os diagnósticos de enfermagem com base na avaliação dos dados e } \\
\text { implementar o plano de cuidados. }\end{array}$ \\
\hline III. & $\begin{array}{l}\text { O enfermeiro perioperatório deve receber capacitação contínua sobre farmacologia de anestesia } \\
\text { local, cálculo total de dose, contraindicações, efeitos desejados, efeitos adversos e, } \\
\text { ressuscitação. }\end{array}$ \\
\hline IV. & $\begin{array}{l}\text { O enfermeiro perioperatório deve orientar o paciente em relação aos cuidados perioperatórios } \\
\text { relacionados à anestesia local. }\end{array}$ \\
\hline V. & $\begin{array}{l}\text { Políticas e procedimentos para o cuidado do paciente que recebe anestesia local devem ser } \\
\text { desenvolvidas, revisadas periodicamente conforme necessário e, permanecerem disponíveis para } \\
\text { a prática assistencial perioperatória. }\end{array}$ \\
\hline
\end{tabular}




\begin{tabular}{|c|c|c|}
\hline \multirow{2}{*}{$\begin{array}{c}\text { Guideline } \\
\text { G_02 }\end{array}$} & \multicolumn{2}{c|}{ Título } \\
\cline { 2 - 3 } & Diretriz para Transferência de Informações de Cuidados dos Pacientes \\
\cline { 2 - 3 } & AORN Guidelines for Perioperative Practice, 2017 & Idioma \\
\hline \multicolumn{2}{c}{ Propósito } \\
\hline
\end{tabular}

Orientar o enfermeiro perioperatório para a transferência segura das informações do paciente cirúrgico por meio de métodos consistentes e confiáveis, a fim de estabelecer uma comunicação aprimorada que evidencie a prática diária dos cuidados prestados.

\section{Recomendações}

O processo de transferência de informações deve ser padronizado para evitar falhas de comunicação; melhorar a precisão, confiabilidade e qualidade da informação. Logo, deve incluir: * Criação de uma equipe multiprofissional (enfermeiros, cirurgiões e anestesiologistas) para desenvolver um processo estruturado, organizado e seguro de transferência de informações de pacientes cirúrgicos;

* Elaborar um documento padronizado para garantir a continuidade, confiabilidade e confidencialidade das informações do paciente cirúrgico, incluindo componentes verbais e escritos; * Todas as fases do atendimento e assistência prestada ao paciente cirúrgico devem ser registradas em documento próprio de transfer6encia de informações, devendo ser acessível para demais setores e equipe multiprofissional;

* Na fase pré-operatória deverão ser registrados os seguintes itens no documento de transferência do paciente cirúrgico:

- nome completo do paciente com data de nascimento;

- evidência da marcação cirúrgica do sítio a ser operado (se aplicável);

- diagnóstico, histórico de alergias, nome cirurgião, tipo de anestesia;

- documentos legais necessários (por exemplo, formulário de consentimento cirúrgico e anestésico assinados);

- prontuário completo com histórico físico e clínico, precauções por isolamento;

- resultados de exames laboratoriais, diagnósticos e, radiológicos;

I.

- tipagem sanguínea, reservas de hemocomponentes;

- equipamento ou instrumentais especiais/consignados;

- presença de implantes ou próteses;

- histórico de sinais vitais (temperatura, pulso, respiração, pressão sanguínea, dor, oximetria de pulso, altura e peso);

- medicamentos em uso diário, incluindo medicação pré-anestésica (se aplicável);

- informações relevantes: cultural, geracional, espiritual e/ou necessidades educacionais do

paciente (escolaridade, idioma);

- riscos cirúrgicos, tais como: hipotermia, trombose venosa profunda, via aérea difícil e infecções;

- protocolos profiláticos aplicáveis (por exemplo: antibioticoprofilaxia, administração de beta-

bloqueador, profilaxia de tromboembolismo venoso (TEV));

- visita da equipe cirúrgica e anestésica.

* Garantir transferência correta e segura das informações durante as passagens de plantão;

* Utilizar modelos padronizados de transferência de informações, como por exemplo:

- SBAR: situação, antecedentes, avaliação, recomendação;

- I PASS the BATON: introdução, paciente, avaliação, situação, preocupações de segurança, resumo, ações, cronograma, propriedade;

- SURPASS: Sistema de Segurança Sustentável;

- SHARED: situação, história, avaliação, solicite, avalie, documento.

* Minimizar interrupções e distrações durante a transferência das informações;

* Apoio da liderança setorial e institucional para a implementação do processo.

II. Minimizar a ansiedade do paciente e seus familiares através do fornecimento de informações relevantes contidas no plano de cuidados, planejado de forma estruturada e individualizada.

III.

Realizar treinamentos para capacitação da equipe multiprofissional. Como estratégia educativa, podemos utilizar a simulação para melhorar a o trabalho em grupo e, assim, tornar o processo de comunicação mais efetivo e seguro, minimizando possíveis eventos adversos. 


\begin{tabular}{|l|l|}
\hline \multirow{3}{*}{ IV. } & $\begin{array}{l}\text { A transferência de informações deve ser informatizada e padronizada com base em políticas e } \\
\text { normas das acreditações internacionais. Este processo deverá ser desenvolvido por uma equipe } \\
\text { multiprofissional para minimizar os fatores de risco do paciente, padronizar a prática assistencial, } \\
\text { direcionar membros da equipe e, estabelecer diretrizes para atividades contínuas de melhoria e } \\
\text { desempenho dos profissionais da saúde. }\end{array}$ \\
\hline & $\begin{array}{l}\text { Um programa de gerenciamento de qualidade deve ser implementado para avaliar e monitorar os } \\
\text { processos de transferência de informações do paciente. Desta forma, o foco deverá ser o paciente } \\
\text { cirúrgico, o processo de transferência de informações e os indicadores de resultado. } \\
\text { Avaliação e acompanhamento regular de processos para a transferência de informações do } \\
\text { paciente pode ajudar na identificação de áreas para melhoria. } \\
\text { Barreiras para uma comunicação efetiva resultante em processos de cuidados com pacientes mal } \\
\text { executados podem resultar em atrasos na intervenção cirúrgica, atrasos na obtenção de } \\
\text { consentimento, e atrasos e/ou duplicações de testes ou tratamentos, colocando assim o paciente } \\
\text { em risco. } \\
\text { Métodos para reduzir as perdas de informações incluem: confirmação e repetição verbal das } \\
\text { informações durante passagens de plantão; utilizar abreviaturas padronizadas e; realizar a } \\
\text { combinação de comunicação verbal e escrita. } \\
\text { Considerar a utilização de uma ferramenta em formato de checklist, para mensurar a efetividade } \\
\text { das transferências de informações entre os membros da equipe multiprofissional. Este processo } \\
\text { permitirá a identificação de pontos de melhoria para minimizar riscos ao paciente cirúrgico. }\end{array}$ \\
\hline
\end{tabular}

\begin{tabular}{|c|c|c|}
\hline \multirow{2}{*}{$\begin{array}{c}\text { Guideline } \\
\text { G_03 }\end{array}$} & \multicolumn{2}{|c|}{ Título } \\
\cline { 2 - 3 } & Donte & Idioma \\
\cline { 2 - 3 } & AORN Guidelines for Perioperative Practice, 2017 & Inglês \\
\hline
\end{tabular}

Auxiliar o enfermeiro perioperatório a documentar cuidados e gerenciar informações dos pacientes cirúrgicos. Além disto, o registro de informações no período perioperatório reflete com precisão a experiência do paciente cirúrgico, sendo essencial para a continuidade dos cuidados de enfermagem.

\section{Recomendações}

Como parte da legislação de enfermagem, os registros dos cuidados de enfermagem perioperatória do paciente cirúrgico devem incluir: plano de cuidados, avaliação, histórico clínico, diagnósticos de enfermagem, indicação de resultados, planejamento, implementação de

I. intervenções e, avaliação do processo em direção ao resultado esperado. $O$ objetivo das intervenções de enfermagem é prevenir possíveis lesões ou complicações do paciente e, tratar os problemas reais do paciente cirúrgico identificados através dos diagnósticos de enfermagem. Logo, os enfermeiros que associam diagnósticos de enfermagem às intervenções planejadas, demostram planejamento cirúrgico efetivo e estruturado em busca de melhores resultados.

A documentação de enfermagem perioperatória deve refletir o cuidado centrado no paciente e ser sincronizada com o fluxo de trabalho de enfermagem, o qual representa o processo cognitivo de atividades dos cuidados de enfermagem, estabelecendo a abordagem para coleta de dados relacionados com cuidados ao paciente cirúrgico. Pois, a qualidade das informações disponíveis para a equipe multiprofissional afeta a qualidade dos cuidados prestados. Algumas pesquisas indicam que as ineficiências no trabalho dos enfermeiros perioperatórios estão associadas com o formato ou a localização dos dados clínicos ao serem identificados na documentação informatizada do paciente. Isto é, demonstrando uma correlação negativa no raciocínio clínico e na tomada de decisões destes profissionais. Os sistemas de informações eficazes são responsáveis por coletar, armazenar, e organizar dados clínicos dos pacientes cirúrgicos para permitir atualizações em tempo real e apoio à decisão clínica, sendo acessíveis aos profissionais de saúde.

A documentação eletrônica de enfermagem perioperatória deve utilizar os dados de enfermagem perioperatória e outros vocabulários que incluem o fluxo de trabalho do processo de enfermagem perioperatório; ou seja, as fases pré-admissão, pré-operatório, intraoperatório e, pós-operatório.

III. A padronização da informação sobre o cuidado do paciente melhora a qualidade dos dados e pode ser usado para suporte de apoio à decisão clínica, troca de informações, pesquisa, elaboração de políticas e, visibilidade de enfermagem.

A documentação clínica pode ser definida como registro da assistência técnica (ou seja, registro de IV. saúde legal) e auxilia no atendimento multidisciplinar do paciente cirúrgico. Os componentes para documentação clínica devem incluir: problemas clínicos; comunicações com outros profissionais sobre cuidados de saúde do paciente; comunicação e educação do paciente e os membros da 


\begin{tabular}{|c|c|}
\hline & $\begin{array}{l}\text { família; registros de medicamentos; reconhecimento de pedidos, implementação, e gestão; } \\
\text { intervenções de cuidados ao paciente; parâmetros clínicos do paciente; respostas e resultados do } \\
\text { paciente, incluindo mudanças no status dele; e planos de cuidados que refletem o } \\
\text { desenvolvimento } \quad \text { social } \text { e quadro cultural do paciente. } \\
\text { A documentação de enfermagem perioperatória deve corresponder aos regulamentos e } \\
\text { legislações e, o plano de cuidados deve incluir: alergias, variáveis culturais, equipamentos } \\
\text { utilizados para atendimento ao paciente (por exemplo, tipo, número do modelo), nomes dos } \\
\text { responsáveis legais e do paciente, considerações nutricionais, pedidos de testes e serviços } \\
\text { prestados, educação e envolvimento do paciente e da família, identificadores de pacientes e dados } \\
\text { demográficos, atributos e status do paciente (por exemplo, imunizações, deficiência), precauções } \\
\text { de segurança, consentimento cirúrgico e, implantes e explantes cirúrgicos. }\end{array}$ \\
\hline V. & $\begin{array}{l}\text { As informações do paciente devem ser seguras, mantidas confidenciais e protegidas de divulgação } \\
\text { não autorizada. O acesso à informação de saúde do paciente deve ser limitado a pessoas } \\
\text { autorizadas, as quais estejam envolvidas no plano de cuidados perioperatórios. }\end{array}$ \\
\hline VI. & $\begin{array}{l}\text { As modificações ao conteúdo existente no registro de cuidados de saúde do paciente devem } \\
\text { cumprir os regulamentos federais e estaduais, os requisitos de acreditação de cuidados de saúde } \\
\text { e as diretrizes de prática nacional. } \\
\text { O registro de atendimento ao paciente é uma representação legal de serviços fornecido pela } \\
\text { organização de cuidados de saúde, sendo o enfermeiro perioperatório obrigado a representar com } \\
\text { precisão o registro de informações do plano de cuidados do paciente cirúrgico. }\end{array}$ \\
\hline VII. & $\begin{array}{l}\text { A equipe perioperatória multiprofissional deve receber educação continuada, a fim de verificar as } \\
\text { competências destes profissionais diante da compreensão dos princípios e desempenho dos } \\
\text { processos de documentação, cuidados ao paciente e, das melhores práticas para manter a } \\
\text { segurança das informações dos pacientes cirúrgicos. }\end{array}$ \\
\hline VIII. & $\begin{array}{l}\text { Políticas e procedimentos para gerenciamento de informações perioperatórias devem ser } \\
\text { desenvolvidos e revisados periodicamente, pois evidenciam grande responsabilidade ao atuarem } \\
\text { como diretrizes operacionais usadas para minimizar os fatores de risco do paciente e, garantir } \\
\text { desempenho contínuo das atividades de melhoria da comunicação e das práticas assistenciais } \\
\text { perioperatórias. Logo, devem incluir informações sobre privacidade e segurança de dados e, } \\
\text { identificar estratégias de redução de risco para mitigar proativamente violações potenciais do } \\
\text { acesso à informação de saúde do paciente cirúrgico. }\end{array}$ \\
\hline IX. & $\begin{array}{l}\text { Um programa de gestão da qualidade através de auditorias deverá ser desenvolvido e } \\
\text { implementado, para verificar a integridade dos dados dentro do registro de cuidados de saúde do } \\
\text { paciente cirúrgico. }\end{array}$ \\
\hline
\end{tabular}

\begin{tabular}{|c|c|c|}
\hline \multirow{4}{*}{$\begin{array}{l}\text { Guideline } \\
\text { G_04 }\end{array}$} & \multicolumn{2}{|l|}{ Título } \\
\hline & \multicolumn{2}{|c|}{ Diretriz para posicionamento do paciente } \\
\hline & Fonte & Idioma \\
\hline & AORN Guidelines for Perioperative Practice, 2017 & Inglês \\
\hline \multicolumn{3}{|c|}{ Propósito } \\
\hline \multicolumn{3}{|c|}{$\begin{array}{l}\text { Orientar o enfermeiro perioperatório, bem como equipe multiprofissional, a fim de minimizar o risco de } \\
\text { complicações relacionadas ao posicionamento do paciente cirúrgico. A atuação da equipe perioperatória será } \\
\text { responsável pela prevenção de lesão por posicionamento, através da provisão e previsão de artefatos para } \\
\text { posicionamento com base nas necessidades individuais do paciente cirúrgico; pelo planejamento operacional de } \\
\text { procedimentos invasivos; pela aplicação dos princípios de mecânica corporal e ergonomia realizando avaliação } \\
\text { contínua durante o período perioperatório e; pela coordenação do posicionamento envolvendo toda a equipe } \\
\text { perioperatória. }\end{array}$} \\
\hline \multicolumn{3}{|c|}{ Recomendações } \\
\hline I. & \multicolumn{2}{|c|}{$\begin{array}{l}\text { Necessário avaliar perfil de pacientes cirúrgicos assistidos para providenciar a aquisição de } \\
\text { materiais e equipamentos seguros para posicionamento cirúrgico, com intuito de minimizar riscos } \\
\text { ao paciente. Isto é, uma das principais funções destes artefatos deve ser redistribuir a pressão } \\
\text { no corpo do paciente, especialmente, nas proeminências ósseas. Além disto, alguns estudos } \\
\text { relatam que o colchão viscoelástico apresenta maior benefício na prevenção de danos ao } \\
\text { paciente cirúrgico durante o posicionamento. }\end{array}$} \\
\hline II. & \multicolumn{2}{|c|}{$\begin{array}{l}\text { O enfermeiro perioperatório deverá rever no dia que antecede o procedimento cirúrgico, as } \\
\text { cirurgias agendadas e o perfil dos pacientes que serão assistidos. Assim serão identificados } \\
\text { potenciais conflitos em relação a disponibilidade dos artefatos para garantir um posicionamento }\end{array}$} \\
\hline
\end{tabular}




\begin{tabular}{|c|c|}
\hline & $\begin{array}{l}\text { cirúrgico com qualidade e segurança. Além disto, a sala operatória deverá ser previamente } \\
\text { organizada conforme tipo de abordagem cirúrgica, lateralidade, posicionamento cirúrgico e, } \\
\text { características especiais do paciente (por exemplo: obesidade). }\end{array}$ \\
\hline III. & $\begin{array}{l}\text { Os materiais e equipamentos de posicionamento e transporte devem ser periodicamente } \\
\text { inspecionados e mantidos em boas condições de funcionamento. Visto que, a manutenção } \\
\text { preventiva garante segurança, diminui os riscos de lesões aos pacientes e, ajuda a fornecer } \\
\text { exposição adequada do sitio cirúrgico. }\end{array}$ \\
\hline IV. & $\begin{array}{l}\text { Durante a avaliação pré-operatória o enfermeiro deverá identificar os riscos do paciente cirúrgico } \\
\text { em desenvolver lesões por pressão. Logo, pacientes com necessidades especiais (por exemplo: } \\
\text { neonatos, idosos, malnutridos, obesos mórbidos, pacientes com doenças crônicas e, pacientes } \\
\text { com lesão por pressão prévia) e procedimentos cirúrgicos acima de três horas, apresentam risco } \\
\text { maior para desenvolvimento de lesões de pele por posicionamento. Portanto, a avaliação pré- } \\
\text { operatória do paciente cirúrgico deverá incluir: } \\
\text { * Idade, peso, altura, índice de massa corporal; } \\
\text { * Condições da pele, estado nutricional; } \\
\text { * Presença de adornos (por exemplo: anéis, brincos, piercings); } \\
\text { * Alergias, comorbidades (tais como: vasculares, respiratório, circulatório, neurológico, supressão } \\
\text { do sistema imunológico); } \\
\text { * Limitação física ou mobilidade prejudicada; } \\
\text { * Resultados laboratoriais; } \\
\text { * Presença de prótese ou correção dispositivos; } \\
\text { * Presença de dispositivos implantados (implantes ortopédicos); } \\
\text { * Presença de dispositivos externos (cateteres, drenos, imobilizadores ortopédicos); } \\
\text { * Presença de pulsos periféricos; } \\
\text { * Percepção sensorial da dor; } \\
\text { * Nível de consciência; } \\
\text { * Considerações psicossociais e culturais. }\end{array}$ \\
\hline V. & $\begin{array}{l}\text { Os enfermeiros perioperatórios deverão avaliar potenciais riscos associados ao transporte e } \\
\text { transferência de pacientes cirúrgicos. Portanto, o transporte seguro de pacientes cirúrgicos será } \\
\text { efetivo com a maca de transporte apresentando mobilidade prática, travas nas rodas, grades } \\
\text { laterais elevadas, elevação da cabeceira e membros inferiores, suporte para soroterapias e } \\
\text { equipamentos. }\end{array}$ \\
\hline VI. & $\begin{array}{l}\text { O enfermeiro perioperatório deverá verificar se os materiais e equipamentos a serem utilizados } \\
\text { durante o posicionamento cirúrgico, os quais apresentam como função redistribuir a pressão } \\
\text { mantendo o alinhamento corporal, atendem as reais necessidades do paciente cirúrgico. Ele } \\
\text { deverá providenciar artefatos de posicionamento com superfície capaz de reduzir a pressão } \\
\text { excessiva sobre as proeminências ósseas do paciente cirúrgico. Visto que, a pressão contra a } \\
\text { pele acima de } 32 \text { mmHg prejudica a perfusão tecidual. Desta forma, alguns estudos relataram } \\
\text { que a utilização de dispositivos para posicionamento, compostos por gel ou viscoelástico, } \\
\text { apresentaram-se eficazes na prevenção de lesões por pressão. Além disto, colchões de espuma } \\
\text { densa tipo "caixa de ovos" podem ser mais eficazes redistribuindo a pressão, se forem feitos de } \\
\text { espuma grossa e densa resistente à compressão. }\end{array}$ \\
\hline VII. & $\begin{array}{l}\text { A equipe perioperatória deverá receber educação continuada, validar competências e atualizar } \\
\text { informações sobre posicionamento do paciente cirúrgico, bem como conhecimento de novas } \\
\text { tecnologias para garantir procedimentos cirúrgicos seguros. Logo, a verificação de competências } \\
\text { apresenta-se como um indicador para mensurar conhecimento da equipe e, identificação de } \\
\text { lesões ao paciente. E, ainda, permitindo desenvolver estratégias e ações corretivas diante de } \\
\text { eventuais falhas do processo. }\end{array}$ \\
\hline VIII. & $\begin{array}{l}\text { Políticas e procedimentos relacionados ao posicionamento cirúrgico devem ser desenvolvidos, } \\
\text { revisados anualmente conforme necessário, e necessitam estar prontamente disponíveis como } \\
\text { protocolos práticos. }\end{array}$ \\
\hline
\end{tabular}

\begin{tabular}{|c|c|c|}
\hline \multirow{2}{*}{$\begin{array}{c}\text { Guideline } \\
\text { G_05 }\end{array}$} & \multicolumn{2}{|c|}{ Título } \\
\cline { 2 - 3 } & Diretriz para a antissepsia da pele do paciente pré-operatório \\
& AORN Guidelines for Perioperative Practice, 2017 & Idioma \\
\hline & Propósito & Inglês \\
\hline
\end{tabular}




\begin{tabular}{|c|c|}
\hline & $\begin{array}{l}\text { ros perioperatórios sobre o preparo pré- } \\
\text { brio; tricotomia pré-operatória; seleção de } \\
\text { armazenamento e eliminação de antiss } \\
\text { o paciente desenvolver infecção de sítio c }\end{array}$ \\
\hline & Recomendações \\
\hline I. & $\begin{array}{l}\text { Os pacientes cirúrgicos deverão tomar banho pré-operatório (noite anterior ou dia da cirurgia) } \\
\text { com sabão a solução degermante antisséptica para reduzir a flora microbiana na pele. Além } \\
\text { disto, loções, emolientes, cosméticos e desodorantes a base de álcool devem ser evitados no } \\
\text { local cirúrgico, pois podem reduzir a eficácia do antisséptico pré-operatório, diminuir a } \\
\text { capacidade de aderência dos curativos à pele do paciente, ou até apresentar um risco de } \\
\text { incêndio quando uma fonte de ignição é usada perto do local cirúrgico. } \\
\text { O paciente submetido a cirurgia de cabeça ou pescoço deverá ser instruído a lavar o cabelo } \\
\text { com shampoo de clorexidina } 4 \% \text { ou iodopolvedine } 7,5 \% \text { para diminuir a flora residual do couro } \\
\text { cabeludo. }\end{array}$ \\
\hline II. & $\begin{array}{l}\text { A remoção de pelos no local cirúrgico deve ser realizada apenas em determinadas situações. } \\
\text { Visto que, ao ser preconizada a remoção de pelos, a utilização do aparelho tricotomizador } \\
\text { apresenta um menor risco de desenvolvimento de infecção de sítio cirúrgico, quando comparado } \\
\text { a utilização da lâmina de barbear. }\end{array}$ \\
\hline III. & $\begin{array}{l}\text { A equipe perioperatória multiprofissional (enfermeiros, cirurgiões, profissionais do controle de } \\
\text { infecção hospitalar) devem selecionar produtos antissépticos seguros e eficazes para preparo } \\
\text { pré-operatório da pele do paciente cirúrgico. Entretanto, não há evidências sobre alguns } \\
\text { antissépticos serem mais eficazes que outros na prevenção de infecção de sítio cirúrgico. } \\
\text { Portanto, a equipe multiprofissional deverá desenvolver uma estratégia de avaliação e seleção } \\
\text { dos produtos antissépticos para preparo pré-operatório da pele do paciente cirúrgico, devendo } \\
\text { estes serem em frascos de uso único com solução colorida. }\end{array}$ \\
\hline IV. & $\begin{array}{l}\text { Os membros da equipe perioperatória devem indicar o preparo pré-operatório da pele do } \\
\text { paciente com produto antisséptico de forma segura e eficaz. Isto é, a demarcação do local } \\
\text { cirúrgico com marcador permanente deverá permanecer visível após a antissepsia pré- } \\
\text { operatória da pele do paciente. } \\
\text { Áreas de maior contaminação (por exemplo: umbigo, prepúcio, unhas, intestino ou vias } \\
\text { urinárias, estoma) no campo cirúrgico devem ser higienizadas antes da realização do preparo } \\
\text { pré-operatório da pele com antisséptico. }\end{array}$ \\
\hline V. & oes do tabr \\
\hline
\end{tabular}

\begin{tabular}{|c|c|c|}
\hline \multirow{4}{*}{$\begin{array}{l}\text { Guideline } \\
\text { G_06 }\end{array}$} & \multicolumn{2}{|l|}{ Título } \\
\hline & \multicolumn{2}{|c|}{ Diretriz para prevenção de trombose venosa profunda } \\
\hline & Fonte & Idioma \\
\hline & AORN Guidelines for Perioperative Practice, 2017 & Inglês \\
\hline \multicolumn{3}{|c|}{ Propósito } \\
\hline \multicolumn{3}{|c|}{$\begin{array}{l}\text { Sugerir a elaboração de um protocolo para a prevenção da trombose venosa profunda (TVP). O documento } \\
\text { fornece orientação para profilaxia de TVP farmacológica e/ou mecânica aos pacientes cirúrgicos. }\end{array}$} \\
\hline \multicolumn{3}{|c|}{ Recomendações } \\
\hline I. & \multicolumn{2}{|c|}{$\begin{array}{l}\text { A criação de um protocolo para a prevenção de TVP inclui o cuidado ao paciente perioperatório, } \\
\text { baseado em evidências e diretrizes da equipe multiprofissional. Este protocolo deverá ser de } \\
\text { simples aplicação, acessível a todos os profissionais de saúde, fornece alternativas ao } \\
\text { tratamento sugerido e, discriminar as contraindicações quando necessário. } \\
\text { O protocolo deverá incluir medidas específicas de prevenção de TVP que abordam fatores de } \\
\text { risco associados ao perioperatório, tais como: posicionamento cirúrgico (profilaxia mecânica) e, } \\
\text { risco de sangramento (profilaxia farmacológica). }\end{array}$} \\
\hline
\end{tabular}


A avaliação pré-operatória do enfermeiro perioperatório fornece informações necessárias para determinar os fatores de risco para TVP e, identificar medidas profiláticas adequadas conforme avaliação individualizada do paciente cirúrgico. A avaliação dos fatores de risco da TVP do paciente pré-operatório deve incluir:

> Estase venosa:

- idade superior a 40 anos;

- câncer (por exemplo, ativo ou oculto) e associado terapia;

- história de doença cardíaca;

- obesidade;

- gravidez e pós-parto;

- descanso prolongado em cama ou imobilização;

- viagem prolongada (ou seja, entre 4 a 10 horas dentro das 8 semanas anteriores);

- cirurgia com duração superior a 30 minutos;

- varizes.

> Lesão na parede do vaso:

- câncer (por exemplo, ativo ou oculto) e associado terapia;

II.

- cateteres venosos centrais;

- queimaduras extensivas;

- histórico prévio de TVP ou acidente vascular cerebral;

- cirurgia;

- trauma (por exemplo, trauma maior, extremidade inferior prejuízo).

$>$ Hipercoagulabilidade:

- câncer (por exemplo, ativo ou oculto) e terapia associada;

- trombofilia herdada ou adquirida (ou seja, condições em que o sangue coagula mais rápido do que o normal);

- uso de contraceptivos orais ou substituição de terapia hormonal;

- gravidez e pós-parto;

- trauma (por exemplo, trauma maior, extremidade inferior prejuízo).

$>$ Outros:

- doença médica aguda;

- processos infecciosos agudos;

- condições inflamatórias;

- fumo.

O enfermeiro perioperatório deve implementar intervenções específicas quando o paciente está recebendo profilaxia mecânica de TVP.

A profilaxia mecânica inclui início de deambulação, exercícios ativos e passivos de pé e tornozelo, uso de meias de compressão graduadas e, dispositivos de compressão pneumática intermitente.

III. As contraindicações incluem: condições que afetam a extremidade inferior (por exemplo, dermatite, gangrena, perna com deformidade, feridas infectadas não tratadas, lesões ou locais cirúrgicos); condições que comprometem a extremidade inferior do fluxo venoso (por exemplo, arteriosclerose grave, outra doença vascular isquêmica, edema de perna); sensibilidade ao látex; e insuficiência cardíaca congestiva grave. As complicações incluem: síndrome compartimental; sensibilidade ou alergia ao látex; paralisia do nervo peroneal; e lesão na pele.

O enfermeiro perioperatório deverá implementar intervenções específicas quando o paciente está recebendo profilaxia farmacológica da TVP. Elas são necessárias para diminuir os riscos de complicações potenciais da profilaxia farmacologia que pode ser utilizada em todo o período perioperatório. A profilaxia farmacológica consiste em medicamentos anticoagulantes que inibem a coagulação do sangue (por exemplo: varfarina; pentasacrideto sintético, heparina de baixo peso molecular; e baixa dose de heparina.

IV. As contraindicações incluem: lesões traumáticas complexas; hemorragia; endocardite infecciosa; neurocirurgia; cirurgia ocular; gravidez; recente sangramento intracraniano, gástrico ou geniturinário; cirurgia recente (ou seja, dentro de 2 dias); e punção lombar recente ou neuraxial (isto é, coluna vertebral, peridural) anestesia ou analgesia (ou seja, dentro de 24 horas).

As complicações incluem: sangramento, síndrome compartimental, formação de hematoma, trombocitopenia induzida por heparina, osteoporose e osteopenia, necrose da pele e urticária em locais de injeção. 


\begin{tabular}{|c|l|}
\hline V. & $\begin{array}{l}\text { O paciente que recebe profilaxia mecânica e seu cuidador designado deverão receber } \\
\text { instruções pré-operatórias e pós-operatórias, incluindo os seguintes tópicos: mecanismo de } \\
\text { profilaxia mecânica; importância da conformidade; importância do uso adequado de tamanho, } \\
\text { meias de compressão graduadas; remoção e reaplicação adequada do dispositivo de } \\
\text { compressão intermitente imediatamente após a instalação; e aplicação adequada, remoção e } \\
\text { reaplicação de meias de compressão graduadas. }\end{array}$ \\
\hline VI. & $\begin{array}{l}\text { Educação inicial e contínua da equipe perioperatória com relação a prevenção da TVP, ao risco } \\
\text { para o paciente e, aos métodos adequados de profilaxia, facilitam o desenvolvimento de } \\
\text { conhecimento, habilidades e atitudes que afetam o cuidado seguro dos pacientes cirúrgicos. }\end{array}$ \\
\hline VII. & $\begin{array}{l}\text { A documentação perioperatória deverá incluir uma avaliação do paciente, plano de cuidados, } \\
\text { diagnósticos de enfermagem e identificação dos resultados desejados e intervenções, bem } \\
\text { como uma avaliação da resposta aos cuidados prestados ao paciente cirúrgico. Neste registro } \\
\text { de informações deverão conter: resultados da avaliação de enfermagem, incluindo fatores de } \\
\text { risco e complicações, se presente; horários de aplicação e remoção para todos } \\
\text { medidas profiláticas mecânicas; o tipo de tamanho do envoltório ou compressão graduada, } \\
\text { meias aplicadas; o identificador e as configurações do mecanismo unidade, se aplicável; o } \\
\text { tempo, a via e a dosagem de todas as medidas farmacológicas profiláticas; o motivo de } \\
\text { qualquer variação do protocolo; e respostas a complicações, se presente. }\end{array}$ \\
\hline VIII. & $\begin{array}{l}\text { Políticas e procedimentos para prevenir a TVP deverão incluir as etapas necessárias para iniciar } \\
\text { e implementar o protocolo e, notificar eventos adversos. O protocolo de prevenção a TVP } \\
\text { também serve como diretriz operacional para minimizar os fatores de risco do paciente diante de } \\
\text { complicações, padronizar a prática, direcionar os membros da equipe e estabelecer programas } \\
\text { contínuos de melhoria de desempenho. }\end{array}$ \\
\hline
\end{tabular}

\begin{tabular}{|c|c|c|}
\hline \multirow{2}{*}{$\begin{array}{c}\text { Guideline } \\
\text { G_07 }\end{array}$} & \multicolumn{2}{c|}{ Título } \\
\cline { 2 - 3 } & \multicolumn{2}{|c|}{ Diretriz para prevenção de transmissão de infecções } \\
\cline { 2 - 3 } & \multicolumn{1}{c|}{ Fonte } & Idioma \\
\hline \multicolumn{1}{c}{ AORN Guidelines for Perioperative Practice, 2017 } \\
\hline $\begin{array}{l}\text { Orientar o enfermeiro perioperatório na implementação de precauções padrão e precauções baseadas em } \\
\text { transmissão (isto é, contato, gotícula, no ar) para prevenir a infecção no período perioperatório. Além disto, } \\
\text { oferece informações sobre precaução diante de patógenos transmitidos pelo sangue, equipamento de proteção } \\
\text { pessoal (EPI), infecções associadas aos cuidados de saúde e organismos multirresistentes, imunização, } \\
\text { atividades de profissionais de saúde com infecções e, lesões exsudativas de pele. }\end{array}$
\end{tabular}

\section{Recomendações}

Os profissionais de saúde deverão utilizar as precauções padrão como base para prevenção de transmissão das doenças infecciosas. Sendo que, as precauções padrão incluem:

1. práticas para higiene das mãos,

2. EPI's,

3. controle ambiental,

4. identificação visível de pacientes em isolamento respiratório,

5. segurança de objetos perfurocortantes.

1. A higiene das mãos é uma das formas mais eficazes de prevenir a transmissão e o controle de infecções nos cuidados a saúde.

2. A equipe perioperatória deverá usar EPI's sempre que exista a possibilidade de exposição a

I. sangue ou outros materiais potencialmente infecciosos.

3. O controle do ambiente deverá garantir segurança na limpeza e higienização, pois as superfícies hospitalares são frequentemente contaminadas com patógenos associados à saúde e podem ser responsáveis pela transmissão cruzada. 4. Os cuidados aos pacientes em isolamento respiratório (por exemplo: resistentes à meticilina, Staphylococcus aureus, resistente a vancomicina, Enterococcus spp, norovírus, Clostridium difficile, Acinetobacter spp) deverão ser realizados por profissionais que estejam paramentados com máscara cirúrgica, avental de manga longa e luvas descartáveis. Solicitar que o paciente ao tossir ou espirrar coloque um lenço cobrindo a boca e o nariz para evitar maior dissipação ambiental dos patógenos.

5. Realizar o descarte de materiais perfurocortantes, imediatamente após a sua utilização, em local apropriado (por exemplo: caixa de perfurocortante). 


\begin{tabular}{|c|c|}
\hline II. & $\begin{array}{l}\text { As precauções de contato devem ser usadas ao fornecer cuidados para pacientes que são } \\
\text { conhecidos ou suspeitos de serem infectados ou colonizados com microrganismos que são } \\
\text { transmitidos por contato direto ou contato indireto. Desta forma, os profissionais perioperatórios } \\
\text { deverão colocar o EPI após a entrada no quarto e descarta-lo na saída, após cuidar de um } \\
\text { paciente cirúrgico em isolamento por contato (por exemplo: resistente à vancomicina, } \\
\text { Clostridium difficile e norovírus). } \\
\text { O enfermeiro perioperatório deverá orientar o paciente cirúrgico em isolamento (contato ou } \\
\text { respiratório), bem como seus familiares, para minimizar sentimentos de isolamento, depressão e } \\
\text { ansiedade. }\end{array}$ \\
\hline III. & $\begin{array}{l}\text { As precauções de gotículas devem ser aplicadas no período ao realizar cuidados em pacientes } \\
\text { com suspeita de infecção por microrganismos, os quais poderão ser transmitidos através de } \\
\text { gotículas. } \\
\text { Para cuidados prestados aos pacientes em precauções de gotículas, além da utilização de } \\
\text { precauções padrão, os enfermeiros perioperatórios deverão restringir o contato destes pacientes } \\
\text { com outros e, ao serem transportados deverão utilizar máscara cirúrgica para reduzir o risco de } \\
\text { transmissão de agentes patogênicos do paciente para o ambiente (por exemplo: adenovírus, } \\
\text { estreptococo do grupo A, gripe, Neisseria meningites). }\end{array}$ \\
\hline IV. & $\begin{array}{l}\text { As precauções no ar devem ser usadas ao fornecer cuidados para pacientes cirúrgicos com } \\
\text { suspeita ou confirmação de microrganismos, que podem ser transmitidos por via aérea (por } \\
\text { exemplo: Mycobacterium tuberculosis, rubéola, Varicela zoster). A transmissão no ar pode } \\
\text { ocorrer quando pequenas partículas que contêm agentes infecciosos são inaladas. Logo, os } \\
\text { enfermeiros perioperatórios deverão utilizar EPI's como precaução padrão (máscara N95) e, } \\
\text { solicitar reserva de filtro bacteriano descartável para ser alocado entre a via aérea do paciente e } \\
\text { o circuito de anestesia no ato anestésico-cirúrgico. }\end{array}$ \\
\hline V. & $\begin{array}{l}\text { Os profissionais de saúde, assim como os enfermeiros perioperatórios, deverão seguir } \\
\text { protocolos padrão para precauções quando houver o risco de exposição ao sangue ou outros } \\
\text { materiais potencialmente infecciosos. Os patógenos transmitidos pelo sangue são } \\
\text { microrganismos patogênicos que estão presentes no sangue humano e podem causar doenças } \\
\text { (por exemplo: hepatite B, HIV). Portanto deverão ser utilizados como EPI's os óculos de } \\
\text { proteção, máscaras cirúrgicas, avental de manga longa e luvas descartáveis. }\end{array}$ \\
\hline VI. & $\begin{array}{l}\text { O enfermeiro perioperatório deverá tomar medidas para prevenir a transmissão de infecções } \\
\text { adquiridas pelo cuidado da saúde ao paciente cirúrgico. As medidas de prevenção de infecção } \\
\text { de sítio cirúrgico se concentram na redução de oportunidades para contaminação microbiana } \\
\text { dos tecidos do paciente ou instrumentos cirúrgicos estéreis. Logo, os métodos para prevenir } \\
\text { infecção de sítio cirúrgico incluem: técnica estéril, implementação de protocolos de limpeza e } \\
\text { higienização do meio ambiente, utilizar barreiras apropriadas e vestuário cirúrgico, realizar } \\
\text { antissepsia adequada da pele e higiene das mãos, minimizando o tráfego de pessoas na sala } \\
\text { operatória, utilizar métodos de esterilização e, realizar profilaxia antimicrobiana pré-operatória. }\end{array}$ \\
\hline VIII. & $\begin{array}{l}\text { Educação inicial e contínua da equipe perioperatória com relação a compreensão dos princípios } \\
\text { da prevenção das infecções e da elaboração de protocolos de precauções (padrão, contato, } \\
\text { gotícula e ar), facilitam o desenvolvimento de conhecimento, habilidades e atitudes que afetam o } \\
\text { cuidado seguro dos pacientes cirúrgicos. }\end{array}$ \\
\hline IX & $\begin{array}{l}\text { Políticas e procedimentos para a prevenção e controle da transmissão de infecções, auxiliam no } \\
\text { desenvolvimento da segurança do paciente, avaliação de qualidade e desempenho de } \\
\text { atividades de melhoria. Sendo, diretrizes operacionais utilizadas para minimizar os fatores de } \\
\text { risco para complicações do paciente cirúrgico. }\end{array}$ \\
\hline
\end{tabular}

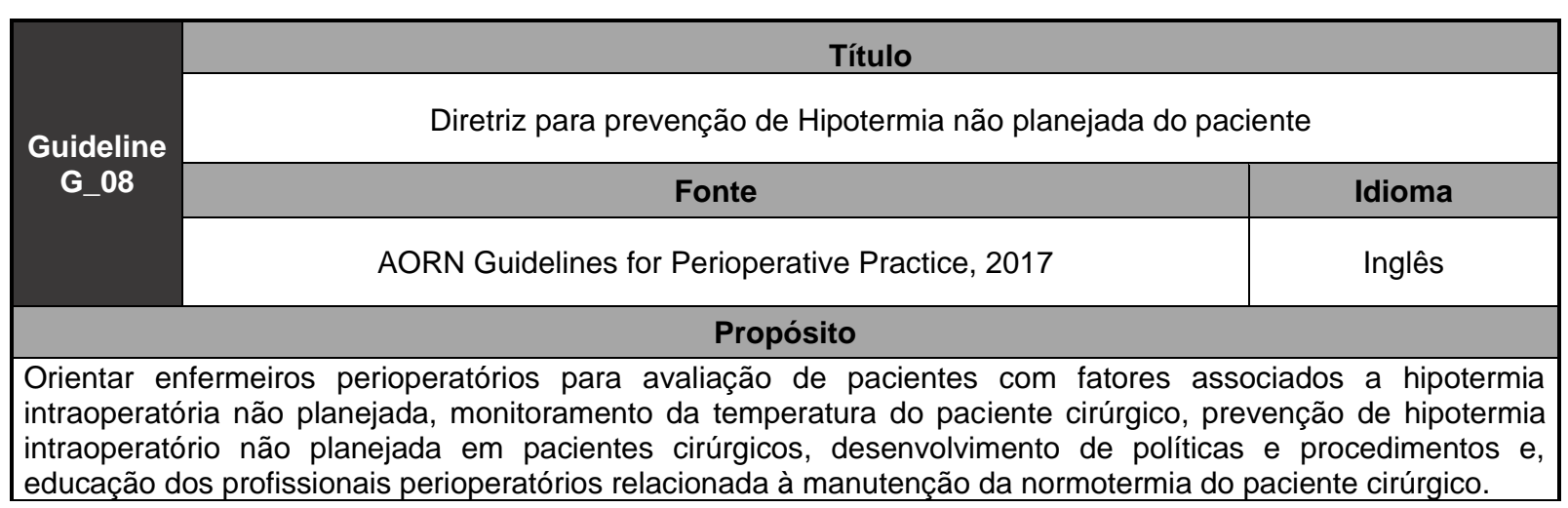




\section{Recomendações}

O enfermeiro perioperatório deverá realizar uma avaliação pré-operatória para identificar a presença de fatores que podem contribuir para o desenvolvimento da hipotermia intraoperatória não planejada no paciente cirúrgico. São eles:

> Fatores relacionados ao procedimento cirúrgico:

* Tipo e duração do procedimento cirúrgico;

* Temperatura da sala de operação inferior a $20^{\circ} \mathrm{C}$;

* Tipo e duração da anestesia planejada;

* Dispositivos (por exemplo, torniquete, dispositivos de compressão intermitente).

I.

$>$ Fatores relacionados ao paciente:

* Idade (por exemplo: peso prematuro e outro baixo peso ao nascer lactentes, $>65$ anos);

* Sexo (feminino);

* Baixa área de superfície corporal ou peso;

* Insuficiência cardíaca congestiva, função ventricular superior, hipotensão arterial;

* Comorbidades preexistentes (por exemplo: hipotireoidismo, hipoglicemia, desnutrição, queimaduras, trauma, desordens neurológicas);

* Doença dos vasos cardíacos, cirurgia cardíaca prévia;

* História de transplante de órgão.

II. Os resultados de temperatura adequados devem ser comunicados antes da cirurgia para a

Mensurar e monitorar a temperatura do paciente em todas as fases do cuidado perioperatório. equipe perioperatória, durante a cirurgia quando a temperatura estiver fora do alcance de normotermia e, para o cuidador responsável após a cirurgia.

Em todas as fases do cuidado perioperatório, o enfermeiro deverá desenvolver um plano de cuidados individualizado e, implementar as intervenções necessárias para prevenção da hipotermia intraoperatória não planejada no paciente cirúrgico. Alguns estudos indicaram que a

III. combinação de métodos de aquecimento (envoltório corporal, cobertor aquecido, curativos úmidos aquecidos, irrigação aquecida e fluidos IV aquecidos), demonstram serem mais efetivos no controle da normotermia do paciente cirúrgico. Além disto, o método de pré-aquecimento do paciente cirúrgico (15 ou 20 minutos) deverá ser realizado quando estes apresentarem risco para desenvolver hipotermia pós-operatória.

Um programa de gestão da qualidade deverá ser desenvolvido e implementado, para identificar

IV. e responder às oportunidades de melhoria relacionado à prevenção da hipotermia intraoperatória não planejada no paciente cirúrgico

\begin{tabular}{|c|c|c|}
\hline \multirow{4}{*}{$\begin{array}{c}\text { Guideline } \\
\text { G_09 }\end{array}$} & \multicolumn{2}{|l|}{ Título } \\
\hline & \multicolumn{2}{|c|}{ Diretriz para uso seguro de dispositivos geradores de energia } \\
\hline & Fonte & Idioma \\
\hline & AORN Guidelines for Perioperative Practice, 2017 & Inglês \\
\hline \multicolumn{3}{|c|}{ Propósito } \\
\hline \multicolumn{3}{|c|}{$\begin{array}{l}\text { Orientar enfermeiros perioperatórios para utilização segura e manutenção de dispositivos geradores de energia; } \\
\text { isto é, equipamentos eletrocirúrgicos, eletrocautérios, aparelhos ultrassônicos e lasers. A energia produzida é } \\
\text { transferida ao paciente por vários métodos, incluindo monopolar, bipolar, bipolar avançado (por exemplo: } \\
\text { selagem de vasos), e dispositivos tripolares (por exemplo: faca de plasma), lasers da classe } 3 \text { e 4, ultrassom } \\
\text { (por exemplo: sistema de ablação de tecido, facoemulsificação) e, coagulação reforçada com argônio. } \\
\text { A eletrocirurgia, que utiliza alta freqüência (ou seja, radiofrequência) de corrente elétrica é rotineiramente usada } \\
\text { para cortar, coagular, dissecar, ablar e encolher os tecidos. Os dissectores ultrassônicos fragmentam o tecido } \\
\text { por vibração. Os dispositivos de corte de ligadura bipolar ou de vedação de vasos utilizam uma combinação de } \\
\text { pressão e calor para permanentemente fundir vasos e tecidos }\end{array}$} \\
\hline
\end{tabular}




\section{Recomendações}

Precauções devem ser tomadas para mitigar o risco de lesões ao paciente e equipe cirúrgica durante o uso do dispositivo gerador de energia. Precauções de segurança contra risco de incêndio ao utilizar os dispositivos geradores de energia incluem:

* Uso de tecnologias diferentes como monopolar ou dispositivos a laser (por exemplo: bipolar, tecnologia de ablação, instrumentos de aplicação não energéticos), em situações identificadas como sendo de alto risco de incêndio;

I.

* Uso de lubrificantes solúveis em água (por exemplo: lubrificante oftálmico) próximo a incisão cirúrgica;

* Uso de esponjas úmidas perto da fonte de ignição;

* Uso proibido de compressas cirúrgicas embebidas em álcool no campo cirúrgico; * Interromper fluxo de oxigênio ou diminuir a porcentagem para o nível mais baixo tolerável, antes de ativar um dispositivo gerador de energia perto da cabeça, face ou pescoço. Pesquisas relatam que a utilização de um dispositivo de ablação de radiofrequência bipolar elimina o risco de incêndio durante cirurgia de cavidade aberta.

Avaliações pré e pós-operatórias são necessárias para avaliar a condição da pele do paciente cirúrgico e, identificar riscos para desenvolvimento de lesões a serem causadas pela placa de eletrocautério (queimadura).

Jóias metálicas, incluindo piercings corporais, implantes subdérmicos e transdérmicos ou implantes microdérmicos, apresentam um risco potencial de queimaduras causadas pela corrente elétrica direta (ou seja, contato ativo do eletrodo).

Tecnologias alternativas (por exemplo, bipolar, ultrassônica) devem ser utilizadas no lugar da eletrocirurgia monopolar quando eletrodos de neuromonitorização (por exemplo, potenciais

II. evocados somatossensoriais estiverem presentes.

Precauções devem ser tomadas quando o paciente apresentar algum dispositivo eletrônico implantado (por exemplo, marcapasso gástrico ou cardíaco; cardioversor implantável; implante coclear; estimulador ósseo). Logo, algumas informações imprescindíveis deverão ser coletadas, tais como: tipo de procedimento cirúrgico agendado e lateralidade; posicionamento do paciente no intraoperatório; riscos potenciais com base no tipo de dispositivo eletrocirúrgico a ser usado (por exemplo: ablação por radiofreqüência, monopolar, bipolar); localização da sala de procedimentos (por exemplo: sala operatória, radiologia intervencionista); e o leito de destino do paciente em período pós-operatório (por exemplo: ambulatorial, paciente internado).

\subsubsection{Síntese do conteúdo da ASA, Guidelines for Patient Care in Anesthesiology}

\begin{tabular}{c|c|c|}
\hline \multirow{2}{*}{$\begin{array}{c}\text { Guideline } \\
\text { G_01 }\end{array}$} & \multicolumn{2}{|c|}{ Título } \\
\cline { 2 - 3 } & Diretrizes práticas para avaliação pré-anestésica \\
\cline { 2 - 3 } & ASA Guidelines for Patient Care in Anesthesiology, 2012 & Idioma \\
\hline & Propósito & Inglês \\
\hline
\end{tabular}

A avaliação pré-anestésica é definida como o processo de avaliação clínica que precede os cuidados de anestesia para um procedimento cirúrgico ou não cirúrgico. A avaliação pré-anestésica é de responsabilidade do anestesiologista e, consiste em múltiplas fontes de informações, podendo incluir histórico clínico, exame físico, entrevista e resultados de exames e avaliações médicas prévias.

As avaliações feitas no processo de avaliação pré-anestésica podem ser utilizadas para educar o paciente, organizar recursos para cuidados perioperatórios e formular planos para cuidados intraoperatórios, recuperação pós-operatória e manejo da dor perioperatória.

Os objetivos da avaliação pré-anestésica são:

(1) avaliar as evidências atualmente disponíveis relativas aos benefícios de saúde da avaliação pré-anestésica,

(2) oferecer um quadro de referência para a realização da avaliação pré-anestésica por anestesiologistas e,

(3) estimular estratégias de pesquisa que possam avaliar os benefícios de saúde de uma avaliação préanestésica. 


\begin{tabular}{|c|l|}
\hline I. & $\begin{array}{l}\text { Histórico pré-anestésico e exame físico: precedem a ordenação, exigência ou realização de } \\
\text { testes específicos de pré anestesia e consiste em avaliação de registros médicos pertinentes, } \\
\text { entrevista com o paciente e exame físico. O momento de uma avaliação pré-anestésica inicial } \\
\text { poderá ser realizado da seguinte forma: sempre antes do dia da cirurgia, antes da cirurgia, e } \\
\text { apenas no dia da cirurgia. O exame físico pré-anestésico deve incluir: um exame de via aérea, um } \\
\text { exame pulmonar com ausculta dos pulmões e, um exame de doença cardiovascular. }\end{array}$ \\
\hline & $\begin{array}{l}\text { Seleção e tempo de testes pré-operatórios: } \\
\text { I. Eletrocardiograma; } \\
\text { II. Avaliação Cardíaca; } \\
\text { III. Radiografia de Tórax; } \\
\text { IV. Avaliação Pulmonar (ou seja, testes de função pulmonar, Espirometria); } \\
\text { V. Nível de hemoglobina e hematócrito; } \\
\text { VI. Estudo de coagulação; } \\
\text { VII. Sorologia química; } \\
\text { VIII. Teste urinário; } \\
\text { IX. Teste de gravidez; } \\
\text { X. Respostas de pesquisa para seleção e cronograma de testes pré-operatórios. }\end{array}$ \\
\hline III. & $\begin{array}{l}\text { Uma avaliação de pré anestesia envolve a avaliação de informações de múltiplas fontes, incluindo } \\
\text { registros médicos, entrevistas pacientes, exames físicos e resultados de testes pré-operatórios. }\end{array}$ \\
\hline
\end{tabular}

\begin{tabular}{c|c|c|}
\cline { 2 - 3 } & \multicolumn{2}{c|}{ Título } \\
\cline { 2 - 3 } $\begin{array}{c}\text { Guideline } \\
\text { G_02 }\end{array}$ & Diretrizes práticas para o tratamento da dor aguda no ambiente perioperatório \\
\cline { 2 - 3 } & Fonte & Idioma \\
\cline { 2 - 3 } & ASA Guidelines for Patient Care in Anesthesiology, 2012 \\
\hline
\end{tabular}

Orientar os anestesiologistas para facilitar a segurança e eficácia do manejo da dor aguda no contexto perioperatório; reduzir o risco de resultados adversos; manter as habilidades funcionais do paciente, bem como físicas e psicológicas, bem-estar; e melhorar a qualidade de vida dos pacientes com dor aguda durante o período perioperatório.

\begin{tabular}{|c|c|}
\hline \multicolumn{2}{|r|}{ Recomendações } \\
\hline I. & $\begin{array}{l}\text { As políticas e procedimentos institucionais incluem (mas não são limitados a): educação e } \\
\text { treinamento para profissionais de saúde, monitoramento dos resultados dos pacientes, } \\
\text { documentação das atividades de monitoramento, monitoramento de resultados em um nível } \\
\text { institucional, disponibilidade de } 24 \text { horas de anestesiologistas fornecendo tratamento de dor } \\
\text { perioperatório, e uso de um serviço dedicado a dor aguda. }\end{array}$ \\
\hline II. & $\begin{array}{l}\text { A avaliação e o planejamento pré-operatório do paciente são parte integrante de gestão da dor } \\
\text { perioperatória. O planejamento é uma estratégia antecipada para analgesia pós-operatória que } \\
\text { integra o gerenciamento da dor no cuidado perioperatório dos pacientes. Fatores do paciente a } \\
\text { serem considerados na formulação de um plano inclui tipo de cirurgia, gravidade esperada da dor } \\
\text { no pós-operatório, condições médicas subjacentes (por exemplo, presença de doença respiratória } \\
\text { ou cardíaca, alergias), a relação risco-benefício para as técnicas disponíveis, e as preferências ou } \\
\text { experiência anterior com dor. Uma história de dor dirigida, um exame físico dirigido, e um plano de } \\
\text { controle da dor deve ser incluído na avaliação anestésica pré-operatória. }\end{array}$ \\
\hline III. & $\begin{array}{l}\text { A preparação do paciente pré-operatório inclui: ajuste ou continuação de medicamentos cuja } \\
\text { cessação súbita pode provocar uma síndrome de abstinência, tratamentos para reduzir dor e } \\
\text { ansiedade pré-existente, pré-medicações antes da cirurgia como parte de um tratamento de dor } \\
\text { analgésico multimodal, e educação do paciente e da família, incluindo técnicas de controle da dor } \\
\text { comportamental. }\end{array}$ \\
\hline IV. & $\begin{array}{l}\text { Técnicas perioperatórias para o tratamento pós-operatório da dor incluem, entre outras, as } \\
\text { seguintes modalidades únicas: analgesia opióide regional (isto é, neuraxial); analgesia controlada } \\
\text { pelo paciente (PCA) com opióides sistêmicos; e analgésico regional periférico, incluindo, mas não } \\
\text { limitado a blocos intercostais, blocos de plexo e infiltração anestésica local de incisões. }\end{array}$ \\
\hline V. & $\begin{array}{l}\text { As técnicas multimodais para o gerenciamento da dor incluem a administração de duas ou mais } \\
\text { drogas que atuam por diferentes mecanismos para fornecer analgesia. Esses medicamentos } \\
\text { podem ser administrados pela mesma via ou por vias diferentes. }\end{array}$ \\
\hline
\end{tabular}


Alguns grupos de pacientes estão em risco especial de controle da dor inadequado e requer considerações analgésicas adicionais. As populações em risco incluem pacientes pediátricos, pacientes geriátricos e pacientes críticos ou cognitivos, ou outros pacientes que podem ter dificuldade em se comunicar.

\begin{tabular}{|c|c|}
\hline \multirow{4}{*}{$\begin{array}{c}\text { Guideline } \\
\text { G_03 }\end{array}$} & Título \\
\hline & Diretrizes práticas para Manejo da Via Aérea Difícil \\
\hline & Idioma \\
\hline & ASA Guidelines for Patient Care in Anesthesiology, 2013 \\
\hline \multicolumn{2}{|r|}{ Propósito } \\
\hline \multicolumn{2}{|c|}{$\begin{array}{l}\text { O objetivo desta diretriz é facilitar o gerenciamento da via aérea difícil e reduzir a probabilidade de resultados } \\
\text { adversos. Os principais resultados adversos associados com a via aérea difícil incluem (mas não estão limitados } \\
\text { para) morte, lesão cerebral, parada cardiopulmonar, desnecessária via aérea cirúrgica, traumatismo aéreo } \\
\text { danos aos dentes. }\end{array}$} \\
\hline \multicolumn{2}{|r|}{ Recomendações } \\
\hline I. & $\begin{array}{l}\text { Com base em associações reconhecidas entre uma via aérea difícil e uma variedade de } \\
\text { características do paciente, algumas características do histórico médico de um paciente ou } \\
\text { registros médicos antecedentes podem estar relacionados à probabilidade de encontrar uma via } \\
\text { aérea difícil. Estudos observacionais de pacientes não selecionados relatam associações entre } \\
\text { várias características do paciente pré-operatório (por exemplo, idade, obesidade, apneia obstrutiva } \\
\text { do sono, história de ronco) e laringoscopia difícil ou intubação. }\end{array}$ \\
\hline II. & $\begin{array}{l}\text { A preparação básica para o manejo da via aérea difícil inclui: disponibilidade de equipamentos } \\
\text { para gerenciamento de uma via aérea difícil (isto é, unidade de armazenamento portátil), informar } \\
\text { o paciente com uma via aérea difícil conhecida ou suspeita, atribuir um indivíduo para prestar } \\
\text { assistência quando uma via aérea é difícil, pré oxigenação pré-anestésica por máscara e, } \\
\text { administração de oxigênio suplementar em todo o processo de manejo da via aérea difícil. }\end{array}$ \\
\hline III. & $\begin{array}{l}\text { Uma estratégia pré planejada de pré indução inclui a consideração de várias intervenções } \\
\text { destinadas a facilitar a intubação deve ocorrer uma via aérea difícil. Intervenções não invasivas } \\
\text { destinados a gerenciar uma via aérea difícil incluem, mas não são limitados a: intubação acordada, } \\
\text { laringoscopia assistida por vídeo, estilos de intubação ou trocadores de tubo, tubo laríngeo, } \\
\text { lâminas laringoscópicas rígidas de variação design e tamanho, intubação guiada por fibra óptica. }\end{array}$ \\
\hline IV. & $\begin{array}{l}\text { A literatura não fornece uma base suficiente para avaliar os benefícios de uma estratégia de } \\
\text { extubação para a via aérea difícil. Para os propósitos desta diretriz, uma estratégia de extubação é } \\
\text { considerada uma extensão lógica da intubação estratégia. }\end{array}$ \\
\hline V. & $\begin{array}{l}\text { Os cuidados de acompanhamento incluem: documentação de via aérea difícil e gestão, informar e } \\
\text { aconselhar o paciente (ou pessoa responsável) da ocorrência e potencial complicações } \\
\text { associadas à via aérea difícil. }\end{array}$ \\
\hline VI. & $\begin{array}{l}\text { Componentes do exame físico pré-operatório da via aérea: } \\
\text { I. Comprimento dos incisivos superiores - Relativamente longo } \\
\text { II. Relação dos incisivos maxilares e mandibulares durante o fechamento normal da mandíbula - } \\
\text { Promover "overbite" (incisivos maxilares anteriores a mandibulares incisivos) } \\
\text { III. Relação dos incisivos maxilares e mandibulares durante a protrusão voluntária da mandíbula - } \\
\text { O paciente não pode trazer incisivos mandibulares anteriores (na frente) dos incisivos maxilares } \\
\text { IV. Visibilidade da úvula - Não visível quando a língua é saliente com o paciente em posição (por } \\
\text { exemplo, classe Mallampati> 2) } \\
\text { V. Forma do palato - Altamente arqueada ou muito estreita } \\
\text { VI. Conformidade do espaço mandibular Stiff, ocupado por massa ou não resiliente - Distância } \\
\text { tireo-mento menor que três larguras de dedos comuns } \\
\text { VII. Comprimento do pescoço - Curto } \\
\text { VIII. Espessura do pescoço - Grosso } \\
\text { IX. Escala de movimento da cabeça e do pescoço - Paciente não pode tocar a ponta do queixo no } \\
\text { peito ou não pode estender o pescoço }\end{array}$ \\
\hline
\end{tabular}




\begin{tabular}{|c|c|c|}
\hline \multirow{4}{*}{$\begin{array}{c}\text { Guideline } \\
\text { G_04 }\end{array}$} & \multicolumn{2}{|l|}{ Título } \\
\hline & \multicolumn{2}{|c|}{ Diretrizes práticas para Manejo Perioperatório da Apneia Obstrutiva do Sono } \\
\hline & Fonte & Idioma \\
\hline & ASA Guidelines for Patient Care in Anesthesiology, 2014 & Inglês \\
\hline \multicolumn{3}{|c|}{ Propósito } \\
\hline \multicolumn{3}{|c|}{$\begin{array}{l}\text { O objetivo desta diretriz é melhorar os cuidados perioperatórios e reduzir o risco de desfechos adversos em } \\
\text { pacientes com apneia obstrutiva do sono confirmada ou suspeita que recebem sedação, analgesia ou anestesia } \\
\text { para procedimentos diagnósticos ou terapêuticos sob cuidado de um anestesiologista. }\end{array}$} \\
\hline \multicolumn{3}{|c|}{ Recomendações } \\
\hline I. & \multicolumn{2}{|c|}{$\begin{array}{l}\text { A avaliação pré-operatória de um paciente para identificação de apneia obstrutiva do sono inclui: } \\
\text { revisão de registro médico, entrevista com paciente/familiar, protocolo de triagem, e exame físico. }\end{array}$} \\
\hline II. & \multicolumn{2}{|c|}{$\begin{array}{l}\text { Os fatores a serem considerados para determinar se o atendimento ambulatorial é apropriado } \\
\text { incluem: estado de apneia do sono, anormalidades anatômicas e fisiológicas, estado das doenças } \\
\text { coexistentes, natureza da cirurgia, tipo de anestesia, necessidade de opióides pós-operatórios, } \\
\text { idade do paciente, adequação da observação pós-descarga e capacidades do ambulatório. }\end{array}$} \\
\hline III. & \multicolumn{2}{|c|}{$\begin{array}{l}\text { A preparação pré-operatória destina-se a melhorar ou a otimizar o estado físico perioperatório do } \\
\text { paciente com apneia obstrutiva do sono e inclui: pressão pré-operatória contínua de pressão aérea } \\
\text { ou ventilação de pressão positiva não invasiva, uso pré-operatório de avanço mandibular ou } \\
\text { aparelhos orais e perda de peso pré-operatória. }\end{array}$} \\
\hline
\end{tabular}

\begin{tabular}{|c|c|c|}
\hline \multirow{3}{*}{$\begin{array}{c}\text { Guideline } \\
\text { G_05 }\end{array}$} & \multicolumn{2}{|c|}{ Título } \\
\cline { 2 - 3 } & Diretrizes práticas para Manejo Perioperatório do Sangue \\
\cline { 2 - 3 } & ASA Guidelines for Patient Care in Anesthesiology, 2015 & Idioma \\
\hline & Propósito & Inglês \\
\hline
\end{tabular}

O objetivo desta diretriz é melhorar o manejo perioperatório de transfusões de sangue e terapias adjuvantes e, reduzir o risco de resultados adversos associados a transfusões, sangramentos ou anemia.

\begin{tabular}{|c|c|}
\hline \multicolumn{2}{|r|}{ Recomendações } \\
\hline I. & $\begin{array}{l}\text { A avaliação pré-operatória de um paciente para identificar fatores de risco para exigir uma } \\
\text { transfusão de sangue ou terapia adjuvante inclui: revisão de registros médicos anteriores, } \\
\text { realização de uma entrevista com paciente ou família, revisão de resultados de testes laboratoriais } \\
\text { existentes e, ordenação de testes laboratoriais adicionais quando indicado. }\end{array}$ \\
\hline II. & $\begin{array}{l}\text { A avaliação de pacientes incluem revisar registros médicos anteriores e entrevistar o paciente ou } \\
\text { família para identificar: } \\
\text { o Transfusão de sangue anterior; } \\
\text { o História de coagulopatia induzida por fármaco (por exemplo, varfarina, clopidogrel, aspirina e } \\
\text { outros anticoagulantes), bem como como vitaminas ou suplementos de ervas que podem afetar } \\
\text { coagulação; } \\
\text { o Presença de coagulopatia congênita; } \\
\text { o História de eventos trombóticos (por exemplo, trombose venosa profunda, embolia pulmonar); } \\
\text { o Fatores de risco para isquemia orgânica (por exemplo, doença cardiorrespiratória) que podem } \\
\text { influenciar a transfusão final gatilho para glóbulos vermelhos (por exemplo, nível de hemoglobina); } \\
\text { - Informar pacientes sobre os potenciais riscos versus benefícios de transfusão de sangue e } \\
\text { induzir suas preferências; } \\
\text { - Reveja os resultados de testes laboratoriais disponíveis, incluindo hemoglobina, perfis de } \\
\text { hematócrito e coagulação; } \\
\text { - Solicitar testes laboratoriais adicionais, dependendo do paciente condição médica (por exemplo, } \\
\text { coagulopatia, anemia); } \\
\text { - Realizar um exame físico do paciente (por exemplo, equimoses, petéquias, palidez); } \\
\text { - Se possível, realize bem a avaliação pré-operatória com bastante antecedência (por exemplo, } \\
\text { vários dias da semana) para permitir para uma adequada preparação do paciente. }\end{array}$ \\
\hline
\end{tabular}


III.

IV.

V.

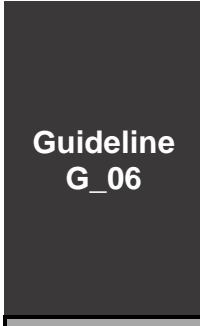

A preparação do paciente em pré procedimento inclui: tratamento de anemia, descontinuação de anticoagulantes e agentes antiplaquetários, e coleta de sangue autólogo (tipagem sanguínea).

Recomendações para preparação do paciente durante pré procedimento:

- Eritropoetina com ou sem ferro pode ser administrada quando possível reduzir a necessidade de sangue alogênico em populações de pacientes selecionadas (por exemplo, insuficiência renal, anemia de doença crônica, recusa de transfusão);

- Administrar ferro para pacientes com anemia ferropriva se o tempo permitir;

- Em consulta com um especialista apropriado, descontinuar terapia de anticoagulação (por exemplo, warfarina, fármacos anti-Xa, agentes de antitrombina) para cirurgia eletiva;

- Transição para um fármaco de ação mais curta (por exemplo, heparina de baixo peso molecular) pode ser apropriado em pacientes selecionados;

IV. - Se clinicamente possível, interrompa o antiagregante não-aspirínico (por exemplo, tienopiridinas tais como clopidogrel, ticagrelor ou prasugrel) por um tempo suficiente em avanço da cirurgia, com exceção de pacientes com história de intervenções coronarianas percutâneas;

- A aspirina pode ser continuada caso a caso;

- O risco de trombose versus o risco de aumento do sangramento deve ser considerado quando se altera o estado da anticoagulação;

- Certifique-se de que o sangue e os componentes do sangue estejam disponíveis para pacientes quando é esperado perda sanguínea significativa;

- Quando o sangue autólogo é preferido, pode-se oferecer ao paciente a oportunidade de doar sangue antes da admissão somente se houver tempo adequado para reconstituição eritropoiética.

A preparação do paciente pré procedimento inclui as seguintes estratégias para reduzir a transfusão alogênica intraoperatória: protocolos de manejo de sangue, reversão de anticoagulantes, antifibrinolíticos para profilaxia de perda excessiva de sangue e hemodiluição normovolêmica aguda.

Os objetivos desta diretriz são: melhorar a qualidade e eficiência dos cuidados com anestesia, estimular a avaliação de práticas clínicas e reduzir a gravidade das complicações relacionadas à aspiração pulmonar perioperatória de conteúdo gástrico.

Os aprimoramentos na qualidade e eficiência dos cuidados com anestesia incluem, entre outros, o uso econômico da medicação preventiva perioperatória, aumento da satisfação do paciente, evitando atrasos e cancelamentos, menor risco de desidratação ou hipoglicemia de jejum prolongado e minimização de morbidade perioperatória.

As práticas clínicas incluem, mas não estão limitadas a, retenção de sólidos e líquidos durante períodos especificos antes da cirurgia e prescrição de agentes farmacológicos para reduzir o volume gástrico e a acidez. As complicações da aspiração incluem, mas não estão limitadas a, pneumonia por aspiração, deficiências respiratórias e morbidades relacionadas.

\section{Recomendações}

A avaliação pré-operatória deverá incluir: revisão dos registros médicos pertinentes, um exame físico e uma pesquisa ou entrevista de pacientes. Além disto, os pacientes devem ser informados sobre os requisitos de jejum e os motivos para eles, com antecedência aos procedimentos. A história, o exame e a entrevista devem incluir avaliação pertinente da doença do refluxo gastroesofágico, sintomas de disfagia ou outros distúrbios da motilidade gastrointestinal, potencial de manejo da via aérea difícil e distúrbios metabólicos (por exemplo, diabetes mellitus) que podem aumentar o risco de regurgitação e aspiração pulmonar.

A recomendação para líquidos claros inclui: não ingerir líquidos claros pelo menos $2 \mathrm{~h}$ antes de procedimentos eletivos que requerem anestesia geral, anestesia regional ou sedação / analgesia (isto é, cuidados de anestesia monitorados). Exemplos de líquidos claros incluem, mas não estão limitados a água, sucos de frutas sem polpa, bebidas carbonatadas, chá claro e café preto. Esses líquidos não devem incluir álcool. O volume de líquido ingerido é menos importante do que o tipo de líquido ingerido.

III. $\quad \begin{aligned} & \text { A recomendação para sólidos e leite não humano inclui: não ingerir refeição leve ou leite não } \\ & \text { humano } 6 \mathrm{~h} \text { ou mais antes de procedimentos eletivos que requerem anestesia geral, anestesia }\end{aligned}$ regional ou sedação / analgesia (por exemplo, cuidados de anestesia monitorados). A ingestão de 


\begin{tabular}{|c|c|}
\hline & $\begin{array}{l}\text { alimentos ou alimentos fritos ou gordurosos pode prolongar o tempo de esvaziamento gástrico. } \\
\text { Tempo adicional de jejum (por exemplo, } 8 \mathrm{~h} \text { ou mais) pode ser necessário nesses casos. Tanto a } \\
\text { quantidade quanto o tipo de alimento ingerido devem ser considerados ao determinar um período } \\
\text { de jejum adequado. Como o leite não humano é semelhante aos sólidos no tempo de } \\
\text { esvaziamento gástrico, a quantidade ingerida deve ser considerada ao determinar um período de } \\
\text { jejum apropriado. }\end{array}$ \\
\hline IV. & $\begin{array}{l}\text { Não é recomendado o uso rotineiro pré-operatório de estimulantes gastrointestinais para diminuir o } \\
\text { risco de aspiração pulmonar em pacientes que não apresentam risco crescente aparente de } \\
\text { aspiração pulmonar. }\end{array}$ \\
\hline V. & $\begin{array}{l}\text { Não é recomendado o uso rotineiro pré-operatório de medicamentos que bloqueiam a secreção de } \\
\text { ácido gástrico para diminuir os riscos de aspiração pulmonar em pacientes que não apresentam } \\
\text { risco crescente aparente de aspiração pulmonar. }\end{array}$ \\
\hline VI. & $\begin{array}{l}\text { Não é recomendado o uso rotineiro pré-operatório de antiácidos para diminuir os riscos de } \\
\text { aspiração pulmonar em pacientes que não apresentam risco crescente aparente de aspiração } \\
\text { pulmonar. Somente antiácidos não partícipes devem ser usados quando os antiácidos são } \\
\text { indicados para pacientes selecionados para outros fins além de reduzir o risco de aspiração } \\
\text { pulmonar. }\end{array}$ \\
\hline VII. & $\begin{array}{l}\text { Não é recomendado o uso rotineiro pré-operatório de antieméticos para reduzir os riscos de } \\
\text { aspiração pulmonar em pacientes que não apresentam risco crescente aparente de aspiração } \\
\text { pulmonar. }\end{array}$ \\
\hline VIII. & Não é recomendado o uso de anticolinérgicos para diminuir os riscos de aspiração pulmonar. \\
\hline IX. & $\begin{array}{l}\text { Não é recomendado o uso rotineiro pré-operatório de múltiplos agentes em pacientes que não } \\
\text { apresentam risco crescente aparente de aspiração pulmonar. }\end{array}$ \\
\hline
\end{tabular}

\begin{tabular}{|c|c|c|}
\hline \multirow{4}{*}{$\begin{array}{c}\text { Guideline } \\
\text { G_07 }\end{array}$} & \multicolumn{2}{|l|}{ Título } \\
\hline & \multicolumn{2}{|c|}{$\begin{array}{l}\text { Diretrizes práticas para Prevenção, Detecção e Gerenciamento de Depressão Respiratória } \\
\text { Associada à Administração de Opióides Neuraxiais }\end{array}$} \\
\hline & Fonte & Idioma \\
\hline & ASA Guidelines for Patient Care in Anesthesiology, 2016 & Inglês \\
\hline \multicolumn{3}{|c|}{ Propósito } \\
\hline \multicolumn{3}{|c|}{$\begin{array}{l}\text { Os objetivos dessas diretrizes são melhorar a segurança do paciente e a qualidade do tratamento anestésico, } \\
\text { reduzindo a incidência e a gravidade da depressão respiratória neuraxial relacionada a opiáceos ou hipoxemia. } \\
\text { Além disso, essas diretrizes destinam-se a reduzir a incidência e a gravidade dos resultados adversos } \\
\text { relacionados à redução da frequência respiratória ou níveis de oxigênio (por exemplo, parada cardíaca, dano } \\
\text { cerebral, morte). }\end{array}$} \\
\hline \multicolumn{3}{|c|}{ Recomendações } \\
\hline I. & \multicolumn{2}{|c|}{$\begin{array}{l}\text { A identificação de pacientes com fatores de risco para depressão respiratória inclui a realização de } \\
\text { uma história focada (por exemplo, revisão de registros médicos) e exame físico. Além disto, a } \\
\text { atenção particular direta deve ser direcionada para sinais, sintomas ou antecedentes de apneia do } \\
\text { sono; doenças ou condições coexistentes (por exemplo, diabetes, obesidade); medicamentos } \\
\text { atuais (incluindo opióides pré-operatórios); e efeitos adversos após a administração de opióides. E, } \\
\text { ainda, um exame físico deve incluir, mas não está limitado, aos sinais vitais basais, via aérea, } \\
\text { coração, pulmão e função cognitiva. }\end{array}$} \\
\hline II. & \multicolumn{2}{|c|}{$\begin{array}{l}\text { A prevenção da depressão respiratória inclui a consideração da ventilação por pressão positiva } \\
\text { não invasiva e seleção de drogas. }\end{array}$} \\
\hline III. & \multicolumn{2}{|c|}{$\begin{array}{l}\text { A menor dose eficaz de opioides neuraxiais deve ser administrada para minimizar o risco de } \\
\text { depressão respiratória. }\end{array}$} \\
\hline
\end{tabular}




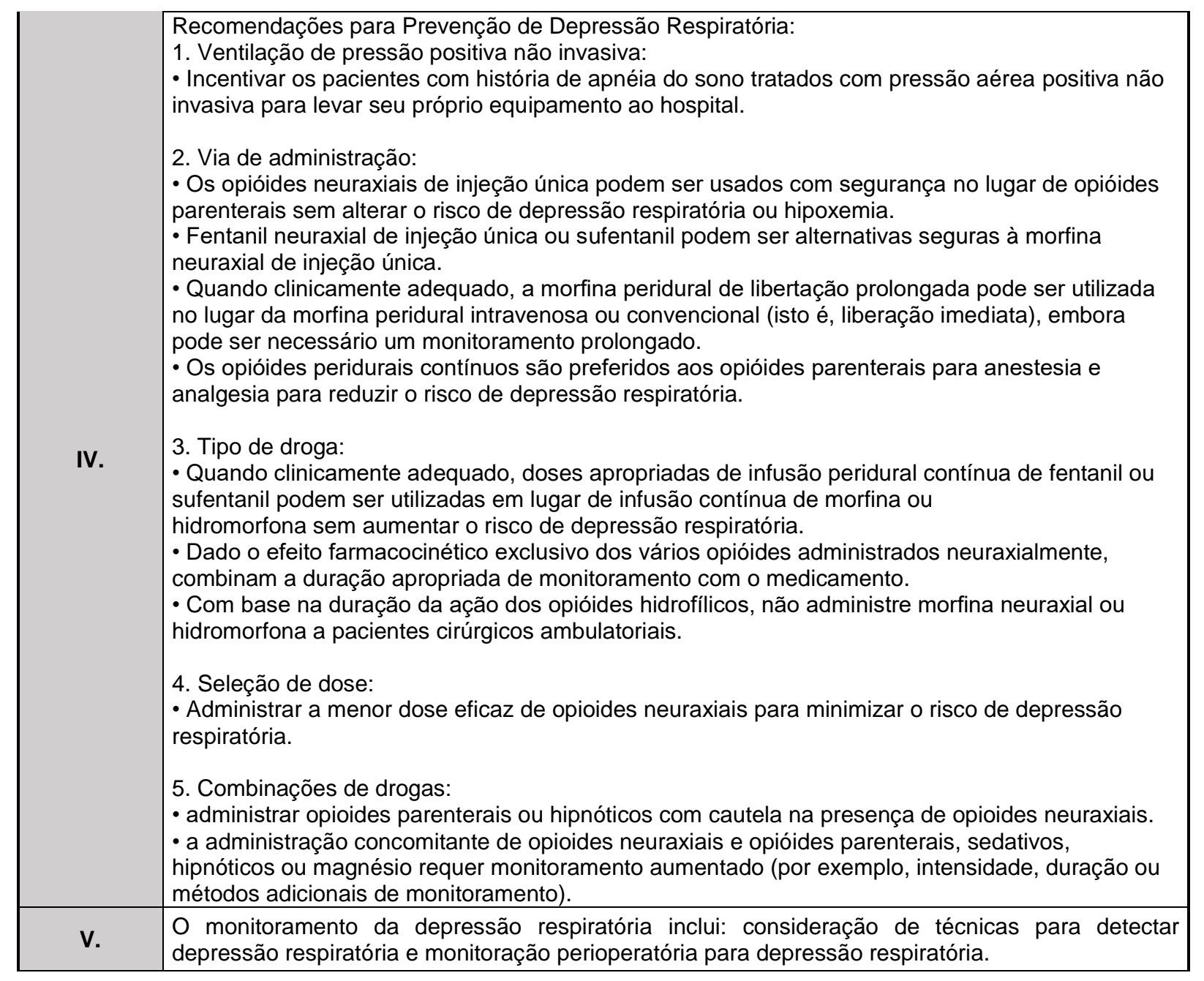

\subsubsection{Síntese do conteúdo da ESA, Guidelines of the European Society of Anaesthesiology}

\begin{tabular}{|c|c|c|}
\hline \multirow{4}{*}{$\begin{array}{l}\text { Guideline } \\
\text { G_01 }\end{array}$} & \multicolumn{2}{|l|}{ Título } \\
\hline & \multicolumn{2}{|l|}{ Diretrizes práticas para jejum perioperatório em adultos } \\
\hline & Fonte & Idioma \\
\hline & ESA Guidelines of the European Society of Anaesthesiology, 2011 & Inglês \\
\hline \multicolumn{3}{|c|}{ Propósito } \\
\hline \multicolumn{3}{|c|}{$\begin{array}{l}\text { Diretriz visa fornecer uma visão geral do conhecimento atual sobre o jejum perioperatório com avaliação da } \\
\text { qualidade da evidência, a fim de permitir que anestesiologistas em toda a Europa integrem esse conhecimento } \\
\text { em seus cuidados diários com os pacientes. }\end{array}$} \\
\hline \multicolumn{3}{|c|}{ Recomendações } \\
\hline I. & \multicolumn{2}{|c|}{$\begin{array}{l}\text { Adultos e crianças devem ser encorajados a beber fluidos limpos (incluindo água, suco livre de } \\
\text { polpa e chá ou café sem leite) até } 2 \mathrm{~h} \text { antes da cirurgia eletiva (incluindo cesariana). }\end{array}$} \\
\hline II. & \multicolumn{2}{|c|}{ Os alimentos sólidos devem ser proibidos por $6 \mathrm{~h}$ antes da cirurgia eletiva em adultos e crianças. } \\
\hline III. & \multicolumn{2}{|c|}{$\begin{array}{l}\text { Os pacientes não devem ter sua operação cancelada ou adiada apenas porque estão mastigando } \\
\text { chiclete, sugando um doce cozido ou fumando imediatamente antes da indução da anestesia. }\end{array}$} \\
\hline
\end{tabular}




\begin{tabular}{|c|l|}
\cline { 2 - 3 } IV. & $\begin{array}{l}\text { Pacientes com obesidade, refluxo gastroesofágico e diabetes e mulheres grávidas que não } \\
\text { trabalham podem seguir com segurança todas as diretrizes acima. }\end{array}$ \\
\hline V. & $\begin{array}{l}\text { Não há provas suficientes de benefício clínico para recomendar o uso rotineiro de antiácidos, } \\
\text { metoclopramida ou antagonistas dos receptores H2 antes da cirurgia eletiva em pacientes não } \\
\text { obesos. }\end{array}$ \\
\hline VI. & $\begin{array}{l}\text { É seguro para os pacientes (incluindo diabéticos) beber bebidas ricas em carboidratos até } 2 \text { h antes } \\
\text { da cirurgia eletiva. }\end{array}$ \\
\hline
\end{tabular}

\begin{tabular}{|c|c|c|}
\hline \multirow{4}{*}{$\begin{array}{l}\text { Guideline } \\
\text { G_02 }\end{array}$} & \multicolumn{2}{|l|}{ Título } \\
\hline & \multicolumn{2}{|c|}{$\begin{array}{c}\text { Diretrizes práticas para avaliação pré-operatória do paciente adulto submetido a cirurgia não } \\
\text { cardíaca }\end{array}$} \\
\hline & Fonte & Idioma \\
\hline & ESA Guidelines of the European Society of Anaesthesiology, 2013 & Inglês \\
\hline \multicolumn{3}{|c|}{ Propósito } \\
\hline \multicolumn{3}{|c|}{$\begin{array}{l}\text { Identificar pacientes para os quais o período perioperatório pode constituir um risco a } \\
\text { mortalidade, além dos riscos associados à doença subjacente. Projetar estratégias } \\
\text { reduzir os riscos perioperatórios adicionais. }\end{array}$} \\
\hline \multicolumn{3}{|c|}{ Recomendações } \\
\hline I. & \multicolumn{2}{|c|}{$\begin{array}{l}\text { (1) Os questionários padronizados pré-operatórios podem ser úteis para melhorar a avaliação da } \\
\text { anestesia em uma variedade de situações; } \\
\text { (2) Se um questionário pré-operatório for implementado, deve-se ter grande cuidado em seu projeto, } \\
\text { e uma versão baseada em computador deve ser usada sempre que possível; } \\
\text { (3) A avaliação pré-operatória deve ser realizada com tempo suficiente antes do procedimento } \\
\text { programado para permitir a implementação de qualquer intervenção pré-operatória aconselhável } \\
\text { visando melhorar o resultado do paciente; } \\
\text { (4) A avaliação pré-operatória deve pelo menos ser completada por um anestesista, mas a triagem } \\
\text { dos pacientes pode ser realizada efetivamente por enfermeiros treinados; } \\
\text { (5) Um membro da farmácia pode ser útil na avaliação pré-operatória, a fim de reduzir as } \\
\text { discrepâncias nas ordens de medicamentos pós-operatórios; } \\
\text { (6) Não há evidências suficientes para recomendar que o modelo preferido seja que um paciente } \\
\text { deve ser visto pelo mesmo anestesista desde a avaliação pré-operatória até a administração de } \\
\text { anestesia. }\end{array}$} \\
\hline II. & \multicolumn{2}{|c|}{$\begin{array}{l}\text { (1) Se a doença cardíaca ativa é suspeitada em um paciente agendado para cirurgia, o paciente } \\
\text { deve ser encaminhado para um cardiologista para avaliação e possível tratamento; } \\
\text { (2) Nos pacientes que estão atualmente tomando a terapia com beta-bloqueador ou estatina, esse } \\
\text { tratamento deve ser continuado no período perioperatório. }\end{array}$} \\
\hline III. & \multicolumn{2}{|c|}{$\begin{array}{l}\text { 1) A espirometria diagnóstica pré-operatória em pacientes não cardiotorácicos não pode ser } \\
\text { recomendada para avaliar o risco de complicações pós-operatórias; } \\
\text { (2) As radiografias de tórax pré-operatórias de rotina raramente alteram o manejo perioperatório } \\
\text { desses casos. Portanto, não pode ser recomendado de forma rotineira; } \\
\text { (3) As radiografias de tórax pré-operatório têm um valor muito limitado em pacientes com mais de } 70 \\
\text { anos com fatores de risco estabelecidos; } \\
\text { (4) Os pacientes com síndrome da apnéia obstrutiva do sono devem ser avaliados cuidadosamente } \\
\text { para uma possível via aérea difícil e atenção especial é recomendada no pós-operatório imediato; } \\
\text { (5) Questionários específicos para diagnosticar síndrome da apnéia obstrutiva do sono podem ser } \\
\text { recomendados quando a polissonografia não está disponível; } \\
\text { (6) O uso de CPAP no período pré-operatório em pacientes com síndrome da apnéia obstrutiva do } \\
\text { sono pode reduzir os eventos hipóxicos; } \\
\text { (7) A espirometria de incentivo pré-operatória pode ser benéfica na cirurgia abdominal superior para } \\
\text { evitar complicações pulmonares pós-operatórias; } \\
\text { (8) A correção da desnutrição pode ser benéfica; } \\
\text { (9) Recomenda-se a cessação do tabagismo antes da cirurgia. Deve começar cedo (pelo menos } 6-8 \\
\text { semanas antes da cirurgia, com uma duração mínima de } 4 \text { semanas). Uma cessação de curto prazo } \\
\text { é benéfica para reduzir a quantidade de carboxihemoglobina no sangue em fumantes pesados. }\end{array}$} \\
\hline IV. & \multicolumn{2}{|c|}{$\begin{array}{l}\text { A diurese deve ser monitorada cuidadosamente ao longo da fase perioperatória e um } \\
\text { gerenciamento adequado de fluidos, a fim de evitar a piora da insuficiência renal pré-existente para } \\
\text { pacientes com risco de insuficiência renal pós-operatória. }\end{array}$} \\
\hline
\end{tabular}




\begin{tabular}{|c|c|}
\hline V. & $\begin{array}{l}\text { (1) Os pacientes com diabetes conhecida devem ser gerenciados de acordo com diretrizes sobre o } \\
\text { manejo de pacientes com doença cardiovascular conhecida ou suspeita; } \\
\text { (2) Não é recomendado verificar a glicemia na avaliação pré-operatória; } \\
\text { (3) A avaliação pré-operatória deve incluir uma avaliação formal do risco de um paciente com } \\
\text { homeostase de glicose desordenada; } \\
\text { (4) Os pacientes com alto risco de homeostase de glicose desordenada devem ser identificados } \\
\text { como necessitando de atenção específica ao controle perioperatório de glicose; } \\
\text { (5) Pacientes com diabetes de longa data devem ser submetidos a uma avaliação cuidadosa das } \\
\text { vias aéreas. }\end{array}$ \\
\hline VI. & $\begin{array}{l}\text { (1) A avaliação pré-operatória de pacientes obesos inclui pelo menos avaliação clínica, } \\
\text { eletrocardiograma, polissonografia e/ou oximetria; } \\
\text { (2) O exame de laboratório é indicado em pacientes obesos para detectar concentrações } \\
\text { patológicas de glicose / HbA1C e anemia; } \\
\text { (3) As circunferências do pescoço de pelo menos } 43 \mathrm{~cm} \text {, bem como um alto índice de Mallampati, } \\
\text { são preditores de intubação difícil em pacientes obesos; } \\
\text { (4) O uso de CPAP no período pré-operatório pode reduzir os eventos hipóxicos em pacientes } \\
\text { obesos. }\end{array}$ \\
\hline VII. & $\begin{array}{l}\text { (1) Se os transtornos de coagulação são suspeitos, o paciente deve ser encaminhado para um } \\
\text { hematologista; } \\
\text { (2) A correção pré-operatória da hemostasia diminui o sangramento perioperatório; } \\
\text { (3) O uso rotineiro de testes de coagulação não é recomendado, a menos que existam fatores de } \\
\text { risco específicos na história. }\end{array}$ \\
\hline VIII. & $\begin{array}{l}\text { (1) A suplementação de ferro pré-operatório pode ser considerada como correção da anemia pré- } \\
\text { operatória; } \\
\text { (2) Não há evidências suficientes para promover o uso rotineiro de doação de sangue autólogo pré- } \\
\text { operatório para reduzir os requisitos de transfusão perioperatória. }\end{array}$ \\
\hline IX. & $\begin{array}{l}\text { (1) O risco, não a idade, deve ser usado para desencadear uma maior avaliação e preparação. A } \\
\text { probabilidade de mortalidade pós-operatória e morbidade depende do risco associado com o grau } \\
\text { de cirurgia; } \\
\text { (2) Os protocolos de cuidados perioperatórios reduzem o delírio pós-operatório em pacientes com } \\
\text { pescoço fraturado do fêmur. }\end{array}$ \\
\hline X. & $\begin{array}{l}\text { (1) A administração de benzodiazepínicos durante } 5 \text { dias perioperatórios reduz a incidência de } \\
\text { síndrome de abstinência alcoólica em pacientes de risco; } \\
\text { (2) A abstinência de álcool durante pelo menos } 1 \text { mês antes da cirurgia reduz a incidência de } \\
\text { complicações perioperatórias. }\end{array}$ \\
\hline XI. & $\begin{array}{l}\text { (1) A avaliação pré-anestésica deve incluir uma entrevista completa para predisposição ao risco } \\
\text { alérgico; } \\
\text { (2) Os pacientes com risco de reações anafiláticas durante a anestesia cirúrgica incluem o seguinte: } \\
\text { - pacientes com alergia documentada a uma das drogas ou produtos que provavelmente serão } \\
\text { utilizados; } \\
\text { - pacientes com história de possível reação alérgica durante uma anestesia anterior; } \\
\text { - pacientes com história de possível alergia ao látex, independentemente da circunstância; } \\
\text { - pacientes com história sugerindo alergia a vegetais, frutas ou cereais, conhecidos por reatividade } \\
\text { cruzada frequente com látex; } \\
\text { (3) Em pacientes com história clínica positiva, o anestesista deve procurar uma opinião e avaliação } \\
\text { de alergia especializada quando possível para orientar suas escolhas (negativas e positivas) para o } \\
\text { protocolo de anestesia e outras drogas; } \\
\text { (4) Os testes cutâneos negativos não garantem a ausência de sensibilização para uma determinada } \\
\text { substância, pois podem tornar-se negativos com o tempo; } \\
\text { (5) Os resultados da avaliação da alergia pré anestesia devem ser visíveis para todos os } \\
\text { prestadores de cuidados, bem como para o paciente. }\end{array}$ \\
\hline XII. & $\begin{array}{l}\text { (1) Os pacientes devem ser questionados explicitamente sobre a ingestão de drogas à base de } \\
\text { plantas, particularmente aquelas que podem causar hemorragia aumentada no período } \\
\text { perioperatório ou que tenham outras interações indesejadas / efeitos colaterais (outros } \\
\text { medicamentos também podem ter em impacto importante na função plaquetária, como por exemplo, } \\
\text { analgésicos, medicamentos anti-inflamatórios ou drogas tomadas para um resfriado comum); } \\
\text { (2) Os medicamentos à base de plantas devem ser descontinuados } 2 \text { semanas antes da cirurgia; } \\
\text { (3) Não há evidências para adiar a cirurgia eletiva, mas para cirurgia de alto risco em } \\
\text { "compartimentos fechados", como neurocirurgia no cérebro, adiamento de casos eletivos podem ser } \\
\text { considerados quando os pacientes tomam drogas à base de plantas, como ginseng, alho e gingko } \\
\text { até o dia da cirurgia. }\end{array}$ \\
\hline
\end{tabular}




\begin{tabular}{|c|c|}
\hline XIII. & $\begin{array}{l}\text { (1) Os pacientes tratados cronicamente com ácido tricloroacético devem ser submetidos a avaliação } \\
\text { cardíaca antes da anestesia; } \\
\text { (2) O tratamento antidepressivo para pacientes cronicamente deprimidos não deve ser interrompido } \\
\text { antes da anestesia; } \\
\text { (3) Os inibidores da monoaminaoxidase irreversíveis devem ser descontinuados pelo menos } 2 \\
\text { semanas antes da anestesia. Para evitar a recaída da doença subjacente, a medicação deve ser } \\
\text { alterada para inibidores da monoaminaoxidase reversíveis; } \\
\text { (4) A incidência de confusão pós-operatória é significativamente maior em pacientes esquizofrênicos } \\
\text { se a medicação foi interrompida antes da cirurgia. Assim, a medicação antipsicótica deve ser } \\
\text { continuada em pacientes com esquizofrenia crônica perioperatória; } \\
\text { (5) A administração de lítio deve ser descontinuada } 72 \text { h antes da cirurgia. Pode ser reiniciado se o } \\
\text { paciente tiver faixas normais de eletrólitos, é hemodinamicamente estável e é capaz de comer e } \\
\text { beber. Os níveis sanguíneos de lítio devem ser controlados dentro de } 1 \text { semana. }\end{array}$ \\
\hline XIV. & $\begin{array}{l}\text { (1) Em pacientes de alto risco sob anticoagulação oral, um gerenciamento para o período } \\
\text { perioperatório é altamente recomendado de acordo com as diretrizes clínicas existentes; } \\
\text { (2) Em procedimentos cirúrgicos menores, como a cirurgia de catarata ou de tecidos moles, deve } \\
\text { ser considerada a continuação da terapia com warfarina. }\end{array}$ \\
\hline XV. & $\begin{array}{l}\text { (1) O rastreio para intubação difícil deve ser realizado, sempre que possível, em todos os pacientes } \\
\text { que necessitem potencialmente de administração de via aérea para anestesia, bem como na UTI. } \\
\text { Este exame inclui um histórico de condições médicas, operações cirúrgicas, histórico de manejo } \\
\text { difícil das vias aéreas e, se disponível, exame de registros anestésicos prévios; } \\
\text { (2) Nenhum sinal preditivo único para o manejo difícil das vias aéreas é suficiente por si só e a } \\
\text { avaliação pré-anestesica precisa da combinação de diferentes critérios de avaliação validados; } \\
\text { (3) O potencial de via aérea difícil deve ser avaliado e depende da presença de dois ou mais dos } \\
\text { seguintes fatores: IMC < } 30 ; \text { protrusão do maxilar severamente limitada; ronco; barba; classificação } \\
\text { Mallampati } 3 \text { ou 4; e idade mínima de } 57 \text { anos; } \\
\text { (4) O potencial de ventilação impossível de máscara deve ser avaliado e depende da presença de } \\
\text { três ou mais dos seguintes fatores: mudanças na radiação do pescoço; masculino sexo; Mallampati } \\
\text { classe } 3 \text { ou 4; e presença de uma barba; } \\
\text { (5) A triagem multimodal sistemática para intubação difícil deve incluir a classificação de Mallampati, } \\
\text { a distância tireo-mento, a abertura da boca; } \\
\text { (6) Deve ser dada especial atenção à avaliação de possíveis intubações difíceis em determinadas } \\
\text { condições médicas, tais como obesidade, síndrome da apnéia obstrutiva do sono, diabetes, coluna } \\
\text { cervical fixa, patologias orolaríngeas e pré-eclâmpsia. Circunferência do pescoço de mais de } 45 \text { cm } \\
\text { é outro sinal de aviso; } \\
\text { (7) A videolaringoscopia é difícil de prever, já que apenas alguns estudos abordaram esta questão } \\
\text { até agora. }\end{array}$ \\
\hline
\end{tabular}

\begin{tabular}{|c|c|c|}
\hline \multirow{4}{*}{$\begin{array}{c}\text { Guideline } \\
\text { G_03 }\end{array}$} & \multicolumn{2}{|l|}{ Título } \\
\hline & \multicolumn{2}{|c|}{ Diretrizes práticas para manejo do sangramento perioperatório severo } \\
\hline & Fonte & Idioma \\
\hline & ESA Guidelines of the European Society of Anaesthesiology, 2016-2017 & Inglês \\
\hline \multicolumn{3}{|c|}{ Propósito } \\
\hline \multicolumn{3}{|c|}{$\begin{array}{l}\text { A gestão do sangramento perioperatório envolve múltiplas avaliações e estratégias para garantir o atendimento } \\
\text { adequado ao paciente. Inicialmente, é importante identificar os pacientes com risco aumentado de sangramento } \\
\text { perioperatório. } \\
\text { Em seguida, estratégias devem ser empregadas para corrigir a anemia pré-operatória e para estabilizar } \\
\text { macrocirculação e microcirculação, para otimizar a tolerância do paciente ao sangramento. } \\
\text { Finalmente, intervenções direcionadas devem ser usadas para reduzir o sangramento intraoperatório e pós- } \\
\text { operatório, e assim evitar a morbidade e mortalidade subsequentes }\end{array}$} \\
\hline \multicolumn{3}{|c|}{ Recomendações } \\
\hline I. & $\begin{array}{l}\text { Antes da cirurgia ou procedimentos invasivos, recomendamos uma } \\
\text { questionário padronizado que considere histórico clínico e familiar de san } \\
\text { detalhadas sobre a medicação do paciente. } \\
\text { Recomendamos o uso de questionários padronizados sobre sangrame } \\
\text { como preferível ao uso rotineiro de testes convencionais de triagem de co } \\
\text { tromboplastina parcial ativada (aPTT), razão internacional normalizada } \\
\text { trombina e contagem de plaquetas em cirurgia eletiva. } \\
\text { Recomendamos a aplicação de algoritmos de intervenção que incorpor } \\
\text { definidos com base na coagulação de ensaio hen }\end{array}$ & $\begin{array}{l}\text { estruturada ou } \\
\text { e, informações } \\
\text { tória de drogas } \\
\text { como tempo de } \\
\text { tempo de pró- } \\
\text { os e alvos pré- } \\
\text { viscoelástico }\end{array}$ \\
\hline
\end{tabular}




\begin{tabular}{|c|c|}
\hline & $\begin{array}{l}\text { monitoramento para orientar a intervenção hemostática individualizada no caso do sangramento } \\
\text { perioperatório. } \\
\text { Se a coagulação de ensaio hemostático viscoelástico não estiver disponível, recomendamos a } \\
\text { aplicação de algoritmos de intervenção que incorporem disparadores pré-definidos com base em } \\
\text { testes de coagulação convencionais. }\end{array}$ \\
\hline II. & $\begin{array}{l}\text { Sugerimos testes de função plaquetária pré-operatória somente em associação com um histórico de } \\
\text { sangramento positivo. } \\
\text { Sugerimos que o teste da função plaquetária pré-operatória seja usado para identificar a diminuição } \\
\text { da função plaquetária causada por condições médicas ou medicamentos antiplaquetários. } \\
\text { O tempo de sangramento é influenciado por muitas variáveis e não é útil para estratificar o risco de } \\
\text { hemorragia. }\end{array}$ \\
\hline III. & $\begin{array}{l}\text { A anemia pré-operatória em adultos e crianças parece ser um forte preditor de transfusão de } \\
\text { sangue perioperatória em vários tipos de condições e cirurgias e pode estar associada a eventos } \\
\text { adversos. } \\
\text { Recomendamos que pacientes com risco de hemorragia sejam avaliados para anemia } 3 \text { a } 8 \\
\text { semanas antes da cirurgia. Se a anemia estiver presente, indique a causa (deficiência de ferro, } \\
\text { insuficiência renal ou inflamação). } \\
\text { Recomendamos tratar a deficiência de ferro com suplementação de ferro. Recomendamos o uso de } \\
\text { ferro intravenoso ao invés do ferro oral. Se outras causas de anemia foram excluídas ou tratadas, } \\
\text { sugerimos agentes estimulantes da eritropoetina. Se a doação de sangue autóloga for realizada, } \\
\text { sugerimos tratamento com agentes estimulantes de ferro e/ou eritropoetina para evitar anemia pré- } \\
\text { operatória e aumento das taxas globais de transfusão. Em pacientes com anemia pré-operatória, } \\
\text { recomendamos o uso de terapia combinada com ferro intravenoso e eritropoetina, juntamente com } \\
\text { uma política de transfusão restritiva. Em pacientes que não possuem câncer com anemia pré- } \\
\text { operatória agendada para cirurgia eletiva de grande porte, recomendamos adiar a cirurgia até a } \\
\text { anemia ter sido corrigida. }\end{array}$ \\
\hline IV. & $\begin{array}{l}\text { Não recomendamos o uso de transfusão de plasma para correção pré-procedural de tempo de pró- } \\
\text { trombina moderado a moderadamente elevado. } \\
\text { Recomendamos o tratamento precoce e direcionado das deficiências dos fatores de coagulação no } \\
\text { plasma. Fontes de fatores de coagulação são concentrados de fatores de coagulação, } \\
\text { crioprecipitado ou altos volumes de plasma, dependendo da situação clínica, tipo de sangramento, } \\
\text { tipo de deficiência e recursos fornecidos. } \\
\text { No tratamento da deficiência do fator de coagulação adquirida, sugerimos a consideração de um } \\
\text { protocolo orientado por proporção (plasma, concentrados de plaquetas) no início do sangramento } \\
\text { maciço descontrolado fora do cenário de trauma seguido de uma abordagem orientada por } \\
\text { objetivos o mais rápido possível. } \\
\text { Sugerimos concentrados de fatores de coagulação para o tratamento primário da deficiência do } \\
\text { fator de coagulação adquirida devido à sua alta eficácia e à sua infecção mínima. } \\
\text { Não recomendamos o uso indiscriminado de transfusão de plasma no manejo da hemorragia } \\
\text { perioperatória. } \\
\text { Sugerimos a transfusão de concentrado de plaquetas em situações de sangramento claramente } \\
\text { relacionadas com fármacos antiplaquetários ou trombocitopenia. }\end{array}$ \\
\hline V. & $\begin{array}{l}\text { Recomendamos que a terapia com aspirina continue perioperatório na maioria dos contextos } \\
\text { cirúrgicos, especialmente a cirurgia cardíaca. Quando a retirada de aspirina antes da cirurgia é } \\
\text { considerada, recomendamos um intervalo de tempo de } 3 \text { dias. Em pacientes com fatores de risco } \\
\text { para complicações vasculares nativas de qualquer tratamento antiplaquetário, não é recomendado } \\
\text { que o tratamento com aspirina seja iniciado pré-operatório. Em pacientes tratados cronicamente } \\
\text { com aspirina para a prevenção secundária de eventos cardiovasculares, exceto aqueles pacientes } \\
\text { com stents coronários, recomendamos a interrupção da aspirina para procedimentos em que haja } \\
\text { um risco de sangramento muito elevado. }\end{array}$ \\
\hline VI. & $\begin{array}{l}\text { Sugerimos que os pacientes com alterações hemostáticas associadas a doenças sistêmicas, } \\
\text { metabólicas e endócrinas sejam gerenciados no período perioperatório em colaboração com um } \\
\text { hematologista. } \\
\text { Sugerimos a descontinuação pré-operatória individualizada do tratamento seletivo com inibidores } \\
\text { da recaptação da serotonina. } \\
\text { Sugerimos a descontinuação pré-operatória individualizada de agentes antiepilépticos, como o } \\
\text { ácido valproico, que pode aumentar o sangramento. } \\
\text { Recomendamos a interrupção pré-operatória de extratos de gingko biloba. }\end{array}$ \\
\hline VII. & $\begin{array}{l}\text { Sugerimos encaminhar o paciente para um hematologista para avaliação e planejamento da } \\
\text { intervenção, se os distúrbios hemorrágicos hereditários forem suspeitos pré-operatório. } \\
\text { Recomendamos o uso de ferramentas de avaliação de sangramento para detectar e prever o risco } \\
\text { perioperatório de sangramento antes da cirurgia e procedimentos invasivos. }\end{array}$ \\
\hline
\end{tabular}




\begin{tabular}{l|l|} 
V cirurgia pode ser realizada de forma segura em pacientes com doença infamatória intestinal \\
quando há um planejamento pré-operatório cuidadoso apropriado, terapia apropriada de \\
substituição e gerenciamento de equipe multidisciplinar. \\
Sugerimos a correção hemostática pré-operatória em pacientes com síndrome do intestino irritável, \\
dependendo do tipo de cirurgia.
\end{tabular}

\begin{tabular}{|c|c|c|}
\hline \multirow{4}{*}{$\begin{array}{c}\text { Guideline } \\
\text { G_04 }\end{array}$} & \multicolumn{2}{|l|}{ Título } \\
\hline & \multicolumn{2}{|c|}{$\begin{array}{c}\text { Diretrizes práticas para profilaxia perioperatória do tromboembolismo venoso perioperatório para } \\
\text { cirurgias em idosos }\end{array}$} \\
\hline & Fonte & Idioma \\
\hline & ESA Guidelines of the European Society of Anaesthesiology, 2016-2017 & Inglês \\
\hline \multicolumn{3}{|c|}{ Propósito } \\
\hline \multicolumn{3}{|c|}{$\begin{array}{l}\text { Identificar pacientes com risco de tromboembolismo venoso (TEV), o qual é conhecido por aumentar com a } \\
\text { idade, assim como o risco de hemorragia. }\end{array}$} \\
\hline \multicolumn{3}{|c|}{ Recomendações } \\
\hline I. & \multicolumn{2}{|l|}{ A idade acima de 70 anos é um fator de risco para TEV pós-operatória. } \\
\hline II. & \multicolumn{2}{|c|}{$\begin{array}{l}\text { Em pacientes idosos, sugerimos identificação de comorbidades aumentando o risco de TEV (por } \\
\text { exemplo, insuficiência cardíaca congestiva, transtorno de circulação pulmonar, insuficiência renal, } \\
\text { linfoma, câncer metastático, obesidade, artrite, terapia de estrogênio pós-menopausa) e correção } \\
\text { se presente (por exemplo, anemia, coagulopatia). }\end{array}$} \\
\hline III. & \multicolumn{2}{|l|}{ Não recomendamos a reposição bilateral do joelho em pacientes idosos e frágeis. } \\
\hline IV. & \multicolumn{2}{|c|}{$\begin{array}{l}\text { Sugerimos o tempo e a dosagem da profilaxia farmacológica para TEV, como na população não } \\
\text { envelhecida. }\end{array}$} \\
\hline V. & \multicolumn{2}{|c|}{$\begin{array}{l}\text { Em pacientes idosos com insuficiência renal, pode ser utilizada heparina não fraccionada com } \\
\text { baixa dose ou dose ajustada em peso. }\end{array}$} \\
\hline VI. & \multicolumn{2}{|c|}{$\begin{array}{l}\text { Nos idosos, recomendamos uma prescrição cuidadosa de profilaxia TEV pós-operatória e } \\
\text { mobilização pós-operatória precoce. }\end{array}$} \\
\hline VII. & \multicolumn{2}{|c|}{$\begin{array}{l}\text { Recomendamos múltiplas intervenções para a profilaxia de TEV em pacientes idosos e frágeis, } \\
\text { incluindo dispositivos de compressão pneumática, e / ou anticoagulantes diretos orais após } \\
\text { reposicionamento do joelho ou do quadril. }\end{array}$} \\
\hline
\end{tabular}

\begin{tabular}{|c|c|c|}
\hline \multirow{4}{*}{$\begin{array}{l}\text { Guideline } \\
\text { G_05 }\end{array}$} & \multicolumn{2}{|l|}{ Título } \\
\hline & \multicolumn{2}{|c|}{ Diretrizes práticas para prevenção e tratamento do delírio pós-operatório. } \\
\hline & Fonte & Idioma \\
\hline & ESA Guidelines of the European Society of Anaesthesiology, 2016-2017 & Inglês \\
\hline \multicolumn{3}{|c|}{ Propósito } \\
\hline \multicolumn{3}{|c|}{$\begin{array}{l}\text { O objetivo desta orientação é apresentar dados baseados em evidências e recomendações consensuais para a } \\
\text { prevenção e tratamento do delírio pós-operatório (DPO). O escopo desta diretriz não é para cobrir o delírio da } \\
\text { unidade de terapia intensiva. Considerando que muitas disciplinas médicas estão envolvidas no tratamento de } \\
\text { pacientes cirúrgicos, uma abordagem baseada em equipe deve ser implementada na prática diária. Esta diretriz } \\
\text { visa promover o conhecimento e a educação no pré-operatório, contexto intraoperatório e pós-operatório não } \\
\text { apenas entre anestesiologistas, mas também entre todos os outros profissionais de saúde envolvidos no } \\
\text { atendimento de pacientes cirúrgicos. }\end{array}$} \\
\hline \multicolumn{3}{|c|}{ Recomendações } \\
\hline I. & \multicolumn{2}{|l|}{ A avaliação pré-operatória do risco de DPO e identificação de pacientes em risco. } \\
\hline II. & \multicolumn{2}{|c|}{ Comunicação sobre esse risco para pacientes, seus familiares e membros da equipe de cuidados. } \\
\hline III. & \multicolumn{2}{|l|}{ Melhores condições pré-operatórias a serem alcançadas. } \\
\hline
\end{tabular}




\begin{tabular}{|c|l|}
\cline { 2 - 2 } IV. & $\begin{array}{l}\text { Evitar no período perioperatório o uso de agentes anticolinérgicos e benzodiazepínicos, exceto } \\
\text { quando necessário. Os benzodiazepínicos podem ser considerados em casos de tratamento para } \\
\text { alcoolismo. }\end{array}$ \\
\hline V. & $\begin{array}{l}\text { Reduzir o estresse cirúrgico, juntamente com o manejo intraoperatório de protetor de órgãos, } \\
\text { incluindo neuromonitorização para evitar anestesia excessivamente profunda. }\end{array}$ \\
\hline VI. & Analgesia eficaz de opiáceos multimodais. \\
\hline VII. & Implementação de programas aprimorados de recuperação. \\
\hline VIII. & $\begin{array}{l}\text { Monitoramento cognitivo visando o reconhecimento do declínio cognitivo pré-operatório e para } \\
\text { detectar DPO o mais cedo possível, inclusive na sala de recuperação anestésica. }\end{array}$ \\
\hline IX. & Tratamento eficaz de DPO por protocolos. \\
\hline X. & Acompanhamento de pacientes com DPO ao longo de sua internação hospitalar. \\
\hline XI. & $\begin{array}{l}\text { Informações do paciente sobre suporte médico adequado, para garantir a continuidade dos } \\
\text { cuidados após a alta. }\end{array}$ \\
\hline
\end{tabular}

Os guidelines foram catalogados conforme figura 1. Nesta fase foi possível identificar quais associações de classe apresentavam guidelines semelhantes. Logo, os guidelines preconizados para a atuação do enfermeiro perioperatório foram parecidos no seguinte aspecto: a SOBECC apresentou quatro guidelines semelhantes a AORN. Já os guidelines preconizados para atuação pré-operatória do anestesiologista foram idênticos da seguinte forma: a ASA evidenciou três guidelines semelhantes a ESA. 
Figura 1 - Catalogação dos Guidelines Nacional e Internacional. São Paulo-SP, 2018.

\section{CATALOGAÇÃO DOS GUIDELINES NACIONAL E INTERNACIONAL}

\begin{tabular}{|c|c|c|}
\hline $\begin{array}{c}\text { Naciona } \\
\text { de }\end{array}$ & $\begin{array}{c}\text { Associação } \\
\text { de Classe }\end{array}$ & Guidelines \\
\hline & $\begin{array}{l}\text { 怘 } \\
\text { ญ् } \\
\text { \& }\end{array}$ & $\begin{array}{l}1 \begin{array}{l}\text { Atuação do enfermeiro perioperatório no período pré-operatório } \\
\text { imediato }\end{array} \\
2 \text { Preparo pré-operatório da pele do paciente cirúrgico } \\
3 \begin{array}{l}\text { Avaliação pré-operatória para determinar fatores de risco para } \\
\text { trombose venosa profunda }\end{array} \\
4 \text { Assistência pré-operatória ao paciente cirúrgico robótico } \\
5 \text { Assistência de enfermagem durante o procedimento anestésico } \\
\text { (fase pré-operatória) } \\
6 \begin{array}{l}\text { Identificação de riscos para o desenvolvimento de lesões } \\
\text { decorrentes do posicionamento cirúrgico }\end{array} \\
7 \text { Prevenção da hipotermia perioperatória }\end{array}$ \\
\hline 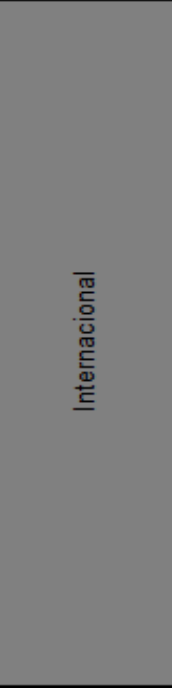 & $\begin{array}{l}z \\
\text { zo } \\
\text { o }\end{array}$ & 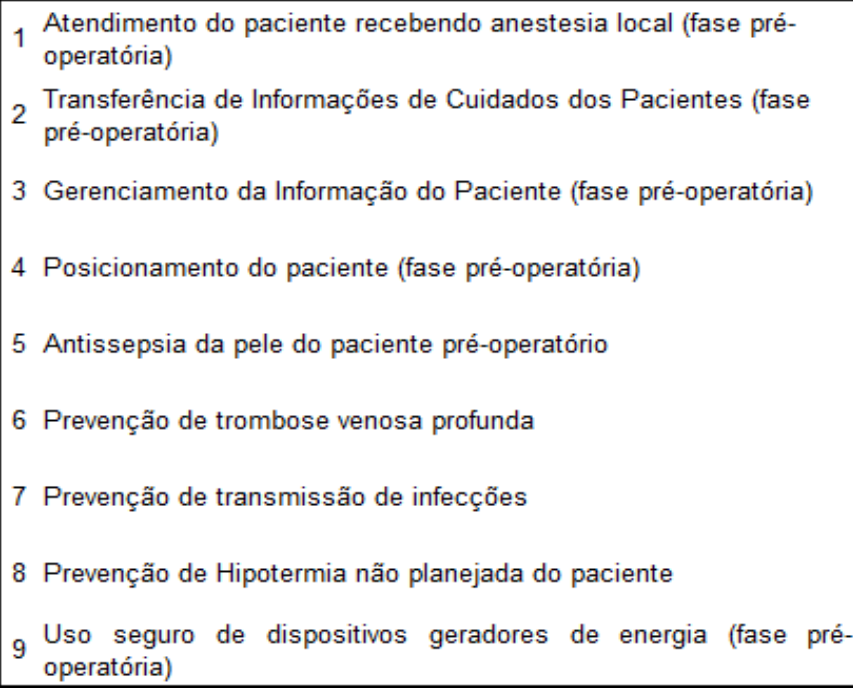 \\
\hline 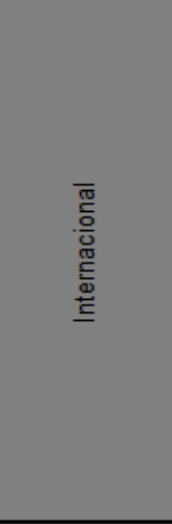 & $\begin{array}{l}\frac{1}{4} \\
\text { क }\end{array}$ & $\begin{array}{l}1 \text { Avaliação pré-operatória } \\
2 \begin{array}{l}\text { Tratamento da dor aguda no ambiente perioperatório (fase pré- } \\
\text { operatória) } \\
3 \text { Manejo da Via Aérea Difícil (fase pré-operatória) }\end{array} \\
4 \begin{array}{l}\text { Manejo Perioperatório da Apneia Obstrutiva do Sono (fase pré- } \\
\text { operatória) }\end{array} \\
5 \text { Manejo Perioperatório do Sangue (fase pré-operatória) } \\
6 \begin{array}{l}\text { Jejum pré-operatório e o uso de agentes farmacológicos para } \\
\text { reduzir o risco de aspiração pulmonar }\end{array} \\
7 \begin{array}{l}\text { Prevenção, Detecção e Gerenciamento de Depressão Respiratória } \\
\text { Associada à Administração de Opioides Neuraxiais }\end{array}\end{array}$ \\
\hline 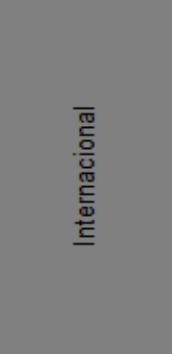 & 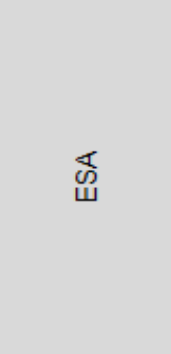 & $\begin{array}{l}1 \text { Jejum perioperatório em adultos } \\
2 \begin{array}{l}\text { Avaliação pré-operatória do paciente adulto submetido a cirurgia } \\
\text { não cardíaca }\end{array} \\
3 \text { Manejo do sangramento perioperatório severo (fase pré-operatória) } \\
4 \begin{array}{l}\text { Profilaxia periperatória do tromboembolismo venoso perioperatório } \\
\text { para cirurgias em idosos }\end{array} \\
5 \text { Prevenção e tratamento do delírio pós-operatório }\end{array}$ \\
\hline
\end{tabular}


Dentre os guidelines semelhantes da SOBECC e AORN pode-se destacar: preparo da pele do paciente pré-operatório (banho pré-operatório com solução antisséptica/ remoção de pelos no local cirúrgico com tricotomizador), prevenção de trombose venosa profunda (profilaxia mecânica com meias compressivas e compressor pneumático intermitente/ profilaxia farmacológica com anticoagulantes), prevenção de riscos para posicionamento cirúrgico (idade, peso, altura, restrição de movimentação, deformidades e risco de lesão por pressão/ disponibilizar materiais e equipamentos para posicionamento cirúrgico seguro) e, prevenção de hipotermia (extremos de idade, baixo peso corporal, distúrbio metabólico, tipo de anestesia/ préaquecimento do paciente de 15 a 20 minutos, minimizar exposição corpórea, monitorar temperatura).

Em relação aos guidelines semelhantes da ASA e ESA pode-se destacar: avaliação pré-operatória (entrevista com o paciente, exame físico e resultados de exames pré-operatórios/ eletrocardiograma, avaliação cardíaca, radiografia do tórax, avaliação pulmonar, nível de hemoglobina e hematócrito, estudo de coagulação, sorologia química, teste urinário, teste de gravidez), manejo do sangramento perioperatório (histórico de transfusão sanguínea, coagulopatia e eventos trombóticos, fatores de risco isquêmicos, nível de hemoglobina/ teste de função plaquetária, anemia pré-operatória, distúrbio hemorrágico hereditário, transfusão de plaquetas prévia a cirurgia) e, jejum pré-operatório (ingestão de líquidos claros até 2 horas antes da cirurgia, ingestão de alimentos sólidos até 6 horas antes da cirurgia e, ingestão de soluções ricas em carboidratos até 2 horas antes da cirurgia).

\subsection{VALIDAÇÃO DO INSTRUMENTO DE AVALIAÇÃO PRÉ-OPERATÓRIA TRANSDISCIPLINAR}

\subsubsection{Validação de Conteúdo}

Cinco juízes especialistas fizeram parte do painel de avaliadores, sendo três enfermeiros, dos quais, dois (40\%) apresentaram mestrado e um (20\%) doutorado em ciências da saúde. Além disto, compuseram o quadro de juízes dois (40\%) médicos anestesiologistas, sendo um deles com titulação de mestrado e o outro 
doutorado em anestesiologia. O tempo de experiência na área de atuação variou entre cinco e mais de 35 anos. Todos os profissionais eram do Estado de São Paulo.

Seguindo a orientação de DeVellis (2016) foram formulados itens, os quais estavam agrupados em sistemas, que abordavam as recomendações e diretrizes práticas dos guidelines nacional e internacional, para avaliarmos qual deles atendia da melhor maneira os critérios propostos. Este conjunto de itens foi submetido à avaliação dos juízes que os avaliaram em relação a relevância, clareza e abrangência (Tabela 2).

Tabela 2 - Questões avaliadas pelos juízes especialistas e resultado do Índice de Validação de Conteúdo Total. São Paulo-SP, 2018.

(continua)

\begin{tabular}{lcccc}
\hline ITENS & RELEVÂNCIA & CLAREZA & ABRANGÊNCIA & TOTAL \\
\hline DADOS GERAIS & CVCic & CVCic & CVCic & CVCt \\
\hline Nome do Paciente & 0,9997 & 0,99968 & 0,99968 & 0,99968 \\
Data de Nascimento & 0,9997 & 0,99968 & 0,99968 & 0,99968 \\
Gênero & 0,9997 & 0,99968 & 0,95968 & 0,986347 \\
Idade & 0,9997 & 0,99968 & 0,99968 & 0,99968 \\
Peso & 0,9997 & 0,99968 & 0,99968 & 0,99968 \\
Altura & 0,9997 & 0,99968 & 0,99968 & 0,99968 \\
Diagnóstico de Base & 0,9997 & 0,95968 & 0,99968 & 0,986347 \\
Nome do Cirurgião & 0,9997 & 0,99968 & 0,99968 & 0,99968 \\
Termos de Consentimento Cirúrgico e Anestésico & 0,9997 & 0,95968 & 0,99968 & 0,986347 \\
\hline HISTÓRICO PESSOAL E PSICOSSOCIAL & CVCic & CVCic & CVCic & CVCt \\
\hline Estado Civil & 0,9997 & 0,99968 & 0,99968 & 0,99968 \\
Escolaridade & 0,9997 & 0,99968 & 0,99968 & 0,99968 \\
Espiritualidade / Religião & 0,9997 & 0,99968 & 0,99968 & 0,99968 \\
Drogas llícitas & 0,9997 & 0,99968 & 0,99968 & 0,99968 \\
Etilismo & 0,9997 & 0,99968 & 0,99968 & 0,99968 \\
Tabagismo & 0,9997 & 0,99968 & 0,99968 & 0,99968 \\
Estado Nutricional & 0,9997 & 0,99968 & 0,99968 & 0,99968 \\
Tipo Sanguíneo & 0,8397 & 0,83968 & 0,83968 & 0,83968 \\
Alergias / Sensibilidade / Intolerância & 0,9997 & 0,99968 & 0,99968 & 0,99968 \\
Cirurgias Anteriores & 0,9997 & 0,99968 & 0,99968 & 0,99968 \\
Medicamentos em Uso Diário & 0,9997 & 0,99968 & 0,99968 & 0,99968 \\
Terapias Complementares & 0,8797 & 0,95968 & 0,87968 & 0,906347 \\
\hline SISTEMA CARDIOVASCULAR & CVCic & CVCic & CVCic & CVCt \\
\hline Tempo de Jejum & 0,9997 & 0,87968 & 0,99968 & 0,95968 \\
Estudo cardíaco basal (pressão arterial, & 0,9997 & 0,99968 & 0,99968 & 0,99968 \\
frequência cardíaca) & & & &
\end{tabular}


Tabela 2 - Questões avaliadas pelos juízes especialistas e resultado do Índice de Validação de Conteúdo Total. São Paulo-SP, 2018.

(continuação)

\begin{tabular}{|c|c|c|c|c|}
\hline ITENS & RELEVÂNCIA & CLAREZA & ABRANGÊNCIA & TOTAL \\
\hline SISTEMA CARDIOVASCULAR & CVCic & CVCic & CVCic & $\mathrm{CVCt}$ \\
\hline $\begin{array}{l}\text { Trombose venosa profunda (profilaxia mecânica } \\
\text { e farmacológica) }\end{array}$ & 0,8397 & 0,83968 & 0,83968 & 0,83968 \\
\hline Insuficiência Cardíaca Congestiva & 0,9997 & 0,99968 & 0,99968 & 0,99968 \\
\hline Infarto Agudo do Miocárdio & 0,9997 & 0,99968 & 0,99968 & 0,99968 \\
\hline Arritmias / Coronariopatias & 0,9997 & 0,99968 & 0,99968 & 0,99968 \\
\hline Valvulopatias / Valvulpatias Periféricas & 0,9997 & 0,91968 & 0,91968 & 0,946347 \\
\hline Outras Patologias & 0,8797 & 0,87968 & 0,87968 & 0,87968 \\
\hline SISTEMA RESPIRATÓRIO & CVCic & CVCic & CVCic & CVCt \\
\hline $\begin{array}{l}\text { Estado respiratório basal (saturação, frequência } \\
\text { respiratória) }\end{array}$ & 0,9997 & 0,99968 & 0,99968 & 0,99968 \\
\hline Doença Pulmonar Obstrutiva Crônica & 0,9997 & 0,91968 & 0,99968 & 0,973013 \\
\hline Mallampati (I, II, III e IV) & 0,9197 & 0,91968 & 0,91968 & 0,91968 \\
\hline Previsão de Via Aérea Difícil & 0,9997 & 0,95968 & 0,99968 & 0,986347 \\
\hline Apnéia do Sono / Asma / Tosse Produtiva & 0,9997 & 0,95968 & 0,95968 & 0,973013 \\
\hline Infecção de Vias Aéreas Superiores / Pneumonia & 0,9997 & 0,99968 & 0,99968 & 0,99968 \\
\hline Dispnéia de Esforço & 0,9197 & 0,83968 & 0,91968 & 0,893013 \\
\hline Outras Patologias & 0,9197 & 0,91968 & 0,91968 & 0,91968 \\
\hline SISTEMA DIGESTÓRIO & CVCic & CVCic & CVCic & CVCt \\
\hline Gastrite / Refluxo Gastresofágico & 0,9997 & 0,95968 & 0,99968 & 0,986347 \\
\hline Esofagite / Úlcera Péptica & 0,9997 & 0,95968 & 0,99968 & 0,986347 \\
\hline Hepatite / Cirrose & 0,9997 & 0,99968 & 0,99968 & 0,99968 \\
\hline Sangramento Digestivo (Alto / Baixo) & 0,9997 & 0,99968 & 0,99968 & 0,99968 \\
\hline Outras Patologias & 0,9197 & 0,91968 & 0,91968 & 0,91968 \\
\hline SISTEMA ENDÓCRINO & CVCic & CVCic & CVCic & CVCt \\
\hline Diabetes Mellitos Tipo I ou II & 0,9997 & 0,95968 & 0,95968 & 0,973013 \\
\hline Doença da Tireoide ou Paratireoide & 0,9997 & 0,99968 & 0,99968 & 0,99968 \\
\hline Doenças da Hipófise & 0,9997 & 0,99968 & 0,99968 & 0,99968 \\
\hline Insuficiência Adrenal & 0,9997 & 0,99968 & 0,99968 & 0,99968 \\
\hline Outras Patologias & 0,9197 & 0,91968 & 0,91968 & 0,91968 \\
\hline SISTEMA NEUROLÓGICO & CVCic & CVCic & CVCic & CVCt \\
\hline Nível de Consciência / Déficit Cognitivo & 0,9997 & 0,91968 & 0,99968 & 0,973013 \\
\hline Convulsões / Labirintopatias / Cefaléias & 0,9997 & 0,91968 & 0,99968 & 0,973013 \\
\hline Alterações de Sensibilidade e Motricidade & 0,9997 & 0,99968 & 0,99968 & 0,99968 \\
\hline Acidente Vascular Encefálico & 0,9997 & 0,95968 & 0,99968 & 0,986347 \\
\hline Lesão Medular & 0,9997 & 0,99968 & 0,99968 & 0,99968 \\
\hline Outras Patologias & 0,9197 & 0,91968 & 0,91968 & 0,91968 \\
\hline SISTEMA HEMATOLÓGICO & CVCic & CVCic & CVCic & CVCt \\
\hline Discrasias Sanguíneas / Anemias & 0,9997 & 0,91968 & 0,99968 & 0,973013 \\
\hline Tranfusão Sanguínea Prévia & 0,9197 & 0,91968 & 0,91968 & 0,91968 \\
\hline Distúrbios de Coagulação & 0,9997 & 0,91968 & 0,99968 & 0,973013 \\
\hline
\end{tabular}


Tabela 2 - Questões avaliadas pelos juízes especialistas e resultado do Índice de Validação de Conteúdo Total. São Paulo-SP, 2018.

(continuação)

\begin{tabular}{|c|c|c|c|c|}
\hline ITENS & RELEVÂNCIA & CLAREZA & ABRANGÊNCIA & TOTAL \\
\hline SISTEMA HEMATOLÓGICO & CVCic & CVCic & CVCic & CVCt \\
\hline Trombose Venosa Pulmonar e Periférica & 0,8797 & 0,87968 & 0,87968 & 0,87968 \\
\hline \multirow{2}{*}{$\begin{array}{l}\text { Equimoses / Hematomas / Epistaxe } \\
\text { Tipagem sanguínea / reserva de } \\
\text { hemocomponentes }\end{array}$} & 0,9997 & 0,99968 & 0,99968 & 0,99968 \\
\hline & 0,9997 & 0,99968 & 0,99968 & 0,99968 \\
\hline Outras Patologias & 0,9197 & 0,91968 & 0,91968 & 0,91968 \\
\hline SISTEMA RENAL & CVCic & CVCic & CVCic & CVCt \\
\hline Infecção Urinária de Repetição & 0,9997 & 0,99968 & 0,99968 & 0,99968 \\
\hline Doença Renal Crônica (Dialítica ou Não Dialítica) & 0,9997 & 0,99968 & 0,99968 & 0,99968 \\
\hline Outras Patologias & 0,9197 & 0,91968 & 0,91968 & 0,91968 \\
\hline SISTEMA TEGUMENTAR & CVCic & CVCic & CVCic & CVCt \\
\hline $\begin{array}{l}\text { Integridade da pele (equimoses, edemas, } \\
\text { hematomas, lesões de pele) }\end{array}$ & 0,9197 & 0,91968 & 0,91968 & 0,91968 \\
\hline Outras Patologias & 0,9997 & 0,99968 & 0,99968 & 0,99968 \\
\hline SISTEMA MUSCULOESQUELÉTICO & CVCic & CVCic & CVCic & CVCt \\
\hline Malformações Osteomoleculares & 0,9997 & 0,99968 & 0,99968 & 0,99968 \\
\hline \multirow{3}{*}{$\begin{array}{l}\text { Limitação física ou mobilidade prejudicada } \\
\text { Algias Lombares / Artrites / Artroses / Hérnias de } \\
\text { Disco } \\
\text { Outras Patologias }\end{array}$} & 0,9997 & 0,99968 & 0,99968 & 0,99968 \\
\hline & 0,9997 & 0,99968 & 0,99968 & 0,99968 \\
\hline & 0,9197 & 0,91968 & 0,91968 & 0,91968 \\
\hline SISTEMA IMUNOLÓGICO & CVCic & CVCic & CVCic & CVCt \\
\hline HIV Positivo & 0,9997 & 0,99968 & 0,99968 & 0,99968 \\
\hline Tuberculose & 0,9997 & 0,99968 & 0,99968 & 0,99968 \\
\hline Infecção Respiratória ou Urinária & 0,9997 & 0,95968 & 0,95968 & 0,973013 \\
\hline Outras Patologias & 0,9197 & 0,91968 & 0,91968 & 0,91968 \\
\hline SISTEMA SENSORIAL & CVCic & CVCic & CVCic & $\mathrm{CVCt}$ \\
\hline $\begin{array}{l}\text { Dificuldades sensoriais (visão, audição, fala, tato, } \\
\text { paladar) }\end{array}$ & 0,9997 & 0,99968 & 0,99968 & 0,99968 \\
\hline Percepção sensorial da dor & 0,9997 & 0,95968 & 0,95968 & 0,973013 \\
\hline Hipotermia & 0,8797 & 0,79969 & 0,83968 & 0,83968 \\
\hline Outras Patologias & 0,9197 & 0,91968 & 0,91968 & 0,91968 \\
\hline EDUCAÇÃO EM SAÚDE & CVCic & CVCic & CVCic & CVCt \\
\hline Classificação ASA (1, 2, 3 e 4) & 0,9997 & 0,99968 & 0,99968 & 0,99968 \\
\hline Dúvidas do procedimento cirúrgico & 0,8397 & 0,79968 & 0,83968 & 0,826347 \\
\hline Nivel de ansiedade & 0,9997 & 0,83968 & 0,99968 & 0,946347 \\
\hline \multirow{2}{*}{$\begin{array}{l}\text { Tipo de anestesia / medicação pré-anestésica } \\
\text { Tipo de isolamento (respiratório de gotículas ou } \\
\text { ar, contato) }\end{array}$} & 0,9997 & 0,95968 & 0,95968 & 0,973013 \\
\hline & 0,9997 & 0,95968 & 0,95968 & 0,973013 \\
\hline Demarcação cirúrgica / lateralidade & 0,9997 & 0,95968 & 0,95968 & 0,973013 \\
\hline Banho pré-operatório com antisséptico & 0,9997 & 0,99968 & 0,91968 & 0,973013 \\
\hline Tricotomia pré-operatória & 0,9997 & 0,95968 & 0,95968 & 0,973013 \\
\hline Protocolos de segurança perioperatória & 0,9997 & 0,87968 & 0,95968 & 0,946347 \\
\hline Presença de próteses, implantes ou adornos & 0,9997 & 0,87968 & 0,95968 & 0,946347 \\
\hline
\end{tabular}


Tabela 2 - Questões avaliadas pelos juízes especialistas e resultado do Índice de Validação de Conteúdo Total. São Paulo-SP, 2018.

(continuação)

\begin{tabular}{lcccc}
\hline ITENS & RELEVÂNCIA & CLAREZA & ABRANGÊNCIA & TOTAL \\
\hline EDUCAÇÃO EM SAÚDE & CVCic & CVCic & CVCic & CVCt \\
\hline Presença de dispositivos externos (cateteres, & 0,9997 & 0,91968 & 0,95968 & 0,95968 \\
drenos, imobilizadores ortopédicos) & 0,9997 & 0,95968 & 0,95968 & 0,973013 \\
Capacidade de tolerar o posicionamento cirúrgico & 0,9997 & 0,99968 & 0,99968 & 0,99968 \\
Outras considerações & CVCic & CVCic & CVCic & CVCt \\
\hline EXAMES DIAGNÓSTICOS & 0,9997 & 0,99968 & 0,95968 & 0,986347 \\
\hline Exames laboratoriais & 0,9997 & 0,99968 & 0,99968 & 0,99968 \\
Exames de imagem & 0,9997 & 0,99968 & 0,99968 & 0,99968 \\
Outros exames & & & & (conclusão)
\end{tabular}

*Legenda: CVCic: Coeficiente de Validação de Conteúdo de cada item com a probabilidade de concordância aleatória entre os juízes; CVCt: Coeficiente de validação de conteúdo total.

Dentre os 93 itens avaliados, em relação a relevância e abrangência, apenas 07 itens (7,52\%) apresentaram CVCic variando de 0,80 a 0,89 e; a clareza demonstrou 09 itens $(9,67 \%)$ com CVCic variando de 0,80 a 0,89. Portanto, 86 itens (92,47\%) obtiveram CvCic superior a 0,90 nos critérios relevância e abrangência, enquanto que 82 itens $(88,17 \%)$ demonstraram CVCic superior a 0,90 no quesito clareza. Assim, 100\% dos 93 itens apresentaram CVCt superior a 0,80.

Nesta VC, embora o CVCt tenha se apresentado acima de 0,80, algumas sugestões foram dadas pelos juízes e, devido relevância das mesmas, foram aceitas pela pesquisadora e incorporadas ao instrumento final. Estas sugestões referem-se à realocação, renomeação, inserção e exclusão de itens repetidos. O único item realocado foi 0 da hepatite (sistema digestório para imunológico). Os itens renomeados foram: outras patologias (outras enfermidades), trombose venosa pulmonar (tromboembolismo pulmonar - TEP), refluxo gastroesofágico (doença do refluxo gastroesofágico - DRGE) e, doença da tireoide ou paratireoide (hipo e hipertireoidismo).

Alguns itens foram sugeridos pelos juízes e, portanto, complementados no instrumento, pois foram avaliados pela pesquisadora como relevantes ao estudo. Sendo eles: jejum de líquidos e sólidos (histórico pessoal e psicossocial), marcapasso e varizes (sistema cardiovascular), enfisema e bronquite (sistema respiratório), náuseas e vômitos pós-operatórios - NVPO (sistema digestório), 
hipertermia (sistema sensorial), classificação ASA 5 e 6 (educação em saúde), protocolos de segurança perioperatória (educação em saúde), presença de próteses, implantes ou adornos - prótese dentária ou capilar, unhas e cílios postiços, piercings (educação em saúde) e, risco de lesão de pele por posicionamento cirúrgico (educação em saúde).

Alguns itens foram analisados pela pesquisadora e identificados como irrelevantes pelo fato de estarem repetidos, sendo excluídos e, então houve o reajuste do instrumento. São eles: infecção respiratória ou urinária (sistema renal / sistema imunológico), tipo sanguíneo (histórico pessoal e psicossocial / sistema hematológico), trombose venosa (sistema cardiológico / sistema hematológico), pneumonia (sistema respiratório / sistema imunológico) e, equimoses e hematomas (sistema hematológico / sistema tegumentar).

O instrumento foi classificado pelos juízes contendo informações relevantes, fácil preenchimento e design apropriado, respeitando a proposta metodológica desta validação.

A versão final do instrumento é apresentada na Figura 2 e, recomenda-se ser informatizado. 
Figura 2 - Instrumento final após Validação de Conteúdo. São Paulo-SP, 2018.

\section{AVALIAÇÃO PRÉ-OPERATÓRIA TRANSDISCIPLINAR (APOT)}

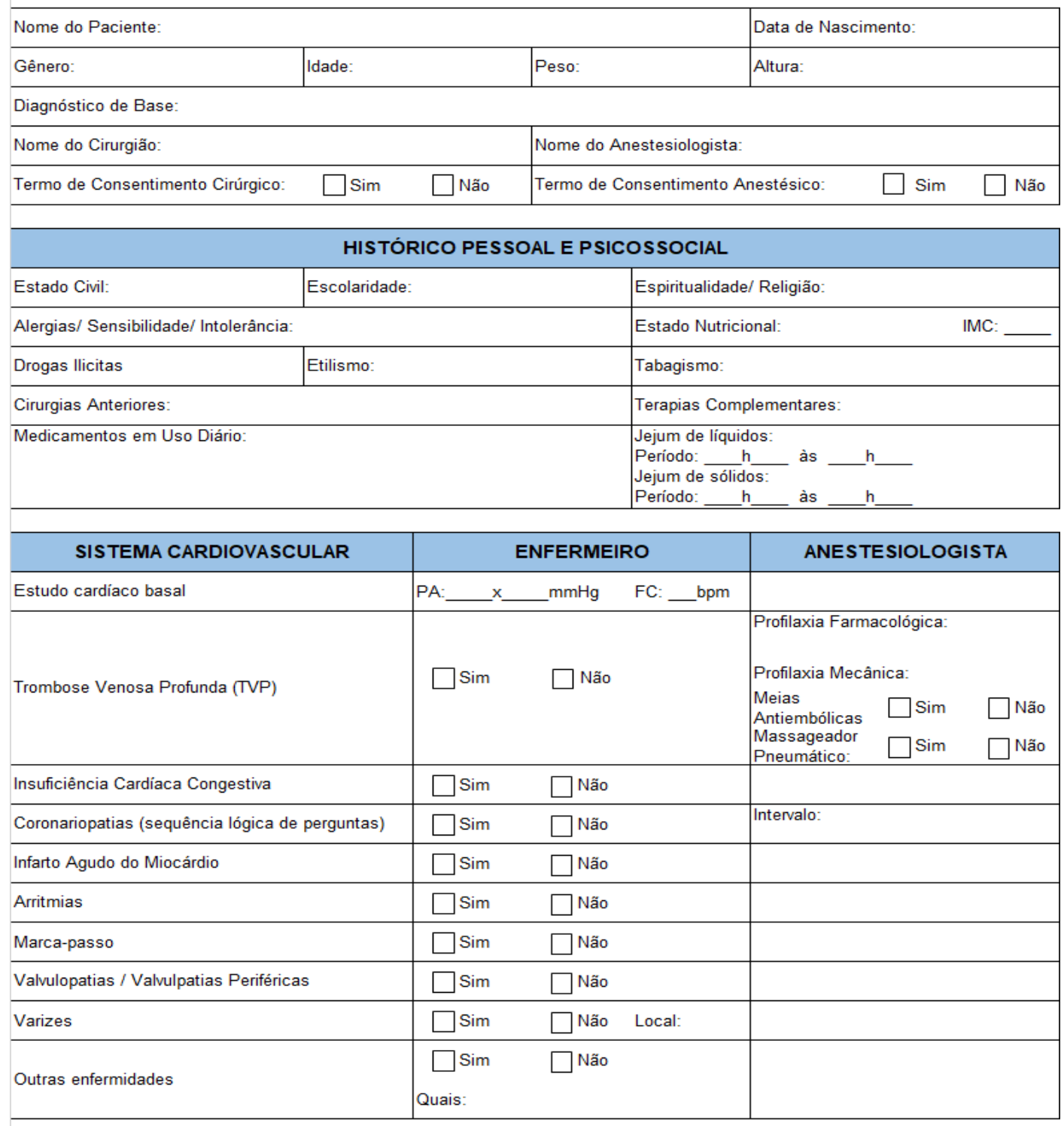

\begin{tabular}{|c|c|c|}
\hline SISTEMA RESPIRATÓRIO & ENFERMEIRO & ANESTESIOLOGISTA \\
\hline Estado respiratório basal & Sat: __ $\%$ & \\
\hline Doença Pulmonar Obstrutiva Crônica (DPOC) & $\square$ Não & \\
\hline Mallampati (I, II, III e IV) & $\begin{array}{l}\text { Distância mento-tireoide: }{ } \mathrm{cm} \\
\text { Circunferência cervical: } \\
\end{array}$ & \\
\hline Previsão de Via Aérea Dificil & Histórico: $\quad \square \operatorname{Sim} \quad \square$ Não & $\square \operatorname{Sim} \quad \square$ Não \\
\hline Apnéia do Sono & $\square \operatorname{Sim} \quad \square$ Não & \\
\hline Asma & $\square \operatorname{Sim} \quad \square$ Não & \\
\hline Bronquite & $\square \operatorname{Sim} \quad \square$ Não & \\
\hline Enfisema & $\square \operatorname{Sim} \quad \square$ Não & \\
\hline Tosse Produtiva & $\square \operatorname{Sim} \quad \square$ Não & \\
\hline Infecção de Vias Aéreas Superiores & $\square \operatorname{Sim} \quad \square$ Não & \\
\hline Pneumonia & $\square \operatorname{Sim} \quad \square$ Não & \\
\hline Tromboembolismo Pulmonar (TEP) & $\square \operatorname{Sim} \quad \square$ Não & \\
\hline Dispnéia de Esforço & $\square \operatorname{Sim} \quad \square$ Não & \\
\hline Outras enfermidades & $\begin{array}{l}\square \operatorname{Sim} \quad \square \text { Não } \\
\text { Quais: }\end{array}$ & \\
\hline
\end{tabular}


Catharina Ferreira de Meira Pachioni

\begin{tabular}{|c|c|c|c|}
\hline SISTEMA DIGESTÓRIO & & NFERMEIRO & ANESTESIOLOGISTA \\
\hline Gastrite / Úlcera péptica / Esofagite & $\square \operatorname{sim}$ & $\square$ Não & \\
\hline Doença do Refluxo Gastroesofágico (DRGE) & $\square \operatorname{sim}$ & $\square$ Não & \\
\hline Cirrose & $\square \operatorname{sim}$ & $\square$ Não & \\
\hline Sangramento Digestivo Alto & $\square \operatorname{sim}$ & $\square$ Não & Volume: \\
\hline Sangramento Digestivo Baixo & $\square \operatorname{sim}$ & $\square$ Não & Volume: \\
\hline Náuseas e vômitos pós-operatórios (NVPO) & $\square \operatorname{sim}$ & $\square$ Não & \\
\hline Outras enfermidades & $\begin{array}{l}\square \operatorname{sim} \\
\text { Quais: }\end{array}$ & $\square$ Não & \\
\hline
\end{tabular}

\begin{tabular}{|l|l|l|l|}
\hline \multicolumn{1}{|c|}{ SISTEMA ENDÓCRINO } & \multicolumn{2}{|c|}{ ENFERMEIRO } & ANESTESIOLOGISTA \\
\hline Diabetes Mellitos Tipo I ou II & $\square$ sim $\square$ Não Dx:_mg/dl & \\
& Insulinodependente: $\square$ Sim $\square$ Não & \\
\hline Hipertireoidismo & $\square \operatorname{sim} \quad \square$ Não TSH: — & \\
\hline Hipotireoidismo & $\square \operatorname{sim} \quad \square$ Não TSH: & \\
\hline Doenças da Hipófise & $\square \operatorname{sim} \quad \square$ Não & \\
\hline Insuficiência Adrenal & $\square \operatorname{sim} \quad \square$ Não & \\
\hline Outras enfermidades & $\square \operatorname{sim} \quad \square$ Não & \\
\hline
\end{tabular}

\begin{tabular}{|l|l|l|}
\multicolumn{1}{|c|}{ SISTEMA NEUROLÓGICO } & \multicolumn{1}{c|}{ ENFERMEIRO } & ANESTESIOLOGISTA \\
\hline Nivel de Consciência / Déficit Cognitivo & $\square$ Orientado $\square$ Desorientado & Glasgow: \\
\hline Convulsões & $\square \operatorname{sim} \quad \square$ Não & \\
\hline Labirintopatias & $\square \operatorname{sim} \quad \square$ Não & \\
\hline Cefaléias & $\square \operatorname{sim} \quad \square$ Não & \\
\hline Alterações de Sensibilidade & $\square \operatorname{sim} \quad \square$ Não Local: & \\
\hline Alterações de Motricidade & $\square \operatorname{sim} \quad \square$ Não Local: & \\
\hline Acidente Vascular Encefálico & $\square \operatorname{sim} \quad \square$ Não & \\
\hline Lesão Medular & $\square \operatorname{sim} \quad \square$ Não & \\
\hline Outras enfermidades & $\square \operatorname{sim} \quad \square$ Não & \\
\hline
\end{tabular}

\begin{tabular}{|l|l|l|}
\hline \multicolumn{1}{|c|}{ SISTEMA HEMATOLÓGICO } & \multicolumn{1}{|c|}{ ENFERMEIRO } & ANESTESIOLOGISTA \\
\hline Discrasias Sanguíneas / Anemias & $\square$ sim $\square$ Não & \\
\hline Quais: & $\square$ sim $\square$ Não & \\
\hline Tranfusão Sanguínea Prévia & $\square$ sim $\square$ Não & \\
\hline Distúrbios de Coagulação & $\square$ sim $\square$ Não & \\
\hline Epistaxe & $\square$ sim $\square$ Não Tipo: & \\
\hline Tipagem sanguinea & $\square$ sim $\square$ Não No Bolsas: & \\
\hline Reserva de hemocomponentes & Quais: & \\
\hline Outras enfermidades & $\square$ sim $\square$ Não & \\
\hline
\end{tabular}


Catharina Ferreira de Meira Pachioni

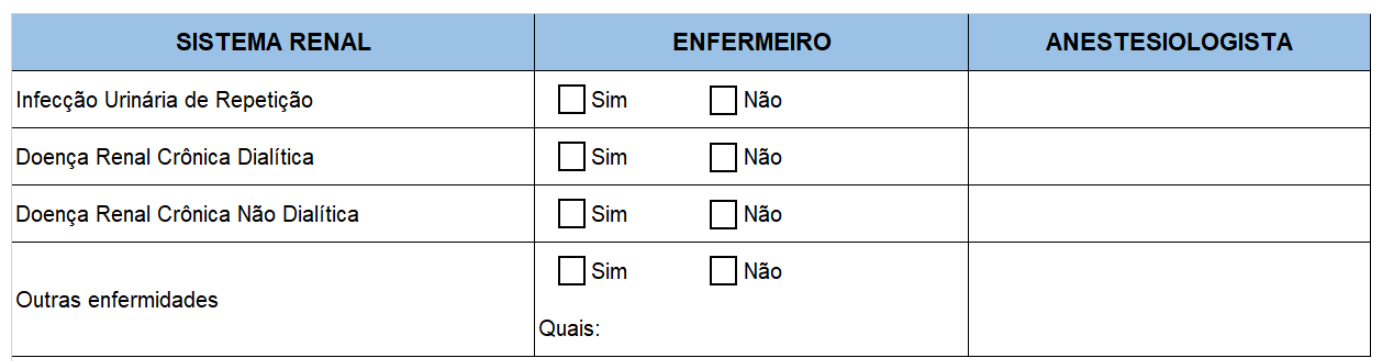

\begin{tabular}{|l|l|l|}
\hline \multicolumn{1}{|c|}{ SISTEMA TEGUMENTAR } & \multicolumn{1}{|c|}{ ENFERMEIRO } & ANESTESIOLOGISTA \\
\hline $\begin{array}{l}\text { Integridade da pele (equimoses, edemas, } \\
\text { hematomas, lesões de pele) }\end{array}$ & $\square$ sim $\square$ Não & \\
\hline Local: & & \\
Outras enfermidades & $\square$ sim $\square$ Não & \\
& Quais: & \\
\hline
\end{tabular}

\begin{tabular}{|c|c|c|c|}
\hline SISTEMA MUSCULOESQUELÉTICO & \multicolumn{2}{|c|}{ ENFERMEIRO } & ANESTESIOLOGISTA \\
\hline Malformações Osteomusculares & $\begin{array}{l}\square \text { sim } \\
\text { Quais: }\end{array}$ & $\square$ Não & \\
\hline Limitação física ou mobilidade prejudicada & $\square \operatorname{sim}$ & $\square$ Não & \\
\hline Algias Lombares & $\square \operatorname{sim}$ & $\square$ Não & \\
\hline Artrites/ Artroses & $\square \operatorname{sim}$ & $\square$ Não & \\
\hline Hérnias de Disco & $\square \operatorname{sim}$ & $\square$ Não & \\
\hline Outras enfermidades & $\begin{array}{l}\square \text { sim } \\
\text { Quais: }\end{array}$ & $\square$ Não & \\
\hline
\end{tabular}

\begin{tabular}{l|l|l|}
\hline \multicolumn{1}{|c|}{ SISTEMA IMUNOLÓGICO } & \multicolumn{1}{|c|}{ ENFERMEIRO } & ANESTESIOLOGISTA \\
\hline HIV Positivo & $\square \operatorname{sim} \quad \square$ Não & Carga Viral: \\
\hline Tuberculose & $\square \operatorname{sim} \quad \square$ Não & \\
\hline Hepatite & $\square \operatorname{sim} \quad \square$ Não & \\
\hline Outras enfermidades & $\square \operatorname{sim} \quad \square$ Não & \\
& Quais: & \\
\hline
\end{tabular}

\begin{tabular}{l|lc|l|}
\hline \multicolumn{1}{|c|}{ SISTEMA SENSORIAL } & \multicolumn{1}{c|}{ ENFERMEIRO } & ANESTESIOLOGISTA \\
\hline $\begin{array}{l}\text { Dificuldades sensoriais (visão, audição, fala, tato, } \\
\text { paladar) }\end{array}$ & $\square$ sim $\quad \square$ Não Qual: & \\
\hline Percepção sensorial da dor & $\square \operatorname{sim} \quad \square$ Não Score: & \\
\hline Hipotermia & $\square \operatorname{sim} \quad \square$ Não To: & \\
\hline Hipertermia & $\square \operatorname{sim} \quad \square$ Não To: & \\
\hline Outras enfermidades & $\square \operatorname{sim} \quad \square$ Não & \\
& Quais: & \\
\hline
\end{tabular}




\begin{tabular}{|c|c|c|c|c|}
\hline \multirow{2}{*}{$\begin{array}{l}\text { EDUCAÇÃo EM SAÚDE } \\
\text { Classificação ASA }(1,2,3,4,5 \text { e } 6) \\
\end{array}$} & \multicolumn{3}{|c|}{ ENFERMEIRO } & \multirow[t]{2}{*}{ ANESTESIOLOGISTA } \\
\hline & $\square \operatorname{sim}$ & $\square$ Não & Qual: & \\
\hline Dúvidas sobre o procedimento cirúrgico & $\begin{array}{l}\square \operatorname{sim} \\
\text { Quais: }\end{array}$ & $\square$ Não & & \\
\hline \multicolumn{5}{|l|}{ Nivel de ansiedade } \\
\hline Tipo de anestesia & $\begin{array}{l}\square \operatorname{sim} \\
\text { Qual: }\end{array}$ & $\square$ Não & & \\
\hline Medicação pré-anestésica & $\begin{array}{l}\square \operatorname{sim} \\
\text { Qual: }\end{array}$ & $\square$ Não & & \\
\hline $\begin{array}{l}\text { Tipo de isolamento (respiratório gotículas ou ar, } \\
\text { contato) }\end{array}$ & $\square$ Sim & $\square$ Não & & \\
\hline $\begin{array}{l}\text { Demarcação cirúrgica / lateralidade } \\
\text { (confirmação do sítio cirúrgico) }\end{array}$ & $\square$ Sim & $\square$ Não & & \\
\hline Banho pré-operatório com antisséptico & $\square \operatorname{sim}$ & $\square$ Não & & \\
\hline Tricotomia pré-operatória & $\square$ Sim & $\square$ Não & & \\
\hline Protocolos de segurança perioperatória & $\square \operatorname{sim}$ & $\square$ Não & & \\
\hline $\begin{array}{l}\text { Presença de próteses, implantes ou adornos } \\
\text { (prótese dentária ou capilar, unhas e cílios postiços, } \\
\text { piercings ) }\end{array}$ & $\begin{array}{l}\square \text { Sim } \\
\text { Qual: } \\
\text { Local: }\end{array}$ & $\square$ Não & & \\
\hline $\begin{array}{l}\text { Presença de dispositivos externos (cateteres, } \\
\text { drenos, imobilizadores ortopédicos) }\end{array}$ & $\begin{array}{l}\square \text { Sim } \\
\text { Qual: } \\
\text { Local: }\end{array}$ & $\square$ Não & & \\
\hline Capacidade de tolerar o posicionamento cirúrgico & $\square \operatorname{sim}$ & $\square$ Não & & \\
\hline Risco de lesão de pele por posicionamento cirúrgico & $\square$ Sim & $\square$ Não & & \\
\hline Outras considerações & $\begin{array}{l}\square \text { Sim } \\
\text { Quais: }\end{array}$ & $\square$ Não & & \\
\hline
\end{tabular}

\begin{tabular}{|l|l|l|}
\hline \multicolumn{1}{|c|}{ EXAMES DIAGNÓSTICOS } & \multicolumn{1}{|c|}{ ENFERMEIRO } & ANESTESIOLOGISTA \\
\hline Exames laboratoriais & $\square$ sim $\square$ Não & \\
\hline Quais: & \\
\hline Exames de imagem & $\square$ sim $\square$ Não & \\
\hline Quais: & $\square$ sim $\square$ Não & \\
\hline & Quais: & \\
\hline
\end{tabular}

\begin{tabular}{|l|l|l|}
\hline \multirow{4}{*}{ OBSERVAÇÕES/ CONSIDERAÇÕES } & ENFERMEIRO & ANESTESIOLOGISTA \\
\cline { 2 - 3 } & & \\
& & \\
\hline
\end{tabular}


Discussão 


\section{DISCUSSÃO}

\subsection{REVISÃO DOS GUIDELINES NACIONAL E INTERNACIONAL}

O referencial teórico é o foco essencial do processo de estruturação do instrumento a ser desenvolvido, pois nele deve estar contido o que realmente será medido (DEVELLIS, 2016). Os guidelines nacional e internacional preconizados pelas associações de classe (SOBECC, AORN, ASA e, ESA), foram utilizados como base para elaboração dos itens do instrumento. Desta forma, o instrumento foi subdividido em sistemas para direcionamento da avaliação, em que o enfermeiro e o anestesiologista poderão destacar pontos importantes de cada entrevista com o paciente cirúrgico. Neste momento será possível esclarecer dúvidas e traçar um planejamento estratégico da assistência perioperatória com qualidade e segurança.

As diretrizes práticas recomendadas pela SOBECC são pautadas nas mesmas evidências encontradas nos guidelines da AORN, mesmo apresentando populações e realidades diferentes. E, estas evidências foram ajustadas pela associação de classe conforme necessidade. Mesmo assim é possível observar algumas semelhança nos guidelines: preparo da pele do paciente pré-operatório, prevenção de trombose venosa profunda, prevenção de riscos para posicionamento e, prevenção de hipotermia.

O preparo da pele do paciente pré-operatório é uma das práticas responsáveis pela prevenção de infecções do sítio cirúrgico. Para tanto é recomendado a realização do banho pré-operatório com solução antisséptica na noite anterior ou no dia da cirurgia. A remoção mecânica dos pelos no local cirúrgico não deverá ser realizada com lâmina de barbear. E, ainda, o paciente deverá evitar a utilização de soluções alcoólicas, loções e emolientes no corpo após o banho. (WOOD; CONNER, 2017; SOBECC, 2017)

A prevenção de trombose venosa profunda deverá estar pautada nos fatores de risco; isto é, idade superior a 40 anos, obesidade, histórico prévio de trombose venosa profunda, tabagismo, trombofilia, câncer, doença cardiovascular, entre outros. Como método profilático mecânico está indicado a utilização de meias de compressão graduada e compressor pneumático intermitente e, profilaxia farmacológica com anticoagulantes. (BURLINGAME et al, 2017; SOBECC, 2017) 
O posicionamento cirúrgico envolve múltiplos aspectos, tais como: idade, peso, altura, lateralidade, comorbidades, tipo de cirurgia, condições da pele, estado nutricional, presença de adornos ou próteses, restrição a movimentação e deformidades. Assim, o enfermeiro perioperatório deverá garantir disponibilidade de equipamentos e dispositivos para minimizar riscos de lesões por posicionamento cirúrgico (Ex.: colchão viscoelástico, colchão "caixa de ovo" e, dispositivos em gel ou espuma). (AORN JOURNAL, 2017; SOBECC, 2017)

A prevenção hipotermia deverá estar fudamentada nos fatores de risco precursores; ou seja, extremos de idade, distúrbio metabólico, benzodiazepínicos, tipo e duração do ato anestésico, baixa superfície corpórea e, temperatura da sala operatória inferior a 20 graus. Como método profilático pode-se destacar o préaquecimento do paciente (15 a 20 minutos) antes da indução anestésica e, minimizar exposição corpórea evitando perda de calor desnecessária. (BURLINGAME, CONNER, 2017; SOBECC, 2017)

Os guidelines recomendados pela ASA e ESA são similares entre si nas seguintes diretrizes práticas: avaliação pré-operatória, manejo do sangramento perioperatório e, jejum pré-operatório.

A avaliação pré-operatória foi abordada nos guidelines da ASA e ESA como devendo ser realizada antes da cirurgia e, deve incluir um exame de via aérea, um exame pulmonar com ausculta dos pulmões e um exame de doença cardiovascular. Além disto, esta avaliação também deverá envolver informação advindas de registros médicos, entrevista com o paciente, exames físicos e resultados de exames laboratoriais e de imagem diagnóstica. (APFELBAUM et al., 2012; DE HERT et al, 2011)

O manejo do sangramento perioperatório busca identificar fatores de risco para transfusão sanguínea ou terapia adjuvante, o qual inclui revisão de prontuário, entrevista com paciente e família, anemia prévia, medicamenros utilizados diariamente e, resultados de exames laboratoriais (teste de coagulação ou função plaquetária). Estes fatores deverão ser monitorados e corrigidos antes da cirurgia, evitando mobidade e mortalidade subsequente. (APFELBAUM et al., 2015; KOZEKLANGENECKER et al, 2017)

Para jejum pré-operatório efetivo são recomendados a ingestão: flúidos claros (água, suco livre de polpa, café sem leite, chá e bebidas carbonatadas) até duas horas antes da cirurgia e, alimentos sólidos e leite não materno até seis horas antes da cirurgia. Caso não seja cumprida poderão haver complicações como pneumonia 
por aspiração, deficiências respiratórias e morbidades relacionadas. (APFELBAUM et al., 2011; SMITH et al., 2011)

Há uma semelhança entre os guidelines da SOBECC, AORN e ESA, em que as associações de classe destacam a importância da prevenção da trombose venosa profunda.

\subsection{VALIDAÇÃO DO INSTRUMENTO DE AVALIAÇÃO PRÉ-OPERATÓRIA TRANSDISCIPLINAR}

Observa-se na Tabela 1 que CVCt variou entre 0,83 e 0,99. Em sua totalidade (100\%), os sistemas obtiveram pontuação superior a 0,80 em cada um dos itens que compunham os sistemas e, portanto, não necessitaram de revisão.

Apesar de todos os 93 itens (100\%) apresentarem CVCt superior a 0,80, alguns deles chamaram a atenção por se encontrarem na faixa de 0,89 a 0,80 e foram abordados detalhadamente. Sendo eles: tipo sanguíneo $(0,83)$, trombose venosa profunda (TVP), trombose venosa pulmonar e periférica $(0,87)$, hipotermia $(0,83)$ e dispneia de esforço $(0,89)$.

A necessidade de identificar previamente o tipo sanguíneo do paciente cirúrgico, possibilita antever situações de urgência e emergência, assim como controle de sangramento intraoperatório. Visto que, a reserva de hemocomponentes é primordial para intervenção imediata de perda sanguínea importante durante o ato cirúrgico, pois garante segurança a procedimentos cirúrgicos críticos e de grande porte. Este item apresentou CVCt igual a 0,83 pelo fato de estar repetido no instrumento, pois já havia sido abordado no sistema hematológico. Portanto, no instrumento final foi excluído.

A trombose venosa profunda é uma das maiores causas de óbito intraoperatório no mundo, porém pode ser facilmente evitada. Desta forma, medidas que diminuem as mortes e complicações causadas por tromboembolismo venoso devem ser adotadas através de identificação dos seus fatores de risco e adequação de sua profilaxia (OKUHARA et al., 2015; MOULIM et al., 2010). Diante disto, apenas um dos juízes destacou a relevância de estratificar a TVP em baixo, moderado, alto e altíssimo risco, justificando o resultado apresentado (CVCt 0,83).

A hipotermia é um evento comumente encontrado em cerca de $70 \%$ dos pacientes submetidos aos procedimentos anestésicos-cirúrgicos, a qual incorre em 
complicações relevantes como alteração na cascata de coagulação e no metabolismo de fármacos, comprometendo a cicatrização. Isto ocorre principalmente devido à ação de anestésicos na termorregulação e à diminuição do metabolismo do paciente (POVEDA; GALVÃO; SANTOS, 2009). Na avaliação realizada pelos juízes, dois deles destacaram a importância de levantar os fatores de risco para hipotermia no intraoperatório. Entretanto, o instrumento busca verificar se o paciente já apresentou em cirurgias ou internações anteriores o evento hipotermia. E, ainda permite a partir do levantamento de dados clínicos do histórico de enfermagem, a elaboração de um plano de cuidados para prevenção de hipotermia perioperatória. Diante do exposto, o item apresentou CVCt igual a 0,83 devido a discordância dos juízes em relação ao item ser inserido como evento manifestado pelo paciente previamente, ao invés de risco para hipotermia.

A dispneia de esforço pode ser provocada por doenças cardíacas, e por este motivo um dos juízes refere que este item, o qual apresentou CVCt igual a 0,89, poderia ser abordado no sistema cardiovascular. Entretanto, o mesmo foi mantido no sistema respiratório por similaridade com os itens deste sistema.

Nos estudos realizados por Lemos, Poveda, Peniche (2017), Silva el al. (2018) e Coluci, Alexandre (2009), o índice de validação de conteúdo apresentou-se maior de 0,80 e, os itens em escore menor foram modificados conforme as sugestões dos juízes especialistas. O índice de validade de conteúdo mede a proporção ou porcentagem de juízes que estão em concordância sobre determinados aspectos do instrumento e de seus itens. E, ainda possibilita inicialmente analisar cada item individualmente e depois o instrumento como um todo (ALEXANDRE; COLUCI 2011).

Os autores Perroca, Jericó, Facundin (2007), Paschoal, Gatto (2006) e Pittelkow, Carvalho (2008) relatam que os maiores índices de cancelamentos cirúrgicos se devem ao não comparecimento e as condições clínicas do paciente. $O$ não comparecimento do paciente se deve por alguns motivos; ou seja, redefinição de data da cirurgia, desconhecimento do agendamento cirúrgico, nova conduta médico-cirúrgica, desistência, dificuldade de internação, falta de leito de internação, tempo cirúrgico excedido, falta de material e, erro na programação cirúrgica. Já a suspensão cirúrgica pelas condições clínicas do paciente pode ocorrer devido ao estado pré-operatório desfavorável (infecções de vias aéreas, preparo cirúrgico inadequado, outras doenças) e, falta de exames pré-operatórios. Logo, estas situações poderiam ser evitadas a partir de uma avaliação (ou visita) pré-operatória 
Catharina Ferreira de Meira Pachioni

multiprofissional adequada, a qual permitiria identificar as condições psicológicas e clínicas do paciente, realizando o planejamento da assistência perioperatória, evitando, portanto, os cancelamentos ou suspensões cirúrgicas.

Alguns itens presentes neste instrumento são essenciais para evitar o cancelamento cirúrgico, sendo eles: alergia ao látex, medicamentos em uso diário, tempo de jejum, diabetes mellitos tipos I e II, exames laboratoriais, exames de imagem e, infecção de vias aéreas superiores.

Em casos de pacientes com histórico de alergia ao látex é recomendado que realizem o procedimento cirúrgico no primeiro horário do dia, pelo fato de ser necessário o rigoroso preparo da sala operatória com ambiente livre de látex, evitando a presença de partículas de látex em suspensão liberadas pelas luvas cirúrgicas (SÁ; MALLOZI; SOLÉ, 2010).

Alguns medicamentos em uso diário como anticoagulantes deverão ser suspensos conforme avaliação de risco-benefício de sangramento devido ao procedimento cirúrgico e risco de trombose por doença adjacente (FERNANDES et al., 2010). Esta conduta deverá ser definida em conjunto com o médico-cirurgião e anestesiologista, permitindo um planejamento cirúrgico adequado e seguro ao paciente.

Caso o tempo de jejum não seja respeitado, o procedimento cirúrgico poderá ser suspenso ou adiado até que se complete o tempo ideal de jejum pré-operatório. Além disto, estudos revelam que a abreviação do jejum pré-operatório com oferta de solução enriquecida de carboidratos $(\mathrm{CHO})$ até duas horas antes da cirurgia, vem sendo observado como um dos fatores benéficos para diminuir a resposta orgânica, a resistência insulínica, o estresse cirúrgico e ainda, melhorar o bem-estar do paciente. Esta prática além de trazer mais conforto e segurança ao paciente, ocasionando rápida recuperação do trauma cirúrgico (NASCIMENTO; PERRONE; PRADO, 2009).

O paciente cirúrgico diabético deverá ser incluído no grupo de alto risco, pois poderão apresentar maiores complicações devido as respostas metabólicas específicas decorrentes do tipo de cirurgia e anestesia. Estas respostas poderão causar aumento dos hormônios de contra-regulação e insulinoressistência. $O$ estresse metabólico causado pelo procedimento cirúrgico incorre no aumento da demanda por insulina, podendo causar descompensação e hiperglicemia. Logo, estes pacientes deverão estar em constante vigilância e acompanhamento perioperatório (PONTES et al, 2018; PAIVA, 2004). 
É necessário levar em consideração a relação risco-benefício da solicitação de exames laboratoriais e de imagem, uma vez que caso estejam ausentes poderá ocasionar o retardo e até suspensão da cirurgia, pois as alterações nos exames implicam em novas abordagens terapêuticas e até riscos para o paciente (FERNANDES et al., 2010).

A infecção de vias aéreas superiores deverá ser detectada na avaliação clínica do paciente, pois se a infecção estiver ativa a cirurgia poderá ser adiada por até duas semanas. Uma vez que o quadro infeccioso causado, por exemplo, por crises asmáticas e doença pulmonar obstrutiva crônica (DPOC) são importantes fatores de risco para complicações pulmonares pós-operatórias. Assim, é recomendado a realização da radiografia de tórax aos portadores de doença pulmonar com piora dos sintomas, ou agudização nos últimos 6 meses, bem como naqueles que serão submetidos a procedimentos cardiotorácicos (FERNANDES et al., 2010).

Portanto, é extremamente importante garantir que todos estes itens sejam esclarecidos ao paciente cirúrgico, pois a ausência ou não conformidade dos mesmos implica em suspensão cirúrgica ou redefinição de conduta anestésicocirúrgica.

Por diversas vezes o paciente cirúrgico é questionado sobre dados clínicos desnecessariamente, desenvolvendo estresse e ansiedade pré-operatória, além de potencializar riscos e complicações trans e pós-operatórias (FREIBERGER; MUDREY, 2011). Logo, o propósito deste instrumento é minimizar situações como estas e, direcionar o plano de cuidados individualizado com perguntas relevantes a assistência perioperatória, diminuindo a ansiedade e respostas psicológicas ao estresse, garantindo segurança durante todo o processo anestésico-cirúrgico.

A ideia de criação deste instrumento foi para direcionar o enfermeiro perioperatório ou enfermeiro assistencial a elaborar um plano de cuidados integral e individualizado, abordando diagnósticos de enfermagem e prescrição de condutas para o período perioperatório, proporcionando continuidade da assistência de enfermagem entre a unidade de internação e o centro cirúrgico (CASTELLANOS; JOUCLAS, 1990). A partir disto, haverá melhora na comunicação entre os membros da equipe multiprofissional e o paciente, evitando cancelamentos cirúrgicos, desgaste emocional do paciente e, diminuindo custos que envolvem o processo cirúrgico, tal como internação prolongada em decorrência de eventos adversos (SILVA; NAKATA, 2005). 
O instrumento apresenta-se útil para alimentar indicadores de qualidade e processos perioperatórios, permitindo identificar o perfil do paciente cirúrgico assistido, através dos principais diagnósticos de enfermagem. Os indicadores podem ser definidos a partir do conceito de redução de riscos e danos ao paciente ocasionados pela assistência à saúde, pois os riscos potenciais de uma intervenção ou do ambiente são evitados ou minimizados (MORENO; ZUCCHI, 2005). Ele ainda funciona como uma barreira de segurança multiprofissional, a fim de minimizar riscos e eventos adversos ao paciente cirúrgico.

Segundo os autores Grittem, Méler, Galevicz (2006) e Santos, Piccoli, Carvalho (2007), os principais diagnósticos de enfermagem encontrados no período pré-operatório são: ansiedade, medo, dor aguda, risco para infecção, dor aguda, déficit de conhecimento, risco para função respiratória alterada, mobilidade física prejudicada, estado nutricional alterado e náuseas. Estes diagnósticos são definidos conforme os dados levantados na avaliação pré-operatória (ou visita pré-operatória) e, serão norteadores do processo de planejamento da assistência de enfermagem perioperatória.

Piccoli e Galvão (2005), desenvolveram um instrumento de coleta de dados para ser aplicado na visita pré-operatória de enfermagem, baseado no modelo conceitual de Levine, o qual está pautado em quatro princípios de conservação, são eles: de energia, da integridade estrutural, da integridade pessoal e da integridade social do paciente; estando estes centrados na intervenção de enfermagem, adaptação e reação dos pacientes à doença. Este instrumento foi dividido em sistemas do corpo humano, fatores de riscos, histórico clínico e social do paciente.

Assim, este instrumento apresenta-se semelhante ao proposto por este estudo, evidenciando a praticidade em sua aplicação, identificação de diagnósticos de enfermagem para estruturar o planejamento da assistência perioperatória e, possibilitando uma assistência integral, individualizada e humanizada ao paciente cirúrgico. Além disto, o instrumento permite o compartilhamento de informações entre a equipe multiprofissional, refletindo o cuidado centrado no paciente

Jorgetto, Noronha e Araújo (2004), implantaram um instrumento de visita préoperatória de enfermagem em um hospital universitário e observaram que os enfermeiros julgaram importante a realização desta visita, destacando alguns benefícios ao paciente, tais como: diminuição de medos, estresse e ansiedade pré cirúrgica. 
Por outro lado, a avaliação pré-operatória realizada pela visita pré-operatória pelo enfermeiro perioperatório pode ser vista como uma sobrecarga de atividades do enfermeiro. Isto é, estudos referem alguns motivos pelos quais os enfermeiros não realizam esta importante atribuição, são eles: elevado número de procedimentos cirúrgicos, déficit de enfermeiros atuando no cento cirúrgico, acúmulo de funções, curto período de internação prévio ao procedimento anestésico-cirúrgico e o déficit no conhecimento científico relacionado aos procedimentos cirúrgicos. Além do fato deste profissional não se dedicar exclusivamente a esta função, pois ainda exerce importante papel em funções administrativas e assistenciais, as quais demandam tempo. No entanto, esta avaliação foi reconhecida como atividade essencial no desenvolvimento do SAEP conforme a Lei do Exercício Profissional de Enfermagem (CONSELHO FEDERAL DE ENFERMAGEM, 1993), devendo ser pautada no conhecimento científico, respeitando a individualidade e integridade do paciente, garantindo segurança e qualidade a assistência cirúrgica (OLIVEIRA; MENDONÇA, 2014; GRITTEM; MÉLER; GALEVICZ, 2006).

Paralelo ao exposto, o enfermeiro perioperatório deve estar atento e capacitado para transmitir as informações cruciais, evitando informações desnecessárias que poderão desencadear estresse cirúrgico (GIVEL; MEIER, 2014).

O objetivo deste estudo foi validar a ferramenta proposta. Para esta ação, os juízes tiveram uma importante participação com contribuições essenciais, a fim de aprimorar o instrumento proposto. O instrumento foi avaliado pelos juízes demonstrando clareza nas informações, apresentação e preenchimento adequados. Portanto, o desenho final do instrumento foi estruturado com base nos guidelines nacional e internacional e nas sugestões dos juízes. 


\section{Conclusão}




\section{CONCLUSÃO}

Com a revisão dos guidelines foram identificadas algumas semelhanças entre a SOBECC e a AORN em quatro categorias (preparo de pele do paciente préoperatório, prevenção de trombose venosa profunda, prevenção de riscos para 0 posicionamento cirúrgico e prevenção da hipotermia), do mesmo modo a ASA e a ESA apresentaram similaridade em três categorias (avaliação pré-operatória, manejo do sangramento perioperatório e jejum pré-operatório).

Em relação a VC, o instrumento apresentou índices satisfatórios na validação de conteúdo pelo CVCt, variando de 0,83 a 0,99 . Portanto, o instrumento foi avaliado pelos juízes demonstrando clareza nas informações, apresentação e preenchimento adequados.

Desta forma, o instrumento proposto denominado Avaliação Pré-Operatória Transdisciplinar (APOT) foi construido e submetido a validação de conteúdo pela equipe multiprofissional garantindo a segurança do paciente cirúrgico no período transoperatório.

Recomenda-se a aplicação-piloto informatizada deste instrumento. 


\section{Implicações para a prática e pesquisa}




\section{IMPLICAÇÕES PARA A PRÁTICA E PESQUISA}

A avaliação pré-operatória do paciente cirúrgico é um tema relevante para a prática clínica, porém pouco estudado. Há destaque para a atuação do enfermeiro perioperatório na execução da visita pré-operatória de enfermagem, a qual é pouco realizada devido a algumas limitações da dinâmica do serviço de enfermagem. É frequente o desvio do enfermeiro de suas atividades de assistência perioperatória devido ao quadro de funcionários quase sempre diminuido nessas unidades, causando sobrecarga e falta de tempo disponível do enfermeiro para atender a esta demanda. A avaliação realizada pelos anestesiologistas se restringe a informações e dados clínicos pertinentes ao ato anestésico-cirúrgico e a dinâmica de serviço é diferente quando comparada ao do enfermeiro.

Diante desta realidade, a criação e validação de um instrumento de avaliação transdisciplinar faz-se essencial para otimizar o tempo dos profissionais envolvidos com a avaliação pré-operatória, melhorar a atuação e comunicação entre a equipe multiprofissional perioperatória, destacando pontos relevantes para a elaboração de um plano de cuidados com qualidade e segurança a ser implementado no período transoperatório e, com a eliminação de repetições de informações e questionamentos. 


\section{Referências}




\section{REFERÊNCIAS}

Aguilar-Nascimento JE, Bicudo-Salomão A, Caporossi C et al. - Acerto pósoperatório: avaliação dos resultados da implantação de um protocolo multidisciplinar de cuidados perioperatórios em cirurgia geral. Rev Col Bras Cir, 2006;33:181-188.

Aldecoa C et al. European Society of Anaesthesiology evidence-based and consensus-based guideline on postoperative delirium. Eur J Anaesthesiol 2017; $34: 192-214$.

Alexandre NMC, Coluci MZO. Validade de conteúdo nos processos de construção e adaptação de instrumentos de medidas. Ciência \& Saúde Coletiva. 2011;16(7):30613068.

Apfelbaum JL et al. Practice Advisory for Preanesthesia Evaluation: A Report by the American Society of Anesthesiologists Task Force on Preanesthesia Evaluation. Anesthesiology 2012; 116:1-1.

Apfelbaum JL et al. Practice Guidelines for Acute Pain Management in the Perioperative Setting: An Updated Report by the American Society of Anesthesiologists Task Force on Acute Pain Management. Anesthesiology 2012; 116:248 -73.

Apfelbaum JL et al. Practice Guidelines for Management of the Difficult Airway: An Updated Report by the Task Force on Difficult Airway Management. Anesthesiology 2013; 118:251-70.

Apfelbaum JL et al. Practice Guidelines for Perioperative Blood Transfusion and Adjuvant Therapies: An Updated Report by the American Society of Anesthesiologists Task Force on Perioperative Blood Transfusion and Adjuvant Therapies. Anesthesiology 2015; 122:241-75.

Apfelbaum JL et al. Practice Guidelines for Preoperative Fasting and the Use of Pharmacologic Agents to Reduce the Risk of Pulmonary Aspiration. Anesthesiology 2011; 114:495-511.

Apfelbaum JL et al. Guidelines for the Prevention, Detection, and Management of Respiratory Depression Associated with Neuraxial Opioid Administration: An Updated Report by the ASA Task Force on Neuraxial Opioids. Anesthesiology 2016; 124:535-52.

AORN Journal. Guideline for Positioning the Patient. AORN Guidelines for Perioperative Practice; 2017. 691-709p.

Barnett JS. An Emerging Role for Nurse Practitioners-Preoperative Assessment. Aorn Journal. 2005; 82(5):825-834.

Bianchi ERF, Caregnato RCA, Oliveira RCB. Modelos de assistência de enfermagem perioperatória. 2 ed. Barueri, São Paulo: Manole; 2016. 33-52p. 
Brasil. Ministério da Saúde. Portaria no 529, de 1ำ de abril de 2013. Institui o Programa Nacional de Segurança do Paciente (PNSP). Brasília: Ministério da Saúde, 2013

Burlingame BL, Conner RL. Guideline for Prevention of Unplanned Patient Hypothermia. AORN Guidelines for Perioperative Practice; 2017. 567-590p.

Burlingame BL, Conner RL. Guideline for Safe Use of Energy-Generating Devices. AORN Guidelines for Perioperative Practice; 2017. 129-155p.

Burlingame B, Wicklin SV, Feldman DL, Graybill-D'Ercole P. Guideline for Prevention of Deep Vein Thrombosis. AORN Guidelines for Perioperative Practice; 2017. 557$565 p$.

Calland JF, Adams RB, Benjamin Jr DK. Thirty-day postoperative death rate at an academic medical center. Ann Surg. 2002;235(5):690-6

Castellanos BEP, Jouclas VMG. Assistência de enfermagem perioperatória: um modelo conceituai. Rev. Esc. Enf. USP, São Paulo. 1990 dez;24(3):359-370.

Coluci MZO, Alexandre NMC. Adaptação cultural de instrumento que avalia atividades do trabalho e sua relação com sintomas osteomusculares. Acta Paul Enferm 2009;22(2):149-54.

CONSELHO FEDERAL DE ENFERMAGEM (COFEN). Decisão COFEN n. 001/2000 de 04/01/2000. Normaliza a implementação da Sistematização da Assistência de Enfermagem (SAE) nas instituições de saúde no âmbito do Estado de São Paulo, COREN-SP 2000;(26):12-3.

Davis LL. Instrument review: getting the most from a panel of experts. Appl Nurs Res. 1992; 5(4):194-197.

De Hert et al. Preoperative evaluation of the adult patient undergoing non-cardiac surgery: guidelines from the European Society of Anaesthesiology. European Journal of Anaesthesiology 2011, Vol 28 No 10.

DeVellis RF. Scale Development: Theory and Application. 4th ed. Los Angeles: Sage; 2016.

Diretrizes práticas em enfermagem cirúrgica e processamento de produtos para saúde - SOBECC/ SOBECC - Associação Brasileira de Enfermeiros de Centro Cirúrgico, Recuperação Anestésica e Centro de Material e Esterilização. $7^{\mathfrak{a}}$ ed. Rev e atual. Barueri, SP: Manole; São Paulo: SOBECC, 2017.

Fernandes et al. Avaliação pré-operatória e cuidados em cirurgia eletiva: recomendações baseadas em evidência. Rev. AMRIGS, Porto Alegre. 2010;54(2):240-258.

Filho GRM, Silva LFS, Ferracini AM, Bähr GL. Protocolo de Cirurgia Segura da OMS: O grau de conhecimento dos ortopedistas brasileiros. Rev Bras Ortop. 2013;48(6):554-562. 
Catharina Ferreira de Meira Pachioni

Fonseca RMP, Peniche ACG. Enfermagem em centro cirúrgico: trinta anos após criação do Sistema de Assistência de Enfermagem Perioperatória. Acta Paul Enferm. 2009;22(4):428-33.

Freiberger MF, Mudrey ES. A importância da visita pré-operatória para sistematização da assistência de enfermagem perioperatória Rev Cie Fac Edu Mei Amb. 2011 mai-out;2(2):1-26.

Giarrizzo-Wilson S, Conner RL. Guideline for Patient Information Management. AORN Guidelines for Perioperative Practice; 2017. 591-616p.

Chard R, Kuhn J, Arcilla MC, Goodman T, Hilbert T. Guideline for Transfer of Patient Care Information. AORN Guidelines for Perioperative Practice; 2017. 711-716p.

Givel JC, Meier B. How much information do patients want or need. World J Surg. 2014 jul; 38(7):1610-1613.

Grant JS, Davis LL. Selection and use of content experts for instrument development. Res Nurs Health. 1997;20(3): 269-274.

Grittem L, Méler MJ, Galevicz AP. Visita pré-operatória de enfermagem: percepções dos enfermeiros de um hospital de ensino. Cogitare Enferm. 2006 set-dez;11(3):24551 .

Gross JB et al. Practice Guidelines for the Perioperative Management of Obstructive Sleep Apnea: a Report by the American Society of Anesthesiologists Task Force on Perioperative Management of Obstructive Sleep Apnea. Anesthesiology 2014; 120:00-00.

Hernández-Nieto H. Contribuciones al análisis estadísticos. 1 ed. Mérida, Venezuela: Universidad de Los Andes; 2002. 183 p.

Japiassu H. Interdisciplinaridade e patologia do saber. Rio de Janeiro: Imago; 1976.

Jorgetto GV, Noronha R, Araújo IEM. Estudo da visita pré-operatória de enfermagem sobre a ótica dos enfermeiros do centro-cirúrgico de um hospital universitário. Rev. Eletr. Enf. 2004;6(2):213-222.

Kozek-Langenecker $S$ et al. European guidelines on perioperative venous thromboembolism prophylaxis: Surgery in the elderly. Eur J Anaesthesiol 2017; 34:17

Kozek-Langenecker SA et al. Management of severe perioperative bleeding: guidelines from the European Society of Anaesthesiology. Eur J Anaesthesiol 2017; 34:332-395.

Lemos CS, Poveda VB, Peniche ACG. Construction and validation of a nursing care protocol in anesthesia. Rev. Latino-Am. Enfermagem. 2017;25:e2952. [Access 16/03/2018]; Available in http://www.scielo.br/pdf/rlae/v25/pt_0104-1169-rlae-25e2952.pdf. .DOI: http://dx.doi.org/1518- 8345.2143.2952. 
Ludwig RB, Paludo J, Fernandes D, Scherer F. Menor tempo de jejum pré-operatório e alimentação precoce no pós-operatório são seguros? ABCD Arq Bras Cir Dig. 2013; 26(1):54-58.

Maziero ECS, Silva AEBC, Mantovani MF, Cruz EDA. Adesão ao uso de um checklist cirúrgico para segurança do paciente. Rev Gaúcha Enferm. 2015;36(4):1420.

Meira CFC, Freria ZF. Assistência do Enfermeiro no Período Pré-operatório. In: Anestesiologia Básica ed. Barueri, São Paulo: Manole; 2010/2011.

Meireles BHS, Erdmann AL. A questão das disciplinas e da interdisciplinaridade como processo educativo na área da saúde. Texto Contexto Enfermagem 1999 janabr; 8(1):149-65.

Mendes FF et al. Avaliação Pré-operatória: Triagem Por Meio de Questionário. Rev Bras Anestesiol. 2013;63(4):347-352.

Moreno Jr MJ, Zucchi P. Avaliação de qualidade em serviços de saúde: acreditação, certificação e programas de melhoria da qualidade dos hospitais públicos e privados do município de São Paulo. RAP. 2005;39(1):7-16.

Moro ET. Jejum pré-operatório. Ver. Fac. Cienc. Med. Sorocaba, 2013;5(1):27-29.

Moulim JL et al. Estudo comparativo entre protocolos para profilaxia da trombose venosa profunda: uma nova proposta. Rev. Bras. Cir. Plást. 2010; 25(3):415-22.

Nascimento JEA, Perrone F, Prado LIA. Jejum pré-operatório de 8 horas ou de 2 horas: o que revela a evidência? Rev. Col. Bras. Cir. 2009;36(4):350-352.

Nygren J, Hausel J, Kehlet H, Revhaug A, Lassen K, Dejong C, Andersen J, von Meyenfeldt M, Ljungqvist $\mathrm{O}$, Fearon KC. A comparison in five European Centers of case mix, clinical management and outcomes following either conventional or fasttrack perioperative care in colorectal surgery. Clin Nutr. 2005;24(3):455-61.

Ogg MJ, Conner RL. Guideline for Care of the Patient Receiving Local Anesthesia. AORN Guidelines for Perioperative Practice; 2017. 617-628p.

Okuhara A, Navarro TP, Procópio RJ, Leite JOM. Incidência de trombose venosa profunda e estratificação dos grupos de risco em serviço de cirurgia vascular de hospital universitário. J Vasc Bras. 2015 Abr-Jun;14(2):139-144.

Oliveira KGB, Balson M, Oliveira SS, Nascimento JEA. A abreviação do jejum préoperatório para duas horas com carboidratos aumenta o risco anestésico? Rev. Bras. Anest, 2009;59(5):577-584.

Oliveira MM, Mendonça KM. Análise da visita pré-operatória de enfermagem: revisão integrativa. Rev. SOBECC, São Paulo. 2014 jul-set;19(3):164-172.

ORGANIZAÇÃO MUNDIAL DA SAÚDE. Segundo desafio global para a segurança do paciente: Cirurgias seguras salvam vidas (orientações para a cirugia segura da 
Catharina Ferreira de Meira Pachioni

OMS). Organização Mundial da Saúde. Organização Pan-Americana da Saúde; Ministério da Saúde; Agência Nacional de Vigilância Sanitária. Rio de Janeiro, 2009.

Paiva I. Diabetes mellitus e cirurgia: preparação do doente diabético para cirurgia. Acta Médica Portuguesa 2004;17: 94-99.

Paschoal MLH, Gatto MAF. Taxa de suspensão de cirurgia em um hospital universitário e os motivos de absenteísmo do paciente à cirurgia programada. Rev Latino-am Enfermagem 2006 jan-fev;14(1):48-53.

Perroca MG, Jericó MC, Facundin SD. Monitorando o cancelamento de procedimentos cirúrgicos: indicador de desempenho organizacional. Rev Esc Enferm USP 2007;41(1):113-9.

Piccoli M, Galvão CM. Visita pré-operatória de enfermagem: proposta metodológica fundamentada no modelo conceitual de Levine. Rev. El. Enf. 2005;7(3):366-372.

Pittelkow E, Carvalho R. Cancelamento de cirurgias em um hospital da rede pública. Einstein. 2008;6(4):416-21.

Pontes JPJ, et al. Avaliação e manejo perioperatório de pacientes com diabetes melito. Um desafio para o anestesiologista. Rev Bras Anestesiol. 2018;68(1):75-86.

Possari JF. Sistematização da Assistência de Enfermagem Perioperatória. In: Possari JF. Centro Cirúrgico: planejamento, organização e gestão. São Paulo: látria; 2004. p. 209-32.

Poveda VB, Galvão CM, Santos CB. Fatores relacionados ao desenvolvimento de hipotermia no período intra-operatório. Rev Latino-am Enfermagem. 2009 mar-abr;17(2).

Roscani ANCP, Filho AGO, Ferraz EM, Freitas MIP. Validação de checklist cirúrgico para prevenção de infecção de sítio cirúrgico. Acta Paul Enferm. 2015;28(6): 553-65.

Sá AB, Mallozi MC, Solé D. Alergia ao látex: atualização. Rev. bras. alerg. imunopatol. 2010;33(5).

Saklad M. Grading of patients for surgical procedures. Anesthesiology. $1941 ; 2(3): 281-4$.

Santos RR, Piccoli M, Carvalho ARS. Diagnósticos de enfermagem emocionais identificados na visita pré-operatória em pacientes de cirurgia oncológica. Cogitare Enferm. 2007 jan-mar;12(1):52-61.

Silva RS et al. Construção e validação de diagnósticos de enfermagem para pessoas em cuidados paliativos. Rev. Latino-Am. Enfermagem, Ribeirão Preto, v. 25, e2914, 2017. Disponível em <http://www.scielo.br/scielo.php?script=sci_ arttext\&pid=S0104-11692017000100362\&lng=pt\&nrm=iso>. acesso em 23 mar. 2018. Epub 03-Ago-2017. http://dx.doi.org/10.1590/1518-8345.1862.2914.

Silva WV, Nakata S. Comunicação: uma necessidade percebida no período préoperatório de pacientes cirúrgicos. Rev Bras Enferm. 2005 nov-dez;58(6):673-6. 
Smith I et al. Perioperative fasting in adults and children: guidelines from the European Society of Anaesthesiology. European Journal of Anaesthesiology 2011, Vol 28 No 8.

Streiner DL, Norman GR. Health Measurement Scales: a pratical guide to their development and use. 4. ed. Nova York, EUA: Oxford University Press, 2008. 431 p.

Spruce L, Conner RL, Retzlaff KJ. Guideline for Prevention of Transmissible Infections. AORN Guidelines for Perioperative Practice; 2017. 507-539p.

Vilela EM, Mendes IJM. Interdisciplinaridade e saúde: estudo bibliográfico. Rev Latino-am Enfermagem 2003 jul-ago;11(4):525-31.

Wiens AG. Preoperative Anxiety in Women. Aorn Journal. July 1998;68(1):74-7, 79-81, 83-8.

Wood A, Conner RL. Guideline for Preoperative Patient Skin Antisepsis. AORN Guidelines for Perioperative Practice; 2017. 51-74p.

World Health Organization. World Aliance for Patient Safety. Guidelines Safe Surgery. 2008. Disponível em <http://www.who.int/patientsafety/safesurgery/en/>. acesso em 23 mar. 2018. 


\section{Apêndices}




\section{APÊNDICES}

\section{APÊNDICE A}

Caro(a) Senhor(a),

Meu nome é Catharina Ferreira de Meira Pachioni, sou enfermeira e estudante de mestrado da Escola de Enfermagem da Universidade de São Paulo. Gostaria de convida-lo(a) como voluntário(a) a participar da pesquisa intitulada AVALIAÇÃO PRÉ-OPERATÓRIA TRANSDISCIPLINAR: ELABORAÇÂO E VALIDAÇÃO DE UM INSTRUMENTO PARA SEGURANÇA DO PACIENTE CIRÚRGICO, que está sendo desenvolvida por mim, sob orientação da Profä. Dra ${ }^{a}$. Aparecida de Cássia Giani Peniche

O período pré-operatório imediato consiste entre a véspera da cirurgia (24h) até o momento em que o paciente é recebido no centro cirúrgico, este período tem como foco planejar a assistência individualizada, bem como um elo para a continuidade do cuidado no período transoperatório. Neste período é realizado a avaliação pré-anestésica pelo médico anestesiologista $\mathrm{e}$, a avaliação préoperatória pelo enfermeiro perioperatório ou enfermeiro da unidade quando o primeiro não puder, a fim de garantir segurança ao paciente cirúrgico. $O$ objetivo desse projeto é criar e validar um instrumento de avaliação pré-operatória multiprofissional para garantir a segurança do paciente cirúrgico no período transoperatório.

Sua participação consistirá na validação de conteúdo da ferramenta elaborada. Para tal, o(a) senhor(a) precisará responder o questionário de avaliação que tem como propósito a avaliação dos componentes da ferramenta em questão.

A validação de conteúdo implica em dizer se a ferramenta proposta consegue avaliar aquilo a que se objetivou, verificando se os componentes deste instrumento são suficientes para medir o que lhe foi proposto.

Assim, esperamos que o $\mathrm{Sr}$ (a) avalie os itens, quanto à relevância, clareza e abrangência, pontuando em uma escala Likert de 1 (um) a 5 (cinco) pontos, correspondendo as seguintes classificações: (5) concordo totalmente, (4) concordo, (3) nem concordo/ nem discordo, (2) discordo e, (1) discordo totalmente.

Se aceitar a participar, por gentileza imprimir e assinar o termo de consentimento livre e esclarecido (encaminhar termo assinado via e-mail) e, responder ao questionário Excel em anexo com data limite até 10 de dezembro de 2017.

Agradeço e estou a disposição para qualquer dúvida pelos seguintes contatos:

Rua Manuel da Nóbrega, 486 - apto 52 A2 - Paraíso (São Paulo/SP), telefone celular: (011) 983650713, e-mail: catharina.meira@usp.br ou catharinameira@gmail.com.

Cordiamente,

Enf ${ }^{a}$. Catharina Ferreira de Meira Pachioni

Graduada e Licenciada - Escola de Enfermagem da USP/ EEUSP. Especialista em Centro Cirúrgico, Recuperação Anestésica e Centro de Material e Esterilização - SOBECC. Mestranda no Programa de Pós-Graduação de Enfermagem em Saúde do Adulto e do Idoso - PROESA/ EEUSP. 


\section{APÊNDICE B}

\section{Termo de Consentimento Livre e Esclarecido}

$\mathrm{O}(\mathrm{A})$ senhor(a) está sendo convidado(a) a participar como juiz de forma voluntária para validação de conteúdo da pesquisa intitulada: AVALIAÇÃO PRÉ-OPERATÓRIA TRANSDISCIPLINAR: ELABORAÇÃO E VALIDAÇÃO DE UM INSTRUMENTO PARA SEGURANÇA DO PACIENTE CIRÚRGICO. Esta pesquisa tem como objetivo geral criar e validar um instrumento de avaliação pré-operatória multiprofissional para garantir a segurança do paciente cirúrgico no período transoperatório.

Sua participação consistirá na validação de conteúdo da ferramenta elaborada, a qual será enviada por correio eletrônico. Para tal, o(a) senhor(a) precisará responder ao questionário que tem como propósito a avaliação dos componentes do instrumento em questão.

Assim, esperamos que o $\mathrm{Sr}$ (a) avalie os itens, quanto à relevância, clareza e abrangência, pontuando em uma escala Likert de 1 (um) a 5 (cinco) pontos, correspondendo as seguintes classificações: (5) concordo totalmente, (4) concordo, (3) nem concordo/ nem discordo, (2) discordo e, (1) discordo totalmente. A relevância considera se os itens do instrumento são pertinentes e representativos para as ações propostas. A clareza avalia a construção dos itens do instrumento em relação à estrutura escrita, permitindo uma leitura adequada, favorecendo a compreensão. A abrangência demonstra se o instrumento engloba todos os itens relacionados ao foco da avaliação.

Não será divulgada a identificação de nenhum voluntário, não existindo nenhum procedimento, risco, danos, despesas pessoais, compensação financeira ou benefícios diretos. No entanto, o(a) senhor(a) ao final do estudo contribuirá para a melhoria da qualidade do serviço de segurança do paciente cirúrgico no período transoperatório. É garantida a liberdade da retirada de consentimento a qualquer momento e/ou da sua participação, sem qualquer prejuízo relacionado.

Em qualquer etapa do estudo o(a) senhor(a) terá acesso aos profissionais responsáveis pela pesquisa para esclarecimento de eventuais dúvidas. O principal investigador é a enfermeira Catharina Ferreira de Meira Pachioni, a qual representa o compromisso de utilizar as informações obtidas perante o julgamento realizado pelos juízes especialistas, mantendo-as em sigilo, e que em momento algum, o Sr(a) será identificado(a). Todas as informações obtidas por meio de sua avaliação ficarão sob a nossa responsabilidade e trabalharemos com elas de forma global. A pesquisadora pode ser encontrada na Rua Manuel da Nóbrega, 486 - apto 52 A2 Paraíso (São Paulo/SP), telefone celular: (011) 98365-0713, e-mail: catharina.meira@usp.br ou catharinameira@gmail.com.

Agradecemos desde já sua valiosa contribuição e colocamo-nos a disposição para outros esclarecimentos necessários.

Este Termo deverá ser rubricado pelo(a) senhor(a) e por mim, nas suas duas páginas e assinado nas duas vias. $\mathrm{O}(\mathrm{a})$ senhor(a) receberá uma via do Termo de Compromisso.

Data:<smiles>CCCC=[Tl]</smiles>

Nome do participante:

Assinatura do participante:

Pesquisadora Enf ${ }^{a}$ Catharina Ferreira de Meira Pachioni

Assinatura do Pesquisador:

Rubrica do participante:

Rubrica do pesquisador: 


\section{APÊNDICE C}

\section{Validação de Conteúdo do Instrumento - Juízes Especialistas}

Prezado juiz(a), nesta fase da pesquisa de validacão de conteúdo, convidamos o(a) juiz(a) a responder se concorda ou não com os itens em relação à relevância, clareza e abrangência. Considere as seguintes questões: os itens estão claros? há itens faltando? há itens redundantes? (Arat et al., 2016). Classifique sua resposta de acordo com a escala Likert descrita abaixo e, se julgar necessário, por favor descreva comentários/sugestões.

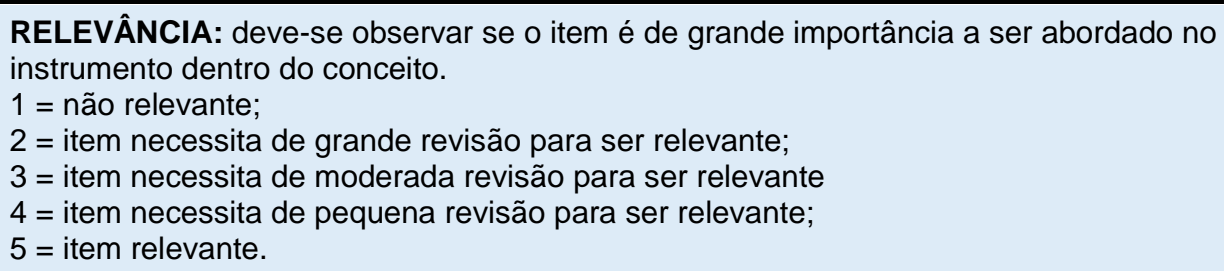

\section{Nome do Profissional:}

Data de Nascimento:

\section{Cargo Atual:}

Maior Titulação:

\section{Área de Titulação:}

Tempo de Experiência na Área: 
AVALIAÇAO PRÉ-ANESTÉSICA: realizada através de uma consulta ambulatorial ou na visita pré-operatória feita pelo médico anestesiologista, para reconhecer as condições clinicas e mentais do paciente. Esta avaliação busca determinar a necessidade de exames complementares, escolher a técnica e a analgesia pós-operatória, e avaliar a necessidade da medicação pré-anestésica de acordo com o porte da cirurgia, por meio de anamnese e exame físico.

AVALIAÇAO PRÉ OPERATÓRIA: realizada através de uma visita feita pelo enfermeiro perioperatório ou enfermeiro da unidade quando o primeiro não puder, para garantir segurança ao paciente cirúrgico. Nesta avaliação podemos identificar as necessidades de cada paciente, sanando suas dúvidas e, traçando intervenções que buscam solucionar os problemas que possam dificultar o procedimento cirúrgico.

Dados Gerais

Nome do Paciente

Data de Nascimento

Gênero

ldade

Peso

Altura

Diagnóstico de Base

Nome do Cirurgião

Termos de Consentimento Cirúrgico e Anestésico
ANESTESIOLOGISTA /

ENFERMEIRO PERIOPERATÓRIO

Relevância

(Score 01 a

05)

Abrangência

(Score 01 a

05)

Clareza

(Score 01 a

05)

Comentários /

Sugestões 


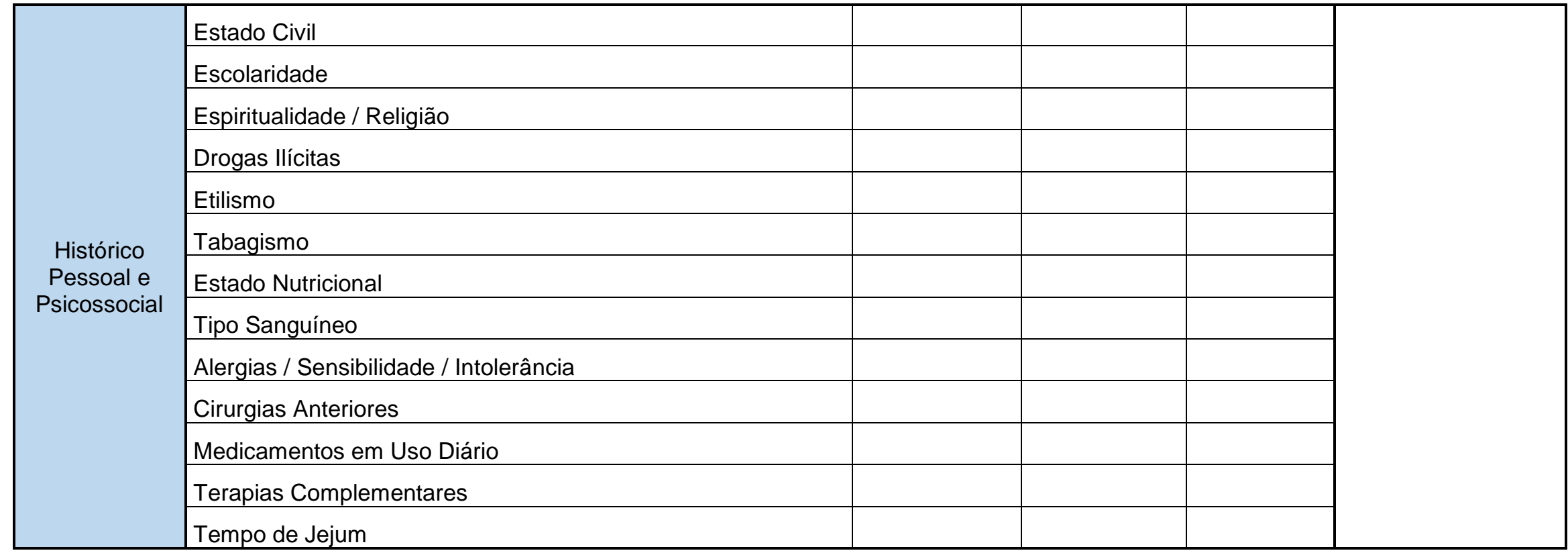

\begin{tabular}{|c|l|l|l|l|}
\hline \multirow{5}{*}{$\begin{array}{c}\text { Sistema } \\
\text { Cardiovascular }\end{array}$} & $\begin{array}{l}\text { Estudo cardíaco basal (pressão arterial, frequência cardíaca) } \\
\text { Trombose venosa profunda (profilaxia mecânica e }\end{array}$ & & \\
\cline { 2 - 5 } & Insuficiência Cardíaca Congestiva & & \\
\cline { 2 - 5 } & Infarto Agudo do Miocárdio & & \\
\cline { 2 - 5 } & Arritmias / Coronariopatias & & \\
\cline { 2 - 5 } & Valvulopatias / Valvulpatias Periféricas & & \\
\cline { 2 - 5 } & Outras Patologias & & & \\
\hline
\end{tabular}




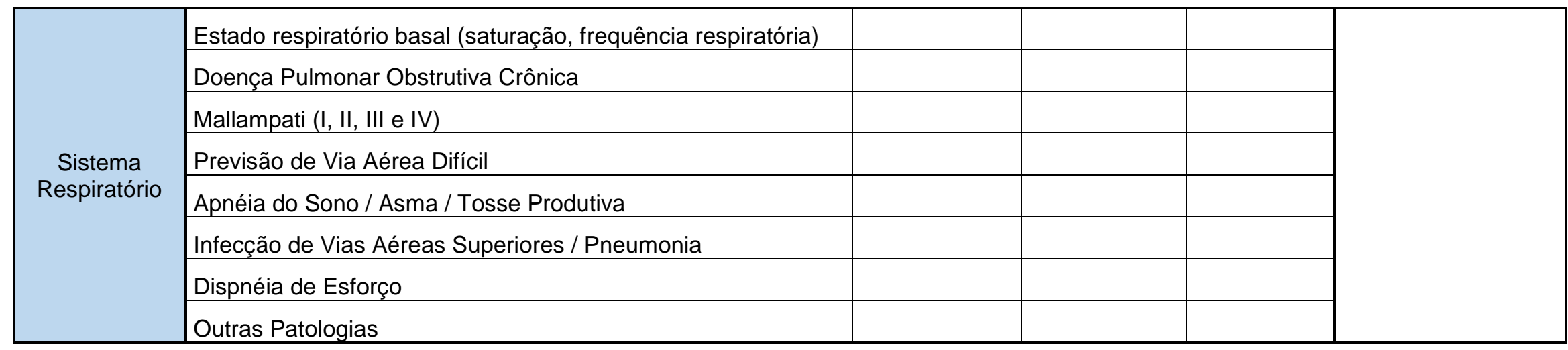

\begin{tabular}{|c|l|l|l|l|}
\hline \multirow{4}{*}{$\begin{array}{c}\text { Sistema } \\
\text { Digestório }\end{array}$} & Gastrite / Refluxo Gastresofágico & & & \\
\cline { 2 - 5 } & Esofagite / Úlcera Péptica & & & \\
\cline { 2 - 5 } & Hepatite / Cirrose & & & \\
\cline { 2 - 5 } & Sangramento Digestivo (Alto / Baixo) & & & \\
\cline { 2 - 5 } & Outras Patologias & & \\
\hline
\end{tabular}

\begin{tabular}{|c|l|l|l|l|}
\hline \multirow{4}{*}{$\begin{array}{c}\text { Sistema } \\
\text { Endócrino }\end{array}$} & Diabetes Mellitos Tipo I ou II & & & \\
\cline { 2 - 5 } & Doença da Tireoide ou Paratireoide & & \\
\cline { 2 - 5 } & Doenças da Hipófise & & & \\
\cline { 2 - 5 } & Insuficiência Adrenal & & & \\
\cline { 2 - 5 } & Outras Patologias & & \\
\hline
\end{tabular}




\begin{tabular}{|l|l|l|l|l|}
\hline \multirow{4}{*}{$\begin{array}{c}\text { Sistema } \\
\text { Neurológico }\end{array}$} & Nível de Consciência / Déficit Cognitivo & & & \\
\cline { 2 - 5 } & Convulsões / Labirintopatias / Cefaleias & & & \\
\cline { 2 - 5 } & Alterações de Sensibilidade e Motricidade & & \\
\cline { 2 - 5 } & Lesão Medular & & & \\
\cline { 2 - 5 } & Outras Patologias & & & \\
\hline
\end{tabular}

\begin{tabular}{|c|l|l|l|l|}
\hline \multirow{5}{*}{$\begin{array}{c}\text { Sistema } \\
\text { Hematológico }\end{array}$} & Discrasias sanguíneas / Anemias & & & \\
\cline { 2 - 5 } & Transfusão Sanguínea Prévia & & \\
\cline { 2 - 5 } & Distúrbios de Coagulação & & \\
\cline { 2 - 5 } & Equimoses / Hematomas / Epistaxe & & \\
\cline { 2 - 5 } & Tipagem sanguínea / reserva de hemocomponentes & & \\
\cline { 2 - 5 } & Outras Patologias & & & \\
\end{tabular}

\begin{tabular}{|l|l|l|l|l|}
\hline \multirow{4}{*}{ Sistema Renal } & Infecção Urinária de Repetição & & & \\
\cline { 2 - 5 } & Doença Renal Crônica (Dialítica ou Não Dialítica) & & & \\
\cline { 2 - 5 } & Outras Patologias & & & \\
\hline
\end{tabular}

\begin{tabular}{|c|l|l|l|l|}
\hline $\begin{array}{c}\text { Sistema } \\
\text { Tegumentar }\end{array}$ & $\begin{array}{l}\text { Integridade da pele (equimoses, edemas, hematomas, } \\
\text { lesões de pele) }\end{array}$ & & & \\
\cline { 2 - 5 } & Outras Patologias & & & \\
\hline
\end{tabular}




\begin{tabular}{|c|l|l|l|l|}
\hline \multirow{4}{*}{$\begin{array}{c}\text { Sistema } \\
\text { Musculoesquel } \\
\text { ético }\end{array}$} & Malformações Osteomoleculares & & & \\
\cline { 2 - 5 } & Limitação física ou mobilidade prejudicada & & \\
\cline { 2 - 5 } & Olgias lombares / Artrites / Artroses / Hérnias de Disco & & \\
\cline { 2 - 5 } & Outras Patologias & & & \\
\hline
\end{tabular}

\begin{tabular}{|c|l|l|l|l|}
\hline \multirow{4}{*}{$\begin{array}{c}\text { Sistema } \\
\text { Imunológico }\end{array}$} & HIV Positivo & & & \\
\cline { 2 - 5 } & Tuberculose & & \\
\cline { 2 - 5 } & Infecção Respiratória ou Urinária & & & \\
\cline { 2 - 5 } & Outras Patologias & & & \\
\hline
\end{tabular}

\begin{tabular}{|l|l|l|l|l|}
\hline \multirow{4}{*}{$\begin{array}{c}\text { Sistema } \\
\text { Sensorial }\end{array}$} & Dificuldades sensoriais (visão, audição, fala, tato, paladar) & & & \\
\cline { 2 - 5 } & Percepção sensorial da dor & & \\
\cline { 2 - 5 } & Hipotermia & & & \\
\cline { 2 - 5 } & Outras Patologias & & \\
\hline
\end{tabular}




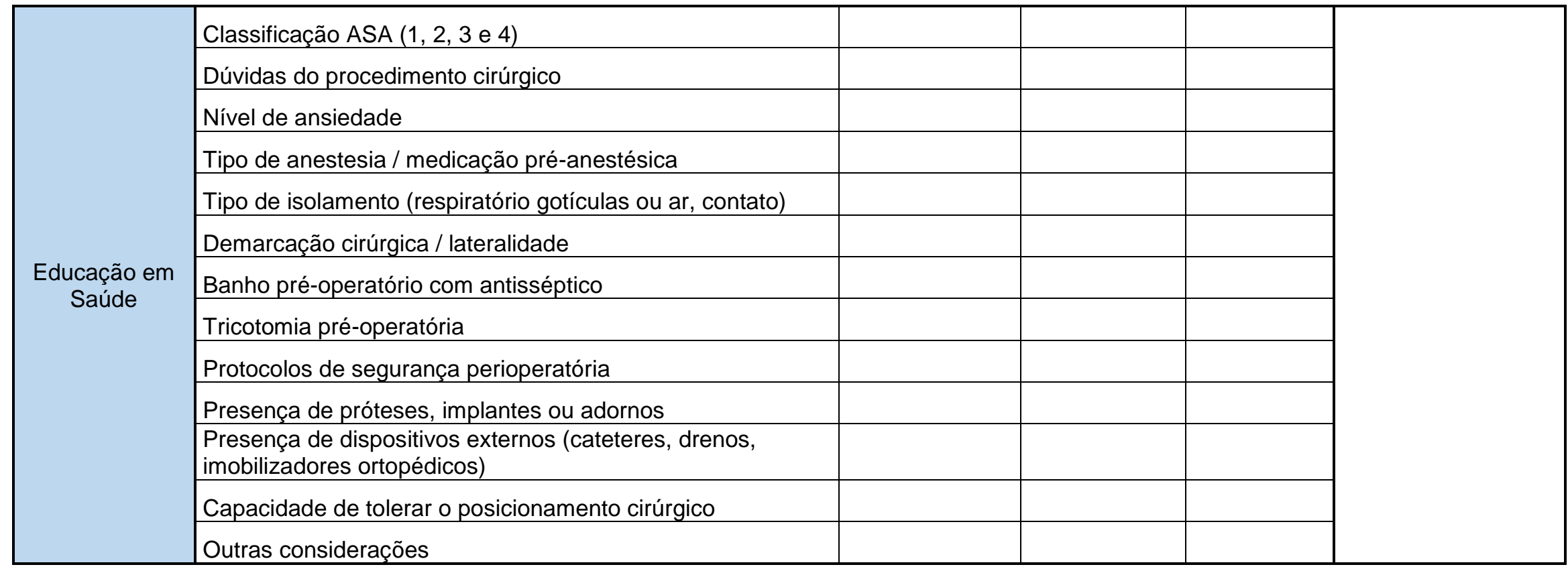

\begin{tabular}{|c|l|l|l|l|}
\hline \multirow{3}{*}{$\begin{array}{c}\text { Exames } \\
\text { Diagnósticos }\end{array}$} & Exames laboratoriais & & & \\
\cline { 2 - 5 } & Exames de imagem & & & \\
\cline { 2 - 5 } & Outros exames & & & \\
\hline
\end{tabular}


APÊNDICE D

Instrumento para Coleta de Dados dos Guidelines Selecionados

\begin{tabular}{|c|c|c|}
\hline \multirow{2}{*}{$\begin{array}{c}\text { Guideline } \\
\text { G_01 }\end{array}$} & \multicolumn{2}{|c|}{ Título } \\
\hline \multicolumn{2}{|c|}{ Fonte } \\
\hline I. & Propósito \\
\hline II. & \\
\hline III. & \\
\hline IV. & \\
\hline V. & \\
\hline
\end{tabular}




\section{APÊNDICE E}

Instrumento de Avaliação Pré-Operatória Transdisciplinar

\begin{tabular}{|c|c|c|c|c|c|}
\hline \multicolumn{6}{|c|}{ AVALIAÇÃO PRÉ-OPERATÓRIA TRANSDISCIPLINAR (APOT) } \\
\hline \multicolumn{4}{|l|}{ Nome do Paciente: } & \multirow{2}{*}{\multicolumn{2}{|c|}{$\begin{array}{l}\text { Data de Nascimento: } \\
\text { Altura: }\end{array}$}} \\
\hline Gênero: & Idade: & \multicolumn{2}{|l|}{ Peso: } & & \\
\hline \multicolumn{6}{|l|}{ Diagnóstico de Base: } \\
\hline \multicolumn{2}{|l|}{ Nome do Cirurgião: } & \multicolumn{4}{|c|}{ Nome do Anestesiologista: } \\
\hline Termo de Consentimento Cirúrgico: & $\square \operatorname{sim}$ & \multicolumn{2}{|c|}{ Termo de Consentimento Anestésico: } & $\square \operatorname{sim}$ & $\square$ Não \\
\hline \multicolumn{6}{|c|}{ HISTÓRICO PESSOAL E PSICOSSOCIAL } \\
\hline Estado Civil: & \multicolumn{2}{|l|}{ Escolaridade: } & \multicolumn{3}{|l|}{ Espiritualidade/ Religião: } \\
\hline \multicolumn{3}{|l|}{ Alergias/ Sensibilidade/ Intolerância: } & \multicolumn{3}{|l|}{ Estado Nutricional: } \\
\hline Drogas Ilicitas & \multicolumn{2}{|l|}{ Etilismo: } & \multicolumn{3}{|l|}{ Tabagismo: } \\
\hline \multicolumn{3}{|l|}{ Cirurgias Anteriores: } & \multicolumn{3}{|l|}{ Terapias Complementares: } \\
\hline \multicolumn{3}{|l|}{ Medicamentos em Uso Diário: } & \multicolumn{3}{|c|}{$\begin{array}{l}\text { Jejum de líquidos: } \\
\text { Período: } \frac{\mathrm{h}}{\mathrm{h}} \text { às } \\
\text { Jejum de sólidos: } \\
\text { Período: }\end{array}$} \\
\hline
\end{tabular}

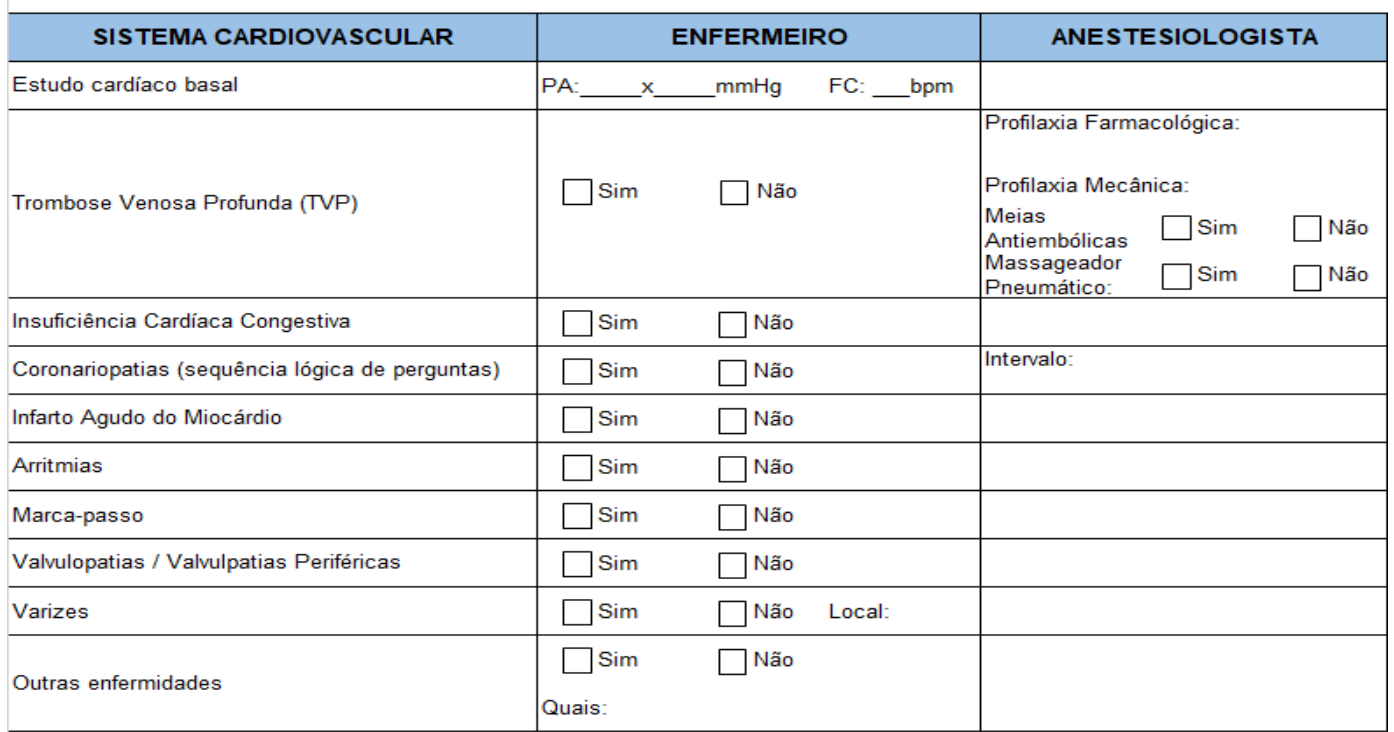

\begin{tabular}{|c|c|c|}
\hline SISTEMA RESPIRATÓRIO & ENFERMEIRO & ANESTESIOLOGISTA \\
\hline Estado respiratório basal & FR: _ & \\
\hline Doença Pulmonar Obstrutiva Crônica (DPOC) & $\square \operatorname{Sim}$ & \\
\hline Mallampati (I, II, III e IV) & $\begin{array}{l}\text { Distância mento-tireoide: }{ }_{\text {Circunferência cervical: }} \mathrm{cm} \\
\mathrm{cm}\end{array}$ & \\
\hline Previsão de Via Aérea Dificil & Histórico: $\quad \square \operatorname{Sim} \quad \square$ Não & $\square \operatorname{sim}$ \\
\hline Apnéia do Sono & $\square \operatorname{sim} \quad \square$ Não & \\
\hline Asma & $\square \operatorname{Sim} \quad \square$ Não & \\
\hline Bronquite & $\square \operatorname{Sim} \quad \square$ Não & \\
\hline Enfisema & $\square \operatorname{Sim} \quad \square$ Não & \\
\hline Tosse Produtiva & $\square \operatorname{Sim} \quad \square$ Não & \\
\hline Infecção de Vias Aéreas Superiores & $\square \operatorname{Sim} \quad \square$ Não & \\
\hline Pneumonia & $\square \operatorname{Sim} \quad \square$ Não & \\
\hline Tromboembolismo Pulmonar (TEP) & $\square \operatorname{Sim} \quad \square$ Não & \\
\hline Dispnéia de Esforço & $\square \operatorname{Sim} \quad \square$ Não & \\
\hline Outras enfermidades & $\begin{array}{l}\square \operatorname{Sim} \quad \square \text { Não } \\
\text { Quais: }\end{array}$ & \\
\hline
\end{tabular}




\begin{tabular}{l|l|l|}
\multicolumn{1}{c|}{ SISTEMA DIGESTÓRIO } & \multicolumn{1}{c|}{ ENFERMEIRO } & ANESTESIOLOGISTA \\
\hline Gastrite / Úlcera péptica / Esofagite & $\square$ sim $\quad \square$ Não & \\
\hline Doença do Refluxo Gastroesofágico (DRGE) & $\square$ sim $\quad \square$ Não & \\
\hline Cirrose & $\square$ sim $\quad \square$ Não & Volume: \\
\hline Sangramento Digestivo Alto & $\square \operatorname{sim} \quad \square$ Não & Volume: \\
\hline Sangramento Digestivo Baixo & $\square \operatorname{sim} \quad \square$ Não & \\
\hline Náuseas e vômitos pós-operatórios (NVPO) & $\square \operatorname{sim} \quad \square$ Não & \\
\hline Outras enfermidades & $\square \operatorname{sim} \quad \square$ Não & \\
\hline
\end{tabular}

\begin{tabular}{|l|l|l|}
\hline \multicolumn{1}{|c|}{ SISTEMA ENDÓCRINO } & \multicolumn{1}{|c|}{ ENFERMEIRO } & ANESTESIOLOGISTA \\
\hline Diabetes Mellitos Tipo I ou II & $\square$ sim $\square$ Não Dx:_mg/dll & \\
\hline Hipertireoidismo & Insulinodependente: $\square$ sim $\square$ Não & \\
\hline Hipotireoidismo & $\square$ sim $\square$ Não TSH: & \\
\hline Doenças da Hipófise & $\square \operatorname{sim} \quad \square$ Não TSH: & \\
\hline Insuficiência Adrenal & $\square \operatorname{sim} \quad \square$ Não & \\
\hline Outras enfermidades & $\square \operatorname{sim} \quad \square$ Não & \\
& $\square \operatorname{sim} \quad \square$ Não & \\
\hline
\end{tabular}

\begin{tabular}{|l|l|l|}
\hline \multicolumn{1}{|c|}{ SISTEMA NEUROLÓGICO } & ENFERMEIRO & ANESTESIOLOGISTA \\
\hline Nivel de Consciência / Déficit Cognitivo & $\square$ Orientado $\square$ Desorientado & Glasgow: \\
\hline Convulsões & $\square \operatorname{sim} \quad \square$ Não & \\
\hline Labirintopatias & $\square \operatorname{sim} \quad \square$ Não & \\
\hline Cefaléias & $\square \operatorname{sim} \quad \square$ Não & \\
\hline Alterações de Sensibilidade & $\square \operatorname{sim} \quad \square$ Não Local: & \\
\hline Alterações de Motricidade & $\square \operatorname{sim} \quad \square$ Não Local: & \\
\hline Acidente Vascular Encefálico & $\square \operatorname{sim} \quad \square$ Não & \\
\hline Lesão Medular & $\square \operatorname{sim} \quad \square$ Não & \\
\hline Outras enfermidades & $\square \operatorname{sim} \quad \square$ Não & \\
& Quais: & \\
\hline
\end{tabular}

\begin{tabular}{|l|l|l|}
\hline \multicolumn{1}{|c|}{ SISTEMA HEMATOLÓGICo } & \multicolumn{1}{|c|}{ ENFERMEIRO } & ANESTESIOLOGISTA \\
\hline Discrasias Sanguíneas / Anemias & $\square$ sim $\square$ Não & \\
\hline Quais: & & \\
\hline Tranfusão Sanguinea Prévia & $\square$ sim $\square$ Não & \\
\hline Distúrbios de Coagulação & $\square$ sim $\square$ Não & \\
\hline Epistaxe & $\square$ sim $\square$ Não & \\
\hline Tipagem sanguínea & $\square$ sim $\square$ Não Tipo: & \\
\hline Reserva de hemocomponentes & $\square \operatorname{sim} \quad \square$ Não No Bolsas: & \\
\hline Outras enfermidades & Quais: & \\
& $\square \operatorname{sim} \quad \square$ Não & \\
\hline
\end{tabular}




\begin{tabular}{|l|l|l|}
\multicolumn{1}{c|}{ SISTEMA RENAL } & \multicolumn{1}{c|}{ ENFERMEIRO } & ANESTESIOLOGISTA \\
\hline Infecção Urinária de Repetição & $\square \operatorname{sim} \quad \square$ Não & \\
\hline Doença Renal Crônica Dialítica & $\square \operatorname{sim} \quad \square$ Não & \\
\hline Doença Renal Crônica Não Dialítica & $\square \operatorname{sim} \quad \square$ Não & \\
\hline Outras enfermidades & $\square \operatorname{sim} \quad \square$ Não & \\
& Quais: & \\
\hline
\end{tabular}

\begin{tabular}{|l|l|l|}
\hline \multicolumn{1}{|c|}{ SISTEMA TEGUMENTAR } & \multicolumn{1}{|c|}{ ENFERMEIRO } & ANESTESIOLOGISTA \\
\hline $\begin{array}{l}\text { Integridade da pele (equimoses, edemas, } \\
\text { hematomas, lesões de pele) }\end{array}$ & $\square$ sim $\square$ Não & \\
\hline Local: & & \\
Outras enfermidades & $\square$ Sim $\square$ Não & \\
& Quais: & \\
\hline
\end{tabular}

\begin{tabular}{|l|l|l|}
\hline \multicolumn{1}{|c|}{ SISTEMA MUSCULOESQUELÉTICO } & \multicolumn{1}{|c|}{ ENFERMEIRO } & ANESTESIOLOGISTA \\
\hline Malformações Osteomusculares & $\square \operatorname{sim} \quad \square$ Não & \\
\hline Quais: & & \\
\hline Limitação física ou mobilidade prejudicada & $\square \operatorname{sim} \quad \square$ Não & \\
\hline Algias Lombares & $\square \operatorname{sim} \quad \square$ Não & \\
\hline Artrites/ Artroses & $\square \operatorname{sim} \quad \square$ Não & \\
\hline Hérnias de Disco & $\square \operatorname{sim} \quad \square$ Não & \\
\hline Outras enfermidades & $\square \operatorname{sim} \quad \square$ Não & \\
& Quais: & \\
\hline
\end{tabular}

\begin{tabular}{|l|ll|l|}
\hline \multicolumn{1}{|c|}{ SISTEMA IMUNOLÓGICO } & \multicolumn{1}{c|}{ ENFERMEIRO } & ANESTESIOLOGISTA \\
\hline HIV Positivo & $\square$ sim $\quad \square$ Não & Carga Viral: \\
\hline Tuberculose & $\square \operatorname{sim} \quad \square$ Não & \\
\hline Hepatite & $\square \operatorname{sim} \quad \square$ Não & \\
\hline Outras enfermidades & $\square \operatorname{sim} \quad \square$ Não & \\
& Quais: & \\
\hline
\end{tabular}

\begin{tabular}{l|lc|l|}
\hline \multicolumn{1}{|c|}{ SISTEMA SENSORIAL } & \multicolumn{2}{c|}{ ENFERMEIRO } & ANESTESIOLOGISTA \\
\hline $\begin{array}{l}\text { Dificuldades sensoriais (visão, audição, fala, tato, } \\
\text { paladar) }\end{array}$ & $\square$ sim $\quad \square$ Não Qual: & \\
\hline Percepção sensorial da dor & $\square \operatorname{sim} \quad \square$ Não Score: & \\
\hline Hipotermia & $\square \operatorname{sim} \quad \square$ Não To: & \\
\hline Hipertermia & $\square \operatorname{sim} \quad \square$ Não To: & \\
\hline Outras enfermidades & $\square \operatorname{sim} \quad \square$ Não & \\
& Quais: & \\
\hline
\end{tabular}




\begin{tabular}{|c|c|c|c|}
\hline \multirow{2}{*}{$\begin{array}{l}\text { EDUCAÇÃO EM SAÚDE } \\
\text { Classificação ASA }(1,2,3,4,5 \text { e } 6)\end{array}$} & \multicolumn{2}{|c|}{ ENFERMEIRO } & \multirow[t]{2}{*}{ ANESTESIOLOGISTA } \\
\hline & $\square \operatorname{sim}$ & $\square$ Não Qual: & \\
\hline Dúvidas sobre o procedimento cirúrgico & $\begin{array}{l}\square \text { sim } \\
\text { Quais: }\end{array}$ & $\square$ Não & \\
\hline \multicolumn{4}{|l|}{ Nivel de ansiedade } \\
\hline Tipo de anestesia & $\begin{array}{l}\square \text { sim } \\
\text { Qual: }\end{array}$ & $\square$ Não & \\
\hline Medicação pré-anestésica & $\begin{array}{l}\square \operatorname{sim} \\
\text { Qual: }\end{array}$ & $\square$ Não & \\
\hline $\begin{array}{l}\text { Tipo de isolamento (respiratório gotículas ou ar, } \\
\text { contato) }\end{array}$ & $\square$ sim & $\square$ Não & \\
\hline $\begin{array}{l}\text { Demarcação cirúrgica / lateralidade } \\
\text { (confirmação do sítio cirúrgico) }\end{array}$ & $\begin{array}{l}\square \text { Sim } \\
\text { Local: }\end{array}$ & $\square$ Não & \\
\hline Banho pré-operatório com antisséptico & $\square \operatorname{sim}$ & $\square$ Não & \\
\hline Tricotomia pré-operatória & $\begin{array}{l}\square \text { sim } \\
\text { Local: }\end{array}$ & $\square$ Não & \\
\hline Protocolos de segurança perioperatória & $\square \operatorname{sim}$ & $\square$ Não & \\
\hline $\begin{array}{l}\text { Presença de próteses, implantes ou adornos } \\
\text { (prótese dentária ou capilar, unhas e cílios postiços, } \\
\text { piercings ) }\end{array}$ & $\begin{array}{l}\square \text { sim } \\
\text { Qual: } \\
\text { Local: }\end{array}$ & $\square$ Não & \\
\hline $\begin{array}{l}\text { Presença de dispositivos externos (cateteres, } \\
\text { drenos, imobilizadores ortopédicos) }\end{array}$ & $\begin{array}{l}\square \text { sim } \\
\text { Qual: } \\
\text { Local: }\end{array}$ & $\square$ Não & \\
\hline Capacidade de tolerar o posicionamento cirúrgico & $\begin{array}{l}\square \operatorname{sim} \\
\text { Tipo: }\end{array}$ & $\square$ Não & \\
\hline Risco de lesão de pele por posicionamento cirúrgico & $\square$ Sim & $\square^{\text {Não }}$ & \\
\hline Outras considerações & $\begin{array}{l}\square \text { sim } \\
\text { Quais: }\end{array}$ & $\square$ Não & \\
\hline
\end{tabular}

\begin{tabular}{|l|l|l|}
\hline \multicolumn{1}{|c|}{ EXAMES DIAGNÓSTICOS } & \multicolumn{1}{|c|}{ ENFERMEIRO } & ANESTESIOLOGISTA \\
\hline Exames laboratoriais & $\square$ sim $\square$ Não & \\
\hline Quais: & \\
\hline Exames de imagem & $\square$ sim $\square$ Não & \\
\hline Quais: & \\
\hline Outros exames & $\square$ sim $\square$ Não & \\
\hline
\end{tabular}

\begin{tabular}{|l|l|l|}
\hline \multirow{2}{*}{ OBSERVAÇÕES/ CONSIDERAÇÕES } & ENFERMEIRO & ANESTESIOLOGISTA \\
\cline { 2 - 3 } & & \\
& & \\
\hline
\end{tabular}

